\title{
CAMA
}

Centre for Applied Macroeconomic Analysis

\section{Sustainable International Monetary Policy Cooperation}

\section{CAMA Working Paper 14/2016 April 2016}

Ippei Fujiwara

Keio University and

Centre for Applied Macroeconomic Analysis, ANU

\section{Timothy Kam}

The Australian National University

\section{Takeki Sunakawa}

The University of Tokyo

\begin{abstract}
We provide new insight on international monetary policy cooperation using a two-country model based on Benigno and Benigno (2006). Assuming symmetry, save for the volatility of (markup) shocks, we show that an incentive feasibility problem exists between the policymakers across national borders: The country faced with a relatively more volatile markup shock has an incentive to deviate from an assumed Cooperation regime to one with Noncooperation. More generally, a similar result obtains if countries differ in size. This motivates our study of a history-dependent Sustainable Cooperation regime which is endogenously sustained by a cross-country, state-contingent contract between policymakers. Under Sustainable Cooperation, the responses of inflation and the output gap in both countries are different from those induced by the Cooperation and Noncooperation regimes reflecting the endogenous welfare redistribution between countries under the state-contingent contract. Such history-contingent welfare redistributions are supported by resource transfers affected through incentive-compatible variations in the terms of trade (or net exports). Such an endogenous cooperative solution may also provide a theoretical rationale for perceived occasional cooperation between national central banks in reality.
\end{abstract}




\section{Keywords}

Monetary policy cooperation, Sustainable plans, Welfare.

\section{JEL Classification}

E52, F41, F42

\section{Address for correspondence:}

(E) cama.admin@anu.edu.au

\section{ISSN 2206-0332}

The Centre for Applied Macroeconomic Analysis in the Crawford School of Public Policy has been established to build strong links between professional macroeconomists. It provides a forum for quality macroeconomic research and discussion of policy issues between academia, government and the private sector.

The Crawford School of Public Policy is the Australian National University's public policy school, serving and influencing Australia, Asia and the Pacific through advanced policy research, graduate and executive education, and policy impact. 


\title{
Sustainable International Monetary Policy Cooperation*
}

\author{
Ippei Fujiwara $^{\dagger} \quad$ Timothy Kam $^{\ddagger} \quad$ Takeki Sunakawa $^{\S}$
}

April 1, 2016

\begin{abstract}
We provide new insight on international monetary policy cooperation using a two-country model based on Benigno and Benigno (2006). Assuming symmetry, save for the volatility of (markup) shocks, we show that an incentive feasibility problem exists between the policymakers across national borders: The country faced with a relatively more volatile markup shock has an incentive to deviate from an assumed Cooperation regime to one with Noncooperation. More generally, a similar result obtains if countries differ in size. This motivates our study of a history-dependent Sustainable Cooperation regime which is endogenously sustained by a cross-country, state-contingent contract between policymakers. Under Sustainable Cooperation, the responses of inflation and the output gap in both countries are different from those induced by the Cooperation and Non-cooperation regimes reflecting the endogenous welfare redistribution between countries under the state-contingent contract. Such history-contingent welfare redistributions are supported by resource transfers effected through incentive-compatible variations in the terms of trade (or net exports). Such an endogenous cooperative solution may also provide a theoretical rationale for perceived occasional cooperation between national central banks in reality.
\end{abstract}

Keywords: Monetary policy cooperation; Sustainable plans; Welfare JEL codes: E52; F41; F42

\footnotetext{
*We have benefitted from the comments from, and discussions with Kosuke Aoki, Gianluca Benigno, Mick Devereux, Chris Edmond, Junichi Fujimoto, Fabio Ghironi, Pierre-Olivier Gourinchas, Aubhik Khan, Jinill Kim, Keiichiro Kobayashi, Anella Munro, Tomoyuki Nakajima, Bruce Preston, Christie Smith, Eric Young, as well as seminar participants at CEF2015, the Econometric Society World Congress 2015, HKUST-Keio-HKIMR Conference on Exchange Rates and Macroeconomics, GRIPS, Meiji University, Tohoku University, Kobe University, The University of Tokyo, Kyoto University, Hitotsubashi University, La Trobe University, Monash University, University of Melbourne, Reserve Bank of New Zealand, and University of Sydney. Kam would like to thank the Bank of Japan for financial support, and fellow colleagues at the BoJ's Institute of Monetary and Economic Studies for their generosity and hospitality. Fujiwara and Sunakawa are grateful for financial support from JSPS KAKENHI Grant-in-Aid for Scientific Research (A) Grant Number 15H01939.

${ }^{\dagger}$ Keio University and The Australian National University. E-mail: ippei.fujiwara@keio.jp

¥The Australian National University. E-mail: tcy.kam@gmail.com

§The University of Tokyo. E-mail: sunakawa@pp.u-tokyo.ac.jp
} 


\section{Introduction}

The debate on the gains from policy cooperation has been at the heart of international finance and open economy macroeconomics. It goes back as far as Hume (1752) who pointed out the existence of cross-country policy spillover. Cooper (1969) raised the possibility that each country may not be able to maximize its own welfare with increasing interdependence through trade or investment in the Mundell-Fleming model. Hamada (1976) formally analyzed the gains from cooperation from a game theoretic perspective. Since then, many have discussed the pros and cons of policy cooperation in theoretical general equilibrium models. Corsetti and Pesenti (2001), Clarida et al. (2002), Benigno and Benigno (2003, 2006), Canzoneri et al. (2005), Corsetti et al. (2010), and Engel (2015) clarified the conditions on when gains from cooperation emerge in the class of New Open Economy Macroeconomics models in the style of Svensson and van Wijnbergen (1989) and Obstfeld and Rogoff (1995).

To date, analyses on international monetary policy cooperation assume that authorities do not have any incentive to deviate from cooperation, or if there is ever any doubt in the modellers' minds, the analyses would proceed to consider the other extreme of (strategic) noncooperation. ${ }^{1}$ In other words, the national central banks are either always equipped with some unspecified commitment technology that ensures international cooperation in all contingencies, or, otherwise under non-cooperation regimes they have no means to improve their individual welfare by undertaking cooperative actions.

However, it is perhaps unrealistic and as we will show-logically unattainable as a policy equilibrium - to assume that each government can fully commit to cooperation under any contingency. Neither is it internally consistent to assume that non-cooperation fully rationalizes the reality of international monetary policy, when there exists another welfare-improving and incentive-feasible policy equilibrium available to all policy makers concerned.

Purpose. One purpose of this paper is to address these important logical-consistency issues when considering the standard paradigms of Cooperation and Non-Cooperation for international monetary policy. Another purpose is to understand how cooperation may be sustained endogenously, albeit in a constrained efficient way, and to study its normative implications in relation to the standard Cooperation versus Non-cooperation approaches.

One might ask why studying such an idealized notion of endogenous international monetary cooperation is interesting. An inquiry into the endogenous sustainability of the cooperative regime, and its consequences, is still unexplored within the international monetary policy literature. Also, a study of such an idealized but incentive feasible institution is of direct relevance to the current state in the global coordination of international monetary policy, and may help inform the design of real-world cooperative policy, or memoranda of understanding between central banks. As a case in point, the recent global financial crisis has renewed interest in the potential for international policy cooperation. In order for the global economy to recover, the need for international monetary policy cooperation is now a topic of discussion among leaders in major policy institutions. For example, Janet Yellen (as Chair of the Board of Governors of the U.S. Federal Reserve), alluded to the importance of "extensive coordination"

\footnotetext{
${ }^{1} \mathrm{~A}$ recent application of such an approach in terms of studying currency unions is Chari et al. (2014).
} 
between countries in the conduct of macroprudential supervision and monetary policy: ${ }^{2}$

[I]f the United States were to go it alone with tough policies, we could see our financial institutions flee in a race to the bottom. But I'm convinced that won't happen. We are working closely with our international counterparts to develop coherent and comprehensive approaches, aided by the Basel Committee on Banking Supervision, the Financial Stability Board, the International Monetary Fund, and other institutions.

Also the Acting Managing Director of the IMF, John Lipsky in his speech on "The Challenges of Economic Policy Cooperation", said that: ${ }^{3}$

A second success is the remarkable increase in global policy cooperation that has taken place in the wake of the 2008-09 global financial crisis. When the world last faced such grave danger-during the Great Depression-countries acted in their own, perceived self-interest with beggar-thy-neighbor policies that in fact deepened the downturn. This time, countries acted together to tackle the crisis.

The most recent evidence of a real-world attempt to formulate a cooperative international monetary policy plan is the Joint Declaration of the Macroeconomic Policy Authorities of Trans-Pacific Partnership (TPP) Countries. ${ }^{4}$ Under the TPP declaration, member countries have agreed to limit "unfair currency practices", by refraining from self-interested exchange rate (or terms of trade) manipulation. The TPP joint declaration also includes the requirement for public reporting of member countries' foreign-exchange intervention and foreign reserves data. Further, there is also a requirement for regular consultations between macroeconomic policy authorities of TPP member countries.

Questions. Given the purpose of this paper, we ask the following questions: First, we ask if there are instances under which a Cooperation presumption in international monetary policy turns out to be incentive infeasible-i.e., such a regime may be a logical impossibility—and why. Second, since a Non-cooperation regime may not be a palatable description of real-world international monetary policies either, we consider if there can be some institution fostering cooperation in an incentive feasible way. We consider an idealized institution where there is an incentive-feasible contract that implements an endogenously sustainable (but constrained efficient) cooperation plan. We name such a regime a Sustainable Cooperation regime. ${ }^{5}$ Given such an idealized institution, we ask what sort of equilibrium it would induce and what its properties are, in terms of risk, resource, or welfare sharing. Third, we ask: Under the Sustainable Cooperation regime, relative to an unattainable cooperation regime, who gains and who

\footnotetext{
${ }^{2}$ Speech on October 11, 2010, at the Annual Meeting of the National Association for Business Economics, Denver, Colorado. Source: http://www.federalreserve.gov/newsevents/speech/yellen20101011a.htm.

${ }^{3}$ Stated on June 21, 2011, at Kurt Viermetz Lecture - The American Academy in Berlin. Source: https://www.imf.org/external/np/speeches/2011/062111.htm.

${ }^{4}$ See e.g., the texts available from the U.S. Treasury at https://www.treasury.gov/initiatives/Pages/jointdeclaration.aspx.

${ }^{5}$ Hereinafter, whenever we mention the three policy regimes or equilibria we consider, we will use initial-letter upper-cases to refer to their nouns-i.e., Cooperation, Non-cooperation or Sustainable Cooperation as a concept of a policy regime or equilibrium. This distinguishes their particular usages from their occasional common-language usages.
} 
loses? We also analyze how differences in the volatility of shocks perturbing the countries, risk aversion and differences in country size matter for our idealized notion of a Sustainable Cooperation institution.

To this end, we set up a linear-quadratic (LQ) New Open Economy macroeconomic framework for optimal monetary policy analysis based on Benigno and Benigno (2006, hereinafter $\mathrm{BB})$. Then we calculate and study the behavior of equilibria, respectively, under each extreme regime of assumed international Cooperation and Non-cooperation. We use these two versions of well-studied policy regimes to compare with the endogenous Sustainable Cooperation regime. Under Sustainable Cooperation, central banks maximize the global social welfare subject to each country's competitive equilibrium restrictions, global resource constraints, and a set of history-contingent sustainability constraints (one for each country). These latter constraints encode the following incentive-feasibility requirements: Should a country have the temptation to walk away from international cooperation, the contract ensures that it, at best, can only be as well-off as in the equilibrium under a Non-cooperation regime. That is, the outside option value to each nation's policymaker is the welfare induced by the Non-cooperation regime, which in itself implies a sustainable equilibrium plan. These credible threats, along with other equilibrium restrictions, induce allocation and pricing processes that are said to be sustainable plans in the language of Chari and Kehoe (1990). ${ }^{6}$

Answers. We provide the following insights in this paper: First, we show that the presumption of international cooperation as a description of global monetary policy settings may turn out to be incentive infeasible-that is it may not be an attainable equilibrium. This insight holds true in both realistic cases of countries facing asymmetric shock volatilities, and, where countries are of unequal size. The country faced with a more volatile (markup) shock, or with a smaller size, has a greater incentive to deviate from Cooperation to Non-cooperation. We show that this is a possible resolution to the tension between two main forces underlying the incentive to deviate from, or to stay in, a cooperative regime. We label these two opposing forces the terms of trade externality channel and the (non)-insularity channel. On the one hand, there is the temptation to exploit a welfare-relevant terms-of-trade externality in the model. ${ }^{7}$ On the other

\footnotetext{
${ }^{6}$ There has been an earlier institutional-design approach that considers sustaining cooperative monetary outcomes as a non-cooperative policy equilibrium (for a survey, see Persson and Tabellini, 2002). The idea is that before the non-cooperative policy equilibrium is played, countries commit at an earlier "contract design" stage to delegate policy-typically under state-contingent linear contracts (Persson and Tabellini, 1995; Jensen, 2000) or simple targeting rules (see Benigno and Benigno, 2006)—which is then implemented by each country's policy maker in the non-cooperative policy game. However, in many instances, such institutional-design problems based on targetingor state-contingent simple (e.g., linear or quadratic) contracts, are not subgame perfect: There exists a profitable deviation to renegotiate the terms of the contract: See for example, Bilbiie (2011) for a monetary-policy setting, and, Kletzer and Wright (2000) in the context of sovereign debt problems. The approach we take is different: By construction, our history-contingent and nonlinear Sustainable Cooperation plan is self-enforcing in the sense that if any country were to ex post deviate from the terms of the plan, the best they can do is play out a Non-cooperation policy equilibrium which is subgame perfect. (We thank Pierre-Olivier Gourichas and Fabio Ghironi for helpful discussions on this point.)

${ }^{7}$ The reason there is a terms-of-trade externality of Home's policy outcome onto Foreign's welfare and viceversa, under Non-cooperation, is because of the existence of markets that insure cross-country consumption risk. When one country attempts to stabilize its output gap, this has a direct externality effect on its neighbor's welfare via the equilibrium asset-pricing relation between two countries' output (gap) and the terms of trade. In this paper, we assume the existence of international markets trading in complete state-contingent consumption claims, as is done in BB. More generally, one could instead consider an incomplete markets setting. However, such additional frictions will merely cloud insights into our study of the Sustainable Cooperation plan.
} 
hand, potential feedback of terms of trade onto a Foreign country's inflation may induce a retaliation to a Home country's attempt to exploit the terms of trade externality (and vice-versa). We study how the resolution between these two opposing forces depends on the degree of risk aversion of agents in each country, and, also on the size of each country. This incentive problem is also exacerbated by greater asymmetry in the volatilities of markup shocks. Moreover, when countries are asymmetric in size, an interesting insight arises: A larger country still needs to worry about its smaller counterpart, since the latter will have more incentive to walk away from a cooperative solution and the outcome matters for the larger country's welfare. A Sustainable Cooperation plan in such a setting would take this into account.

Second, given the possible incentive infeasibility of assumed Cooperation regimes, it is then important to understand the nature of endogenously sustainable monetary policy cooperation and its attendant effects. Under Sustainable Cooperation, the responses of inflation and output gap in both countries are different from the ones under the Cooperation and Non-cooperation regimes, reflecting the impact of occasionally binding sustainability constraints. Whenever the sustainability constraint in the Home country binds, a history-contingent pseudo-weight on each country's social welfare shifts toward favoring the Home country welfare-i.e., the sustainable equilibrium has to redistribute welfare (or equivalently in allocation terms, increase net exports) in favor of the Home country within the Sustainable Cooperation regime.

Third, we also show that a Sustainable Cooperation equilibrium is typically close, or equivalent, to a particular point on a cooperative equilibrium Pareto frontier (in welfare terms), but not the originally assumed Cooperation solution. That is, there is a corresponding Pareto allocation that is payoff equivalent to the Sustainable Cooperation solution. In the case where countries have asymmetric shock volatilities, for example, the equivalent Pareto planner will have to assign a higher Pareto weight to the country that is faced with the more volatile shock (or a greater temptation to walk away from Cooperation.) Nevertheless, by construction, under such a Sustainable Cooperation plan, each country is still better off than acting under Noncooperation.

The remainder of this paper is laid out as follows: In Section 2, we describe the model setup (competitive equilibrium) and discuss the policymakers' social welfare measures relevant to the regimes we consider. In Section 3, we consider the two standard policy regimes studied in the literature: Cooperation and Non-cooperation. Then we will characterize equilibrium under the regime of Sustainable Cooperation in Section 4. As a generalization, we look at different country sizes as well in Section 5. Throughout we provide explanations for the different equilibrium behaviors under these three regimes and their welfare consequences. We conclude with Section 6. A detailed description of the microfoundations and welfare approximation for the LQ framework used in the paper is given in Appendix A. The optimal trade-offs for the policymakers under each regime, including computational procedure for the equilibrium under Sustainable Cooperation, are derived in Appendix B. 


\section{LQ Framework}

The environment is a two-country New Keynesian (NK) model based on BB. For the purposes of our study, we will present the model in terms of its (approximate) LQ characterization. ${ }^{8}$ We will first describe the competitive equilibrium of the two country model (for any given feasible monetary policy) in Section 2.1.

The model underlying the competitive equilibrium characterization is as follows: There are two countries-Home and Foreign. In each country, there is a representative household. Each household consumes bundles of differentiated goods produced in Home and Foreign countries. Each household also provides firm-specific labor to firms within the country. Firms in each country produce differentiated goods under monopolistic competition and sticky prices, given the demand function of the households in both countries. For clarity of exposition in the main text of this paper, we will focus mainly on the case where both countries are symmetric in size. ${ }^{9}$

There are internationally complete markets for state-contingent consumption claims and the law of one price holds for all goods. As in BB, these two assumptions help to simplify the equilibrium descriptions later: The real exchange rate is unity and consumption is equalized between the two countries. Each country also has a monetary policymaker who maximizes a social welfare function, given the equilibrium conditions of the whole economy. In order to isolate our focus on incentive-feasibility problems in terms of international monetary policy cooperation, we abstract from time-consistency issues within each country. In particular, we assume that each country's policymaker commits to maximizing its own citizen's ex-ante welfare. $^{10}$

To discipline our analyses, we restrict attention to equilibria under the following settings: Consumption is the only component of GDP, the two countries are symmetric in terms of taste, technology and market sizes, and the steady state markup is unity. ${ }^{11}$ Without loss of generality, we assume that the two countries are also symmetric in terms of their initial levels of assets. We further assume that the elasticity of substitution between domestic and foreign goods is equal to one. Under these assumptions, BB showed that in response to technology shocks, (i) the flexible-price allocation is constrained optimal under cooperation, and (ii) there are no gains by deviating from cooperation to non-cooperation. These results also hold in our model. Given this insight, we will only focus on inefficient markup shocks as the only sources of policy incentive to cooperate or not. ${ }^{12}$ In the open economy considered here, the good markets are integrated across countries so that in equilibrium the terms of trade will be a part of the firm's real marginal cost.

In Section 2.2, we will present and discuss the relevant social welfare criteria relevant to the three policy regimes to be considered-Cooperation, Non-cooperation, and Sustainable Coop-

\footnotetext{
${ }^{8}$ This representation provides a connection to the existing literature that also uses the same methodology.

${ }^{9}$ In a more general setting of this model (see Section 5), Home's country size will be indexed by, and is increasing in, a parameter $\gamma \in(0,1)$. On the flipside, Foreign's size is $1-\gamma$. The two countries are symmetric in size if $\gamma=1 / 2$

${ }^{10}$ We adopt the timeless perspective to derive the LQ approximation (Benigno and Woodford 2005, 2012). This allows us to restrict attention to equilibrium (policy trade-off) conditions that are time-invariant.

${ }^{11}$ This is achieved by assuming subsidies that eliminate positive rents in the steady state. Thus, a markup shock in this paper can also be interpreted as a structural shock to this subsidy.

${ }^{12} \mathrm{As}$ in the case of the closed economy, markup shocks generate a trade-off between inflation and the output gap represented in the NK Phillips curve.
} 
eration. ${ }^{13}$ The criterion function will turn out to be the same in the Cooperation and Sustainable Cooperation problems. The social welfare in each setting considered will be representable by a purely quadratic function, which accurately approximates the indirect utility of the representative household in each country up to second order. ${ }^{14}$ Here, we will also highlight the terms of trade mechanisms underlying a potential policy externality problem. This externality is what gives rise to a temptation for international monetary policymakers to walk away from a cooperative solution.

\subsection{Competitive equilibrium}

The equilibrium behavior of households and firms, as far as optimal policy is concerned, is sufficiently summarized by the NK Phillips curve: ${ }^{15}$

$$
\pi_{t}=\beta \mathbb{E}_{t} \pi_{t+1}+k \mu_{t}+k\left[(\rho+\eta) y_{t}+\frac{1}{2}(1-\rho) s_{t}\right],
$$

and

$$
\pi_{t}^{*}=\beta \mathbb{E}_{t} \pi_{t+1}^{*}+k \mu_{t}^{*}+k\left[(\rho+\eta) y_{t}^{*}+\frac{1}{2}(1-\rho) s_{t}^{*}\right] .
$$

All the variables are natural logarithmic transforms of their original levels. ${ }^{16}$ The variables with an asterisk $(*)$ are of the Foreign country and the ones without asterisk refer to Home country variables. The variable $y_{t}$ corresponds to output, $\pi_{t}$ is net producer price inflation rate, and $s_{t}:=p_{F, t}-p_{H, t}$ is the (Home) terms of trade, measured as the relative price level between Foreign and Home goods. The exogenous variable, $\mu_{t}$, is the markup shock, which follows a Markov process. The parameters are as follows: $\beta \in(0,1)$ is the discount factor, $\rho>0$ is the coefficient of relative risk aversion, $\eta>0$ is the Frisch elasticity of labor disutility, $\alpha \in(0,1)$ is the probability of prices being fixed per period (as in Calvo, 1983), and $\sigma>0$ is the elasticity of substitution among differentiated products. The composite parameter $k=$ $(1-\alpha)(1-\alpha \beta) /[\alpha(1+\sigma \eta)]$ is the slope of the log-linearized NK Phillips curve. ${ }^{17}$

Under internationally complete asset markets and the law of one price, the equilibrium terms of trade is given by

$$
s_{t}:=p_{F, t}-p_{H, t}=y_{t}-y_{t}^{*},
$$

where $p_{H}$ and $p_{F}$ are Home and Foreign producer prices. An increase (decrease) in $s_{t}$ means deterioration (improvements) in the Home terms of trade.

\footnotetext{
${ }^{13}$ Note that we will use upper-case letters when referring to the names of these regimes.

${ }^{14}$ The competitive equilibrium conditions are approximate linear constraints, representing the optimizing behavior of households and firms, hence the LQ approach. However, when we consider the case of Sustainable Cooperation, the problem is no longer a standard LQ problem, since the sustainability constraints, albeit involving quadratic forms, will only be occasionally binding.

${ }^{15}$ Note that consumption Euler equations are redundant, as each country can adjust nominal interest rates to offset the effect of the interest rate gap on the output gap. Thus we do not present them here.

${ }^{16}$ The steady state equilibrium allocations of output, inflation and terms of trade turn out to be 1 . The steady state levels of the markups shocks are also unity.

${ }^{17}$ These are the structural parameters related to the households' preference and firms' technology representations in the original model. See Appendix A.1.
} 


\subsubsection{A "(Non)-insularity" channel: Terms of trade effects on country inflation rates}

Note that under the law of one price, we have $s_{t}^{*}=-s_{t}$. There is a connection between the terms of trade and a notion of insularity in terms of each country's competitive equilibrium description-i.e., (1) and (2). Taking policy as given, How exposed (or insular) a country's competitive equilibrium characterization is to the terms of trade, $s_{t}$, depends crucially on the constant relative risk aversion parameter $\rho>0$. When households are more risk averse $(\rho>1)$, an increase in $s_{t}$ lowers Home marginal costs and hence Home inflation since $(1-\rho) s_{t}<0$. By the same token, it raises Foreign inflation since $(1-\rho) s_{t}^{*}>0$, and this resembles the effect of a positive markup shock on Foreign inflation. When $\rho<1$, the opposite is true. When $\rho=1$, two countries are said to be insular in terms of their competitive equilibrium characterization.

There are two opposing forces explaining why $\rho$ determines how equilibrium terms of trade feeds back onto Home (and Foreign) inflation. Suppose foreign output falls (rises), holding all else constant. On the one hand, internationally complete asset markets, under the law of one price, imply that in equilibrium the Home terms of trade deteriorates (improves)—see (3). A rise (fall) in $s_{t}$ means that the purchasing power of Home agent's wages becomes lower (higher) relative to Foreign agents, which tends to raise (lower) firm's real marginal cost as a result of expenditure switching toward Home-produced goods. Therefore Home inflation tends to rise (fall). On the other hand, the rise (fall) in $s_{t}$ results in a fall (rise) in Home consumption, holding all else constant. This acts through a market clearing condition and the effect of the terms of trade on Home and Foreign demand for Home goods. ${ }^{18}$ Lower (higher) Home consumption raises (lowers) the shadow value of work and through labor market clearing, that tends to lower (raise) Home firms' real marginal cost, and therefore Home inflation tends to fall (rise). ${ }^{19}$ When $\rho>1$, the second channel dominates the first, hence we see a negative relation between Home terms of trade $\left(s_{t}\right)$ and Home inflation $\left(\pi_{t}\right)$ in (1). When $\rho<1$, the first channel dominates the second, so that there is positive relation between Home terms of trade $\left(s_{t}\right)$ and Home inflation $\left(\pi_{t}\right)$ in (1).

The special case is when $\rho=1$, where the two opposing channels cancel out: We label this the case of the economies being insular. The converse logic holds between Foreign terms of trade and inflation in (2). Hereinafter, whenever we consider the environment with $\rho \neq 1$, this channel will be referred to as the non-insularity channel. However, note that the case of $\rho=1$ does not imply that there is no spillover effects from one country's policy outcomes to another in terms of welfare. We will discuss this ever-present welfare relevant terms of trade externality channel in the next section.

\subsection{Welfare criteria and terms of trade externality}

Each country's social welfare function summarizes the households' (competitive equilibrium) value function beginning from date-0. In Appendix A.2 we show how these welfare functions

\footnotetext{
${ }^{18} \mathrm{~A} \log$-linear version of this says $c_{t}=y_{t}-\frac{1}{2} s_{t}$, and for this thought experiment, we have held $y_{t}$ fixed.

${ }^{19}$ In the terminology of Clarida et al. (2002), the former is "the terms of trade effect" while the latter is "the risk sharing effects." For the discussion on this issue in more general setting, see Tille (2001).
} 
can be approximated up to second-order accuracy as: ${ }^{20}$

$$
\begin{aligned}
& V_{0}=-\mathbb{E}_{0} \sum_{t=0}^{\infty} \beta^{t} U_{t}, \\
& :=-\frac{1}{4} \mathbb{E}_{0} \sum_{t=0}^{\infty} \beta^{t}\left[\begin{array}{c}
(\eta+\rho) \underbrace{\left(y_{t}-\frac{1}{\eta+\rho} \mu_{t}\right)^{2}}_{\equiv x_{t}}+\frac{\sigma}{k} \pi_{t}^{2}+\frac{1}{2}(1-\rho) s_{t}^{2} \\
+(\eta+\rho) \underbrace{\left(y_{t}^{*}+\frac{1}{\eta+\rho} \mu_{t}^{*}\right)^{2}}_{\equiv \tilde{x}_{t}^{*}}+\frac{\sigma}{k}\left(\pi_{t}^{*}\right)^{2}
\end{array}\right] \text {, }
\end{aligned}
$$

for the Home country, and,

$$
\begin{aligned}
& V_{0}^{*}=-\mathbb{E}_{0} \sum_{t=0}^{\infty} \beta^{t} U_{t}^{*}, \\
&:=-\frac{1}{4} \mathbb{E}_{0} \sum_{t=0}^{\infty} \beta^{t}\left[\begin{array}{c}
(\eta+\rho) \underbrace{\left(y_{t}^{*}-\frac{1}{\eta+\rho} \mu_{t}^{*}\right)^{2}}_{\equiv x_{t}^{*}}+\frac{\sigma}{k}\left(\pi_{t}^{*}\right)^{2}+\frac{1}{2}(1-\rho)\left(s_{t}^{*}\right)^{2}] \\
+(\eta+\rho) \underbrace{\left(y_{t}+\frac{1}{\eta+\rho} \mu_{t}\right)^{2}}_{\equiv \tilde{x}_{t}}+\frac{\sigma}{k} \pi_{t}^{2}
\end{array}\right],
\end{aligned}
$$

for the Foreign country. ${ }^{21}$

We note that these welfare functions have been derived by taking a second-order Taylor expansion of household lifetime utility functions and of relevant competitive equilibrium conditions. As part of the derivation, a "timeless perspective" assumption is required: From each country's domestic perspective, the policymakers are assumed to be able to commit to implementing their particular policy plan that is assumed to have been in place in some infinite past leading up to an arbitrary date 0 (see e.g., Benigno and Benigno, 2006; Benigno and Woodford, 2005, 2012). ${ }^{22}$ This is taken to hold in each policy regime-Cooperation, Non-cooperation, or what we will term Sustainable Cooperation—-that we will study later.

\subsubsection{Terms-of-trade externality channel and Non-cooperation regime}

Note that the targets of Home and Foreign output in the welfare criteria (4) and (5) are nonzero and different between the countries. Observe also that each country's welfare depends on the output and markup shock from its foreign counterpart. This arises as there is a terms-of-

\footnotetext{
${ }^{20}$ In Appendix A.2 these functions are derived for a more general setting where country sizes are allowed to differ. In the presentation here, we have the special case where countries are symmetric.

${ }^{21}$ More precisely, the date- 0 values are state-dependent: $V_{0}:=V\left(s_{-1}, \tau_{0}\right)$ and $V_{0}^{*}:=V\left(s_{-1}, \tau_{0}\right)$. Generically (and in the Sustainable Cooperation regime later) the relevant states are $s_{t}=\left(y_{t-1}, y_{t-1}^{*}, v_{t-1}\right)$ and $\tau_{t}=$ $\left(\mu_{t}, \mu_{t}^{*}, \mu_{t-1}, \mu_{t-1}^{*}\right)$, where $v_{t}$ is an endogenous and auxiliary state variable interpretable as a pseudo-Pareto weight on Home's welfare in a Sustainable Cooperation regime. Note that in the other regimes of Cooperation and Noncooperation, this auxiliary state is redundant.

${ }^{22}$ Note that by an arbitrary date 0 , we mean the time at which one (i.e., the observer) begins recording the history of event in the model economy. This is different to the date at which the policy plan was designed and put in place (which was in some infinite past). Further discussion on this technicality can be found in Appendix A.2. See especially the ensuing remarks in Appendix A.3.
} 
trade externality underlying the openness of the economies discussed above. On the one hand, the policymakers desire to set output so that the welfare-relevant output gaps in Eqs. (4) and (5) are close to zero. On the other, they also want to stabilize domestic and foreign inflation. To fix ideas, suppose that there is a positive Home markup shock. The Home policymaker wishes to set the domestic output $y_{t}=\mu_{t} /(\eta+\rho)>0$ as in Eq. (4) so that output gap $x_{t}:=$ $y_{t}-\mu_{t} /(\eta+\rho)$ is zero. However, doing so harms the Foreign policymaker, as the welfarerelevant gap in the Foreign country (i.e., the terms-of-trade spillover effect on Foreign) becomes $\tilde{x}_{t}:=y_{t}+\mu_{t} /(\eta+\rho)=2 \mu_{t} /(\eta+\rho)$ in equation (5). This illustrates that there is a conflict of interest in the nature of the problem if the central banks behave independently of each other, ceteris paribus.

One way to expound on this potential externality problem when considering each country's policy problem separately, is as follows: Consider an intermediate step in arriving at the approximating per-period social welfare functions $U_{t}$ and $U_{t}^{*}$, respectively, found in equations (4) and (5). This intermediate step would produce the following pair of expressions:

$$
\begin{aligned}
U_{t} & =\frac{1}{2} s_{t}-\frac{1-\rho}{2}\left(y_{t}-\frac{1}{2} s_{t}\right)^{2}+\frac{1+\eta}{2} y_{t}^{2}+\frac{\sigma}{k} \pi_{t}^{2}, \\
U_{t}^{*} & =-\frac{1}{2} s_{t}-\frac{1-\rho}{2}\left(y_{t}^{*}+\frac{1}{2} s_{t}\right)^{2}+\frac{1+\eta}{2}\left(y_{t}^{*}\right)^{2}+\frac{\sigma}{k}\left(\pi_{t}^{*}\right)^{2} .
\end{aligned}
$$

Of course, one cannot stop at this point in deriving the approximate welfare functions. ${ }^{23}$ For our exposition here, this break-down of the steps is nevertheless instructive. Note that a naïve addition of these two terms, $U_{t}+U_{t}^{*}$, yields an expression equivalent to the per-period loss in the global welfare function (6), as the linear terms of $s_{t}$ are canceled out. That means that under global cooperation of monetary policy, there is no terms of trade externality problem. However, if the social welfare in each country is considered separately under independent national monetary-policy making, $s_{t}$ is substitutable for a quadratic approximation of the Home and Foreign Phillips curves. This results in the non-zero output targets in Eqs. (4) and (5). In words, and policy-wise, this implies that by manipulating the terms of trade externality on other nations, domestic policymakers can potentially reduce their own losses arising from inflation and output fluctuations, where the latter is aimed at by setting a non-zero output target for their own country. This is because the independent and selfish policymakers know the nexus between their policies and the terms of trade. In turn, they know the net effect of the terms of trade on output gap, all else equal, but they do not care what happens to the other country's welfare.

\footnotetext{
${ }^{23}$ If taken at face value, the linear terms in the intermediate welfare approximation step may induce spurious welfare evaluation in the LQ framework (see e.g., Kim and Kim, 2003, 2007).
} 


\subsubsection{Welfare under Cooperation regime}

Consider next the case where Home and Foreign countries face a consolidated or global social welfare function. From Eqs. (4) and (5), the global social welfare function is obtained as ${ }^{24}$

$$
\begin{aligned}
V_{0}^{W}= & \frac{1}{2} V_{0}+\frac{1}{2} V_{0}^{*}, \\
= & -\frac{1}{2} \mathbb{E}_{0} \sum_{t=0}^{\infty} \beta^{t}\left[U_{t}+U_{t}^{*}\right], \\
= & -\frac{1}{4} \mathbb{E}_{0} \sum_{t=0}^{\infty} \beta^{t}\left[(\eta+\rho) y_{t}^{2}+(\eta+\rho)\left(y_{t}^{*}\right)^{2}\right. \\
& \left.\quad+\frac{1-\rho}{2}\left(y_{t}-y_{t}^{*}\right)^{2}+\frac{\sigma}{k} \pi_{t}^{2}+\frac{\sigma}{k}\left(\pi_{t}^{*}\right)^{2}\right] .
\end{aligned}
$$

Here, the targets of Home and Foreign output are zero for both countries, whereas they are non-zero in Eqs. (4) and (5). This echoes our insight earlier that if there is (by construction) a consolidated global policymaker, or equivalently, the two policymakers cooperate in all contingencies, then the terms of trade externality is fully internalized. That is, there is no conflict of interest between the countries over $s_{t}$ when we deal with the Cooperation regime.

\subsubsection{Time-0 vs. timeless perspectives on welfare}

In the welfare analyses later, we will utilize two different welfare metrics depending on the nature of our question. ${ }^{25}$ First, if we are only interested in a decomposition into the components comprising the welfare outcome within a particular policy regime, then we evaluate welfare with respect to the ergodic and unconditional distribution of a given policy regime's equilibrium. We call this measure the unconditional welfare measure, or, elsewhere this is often interpreted as a welfare metric under the timeless perspective. ${ }^{26}$ By taking unconditional expectation of (4) and (5), the unconditional welfare functions for Home and Foreign, respectively, are

$$
\begin{aligned}
E V= & -(1-\beta)^{-1} \frac{1}{4} \mathbb{E}\left[(\eta+\rho) x_{t}^{2}+(\eta+\rho)\left(\tilde{x}_{t}^{*}\right)^{2}\right. \\
& \left.+\frac{1-\rho}{2} s_{t}^{2}+\frac{\sigma}{k} \pi_{t}^{2}+\frac{\sigma}{k}\left(\pi_{t}^{*}\right)^{2}\right], \\
E V^{*}= & -(1-\beta)^{-1} \frac{1}{4} \mathbb{E}\left[(\eta+\rho)\left(x_{t}^{*}\right)^{2}+(\eta+\rho) \tilde{x}_{t}^{2}\right. \\
& \left.+\frac{1-\rho}{2} s_{t}^{2}+\frac{\sigma}{k} \pi_{t}^{2}+\frac{\sigma}{k}\left(\pi_{t}^{*}\right)^{2}\right],
\end{aligned}
$$

where $x_{t}=y_{t}-\frac{1}{\eta+\rho} \mu_{t}, \tilde{x}_{t}=y_{t}+\frac{1}{\eta+\rho} \mu_{t}, x_{t}^{*}=y_{t}^{*}-\frac{1}{\eta+\rho} \mu_{t}^{*}, \tilde{x}_{t}^{*}=y_{t}^{*}+\frac{1}{\eta+\rho} \mu_{t}^{*}$, and $\mathbb{E}[\cdot]$ denotes an expectations operator with respect to a regime's equilibrium (unconditional) distribution of state variables.

\footnotetext{
${ }^{24}$ As shown in Appendix A.2, naturally, this can be obtained directly by approximating the global welfare.

${ }^{25}$ For further details behind the discussion in this section, please see Appendix A.3.

${ }^{26}$ By construction, the measured welfare outcome from this metric encodes an infinitely (in practice, sufficiently) long history of (within-country) commitment policy outcomes. Thus, we can also call this welfare metric one under the timeless perspective. See also its usage earlier by McCallum and Nelson (2004) and Sauer (2010). See its usage in Figure 2 on page 18 and Figure 6 on page 29 below.
} 
The nice feature of these measures is that they are decomposable into the unconditional volatility (variance) of each welfare function argument from (4) and (5), respectively. This facilitates additional insights into what account for welfare outcomes. (See the discussions around Figure 2 on page 18, and, Figure 6 on page 29 in the paper later.)

Second, we also consider another measure of conditional welfare for each country-i.e., the functions derived earlier as (4) and (5). The unconditional welfare metric above cannot be used, if our question is one of comparing relative welfare outcomes across different policy regimes. That is because given each regime's equilibrium outcome, the corresponding implementation of an unconditional welfare measure would be with respect to an ergodic distribution likely to be different from another regime's or equilibrium's outcome- -hence any welfare comparison using that metric would be meaningless, if not misleading as it involves arbitrary orderings of welfare numbers. Thus, we can only compare welfare outcomes across different equilibria or regimes if these welfare measures are conditioned on the same initial states, using the functions derived as (4) and (5). This, we label the time-0 conditional welfare measure. Later, we also call this the stochastic steady-state welfare measure. ${ }^{27}$

\section{Cooperation vs. Non-cooperation}

We now use the LQ framework to first discuss the two polar regimes of Cooperation and Noncooperation. Here we will first characterize the equilibria (including their policy trade-off descriptions) under these two regimes (in Section 3.1), compare their equilibrium behaviors and provide some intuition behind the mechanics of these outcomes (in Section 3.2). From these insights, in Section 3.3, we then address the first question raised in this paper: Under what conditions in our model will an assumed Cooperation regime fail to be incentive feasible?

Since there are no analytical solutions for equilibria under all the policy regimes we consider in this paper, we will have to analyze these regimes numerically. For all of our computational analyses, the model is parametrized by the settings summarized in Table 1. We follow BB with some exceptions: The elasticity of substitution between domestic and foreign goods is equal to one and Calvo parameters are the same in Home and Foreign countries. The exogenous markup shocks are assumed to be finite-state Markov chains. Each country's Markov chain is independent from the other's. We set, $\mu \in M=\left\{-\sigma_{\varepsilon}, 0, \sigma_{\varepsilon}\right\}$ and $\mu^{*} \in M^{*}=\left\{-\sigma_{\varepsilon}^{*}, 0, \sigma_{\varepsilon}^{*}\right\}$, respectively for the Home and Foreign country markup shocks. The shocks' Markov (matrix)

\footnotetext{
${ }^{27}$ In the numerical exercises below, we condition these welfare measures on the same initial natural states, where the initial lagged output states are $y_{-1}=y_{-1}^{*}=0$. (See Figure 3 on page 21, Figure 9 on page 35, Figure 7 on page 30 and the discussions surrounding them in Sections 3.3 and 4.3.) However, there will be another auxiliary state variable $v$, interpretable as the (relative) pseudo-Pareto weight, when one considers the Sustainable Cooperation regime later. (This variable is non-existent in the other two regimes of Cooperation and Non-cooperation.) In this case, we also need to start the Sustainable Cooperation equilibrium outcome off at some point for the initial auxiliary state $v_{-1}$, apart from setting the same initial natural state, $y_{-1}=y_{-1}^{*}=0$, when comparing this regime's stochastic steady-state welfare measure with the other regimes'. In the paper we consider two possible cases: In the baseline setting we have $v_{-1}=1 / 2$, which is the deterministic steady state of the model and is the same as the time-invariant Pareto weight in the Cooperation regime. Also, this is the convention in defining a Ramsey equilibrium steady state value (King and Wolman, 1999; Khan et al., 2003). We also consider $v_{-1}$ being equal to the stochastic steady state of the model, i.e., its asymptotic upper bound (in short we called it "u.b.") in a particular Sustainable Cooperation equilibrium, but this does not change our results. Note that even though we adopt the LQ approximation, the deterministic and stochastic steady state values are different due to the occasionally binding sustainability constraints.
} 
operator is given by $p: \Delta(M) \rightarrow \Delta(M)$, where $p(\cdot \mid x)_{(1 \times 3)}=\left[\left(1-\rho_{x}\right) / 2, \rho_{x},\left(1-\rho_{x}\right) / 2\right]$ denotes the conditional distribution for next-period state $x^{\prime}$, for each $x, x^{\prime} \in\left\{\mu, \mu^{*}\right\}$. Since we are not performing an empirical or quantitative exercise, for simplicity, we set $\rho_{\mu}=\rho_{\mu}^{*}=0.5$, $\sigma_{\varepsilon}=1.0$ and $\sigma_{\varepsilon}^{*}=0.2$-i.e., there is asymmetric volatility between the Home and Foreign countries, but each period, the shocks are drawn independently from an identical distribution. ${ }^{28}$ Also, where relevant to our questions, we will vary parameters such as the coefficient of relative risk aversion $\rho$ to illustrate the intuitions developed earlier. As the equilibrium under Sustainable Cooperation can be obtained only numerically, we use the same policy function iteration method to solve for the other equilibria under Cooperation and Non-cooperation and compare the equilibria under different regimes.

Table 1: Parameter values.

\begin{tabular}{lll}
\hline & Parameters & Values \\
\hline$\beta$ & subjective discount factor & 0.99 \\
$\eta$ & Frisch elasticity & 0.47 \\
$\rho$ & coefficient of relative risk aversion & $\{0.5,1.0,1.5\}$ \\
$\alpha$ & Calvo parameter & 0.75 \\
$\sigma$ & elasticity of substitution among differentiated products & 10.0 \\
\hline
\end{tabular}

\subsection{Equilibrium policy trade-offs}

Policymakers under an assumed Cooperation regime maximize the global social welfare function (6) subject to the Phillips curves (1) and (2). The first-order necessary conditions (FONCs) in the Cooperation regime are (1) and (2), appended with the optimal trade-offs for the policymakers for every state and date $t \geq 0:{ }^{29}$

$$
\begin{aligned}
& -\sigma \pi_{t}=y_{t}-y_{t-1}, \\
& -\sigma \pi_{t}^{*}=y_{t}^{*}-y_{t-1}^{*} .
\end{aligned}
$$

Because of commitment to future policies inherent in both of the Cooperation and Non-cooperation regimes, lagged output appears in each countries' equation-i.e., the policymakers conduct history-dependent policies in both regimes. Also, as shown by BB, in the Cooperation regime, the optimal targeting rules are always inward-looking in the sense that the optimal trade-off only involves each policymaker's own-country variables.

In contrast, a policymaker in the Non-cooperation regime maximizes the social welfare function in his country given the other country's outcome. The policymaker in the Home country maximizes (4) subject to the Philips curves (1) and (2), given $\pi_{t}^{*}$, and the policymaker in the Foreign country maximizes (5) subject to the Philips curves (1) and (2), given $\pi_{t}$. The FONCs,

\footnotetext{
${ }^{28}$ We actually solve the model using a Markov chain approximation of the shock process. We delay the details until Section 4.1 below.

${ }^{29}$ See Appendix B.1 for the derivation of Eqs. (9)-(12).
} 
for every state and date $t \geq 0$, in the Non-cooperation regime are (1) and (2), along with

$$
\begin{aligned}
& -\sigma \pi_{t}=y_{t}-\xi_{t}-\left(y_{t-1}-\xi_{t-1}\right), \\
& -\sigma \pi_{t}^{*}=y_{t}^{*}-\xi_{t}^{*}-\left(y_{t-1}^{*}-\xi_{t-1}^{*}\right),
\end{aligned}
$$

where

$$
\xi_{t}=\frac{(1+\rho+2 \eta) \mu_{t}-(1-\rho) \mu_{t}^{*}}{2(1+\eta)(\eta+\rho)} \quad \text { and } \quad \xi_{t}^{*}=\frac{(1+\rho+2 \eta) \mu_{t}^{*}-(1-\rho) \mu_{t}}{2(1+\eta)(\eta+\rho)}
$$

stem from the Home and Foreign target outputs in Eqs. (4) and (5), and they reflect the terms of trade externality. ${ }^{30}$ (Recall the previous discussion in Section 2.2).

In what follows, we dissect the differences between the equilibria under Cooperation and Non-cooperation. First, we describe and compare their induced dynamics. Then we provide counterexamples to the presumption that Cooperation is always and everywhere incentive feasible, and we explain the forces underlying such incentive infeasibility of a Cooperation regime.

\subsection{Dynamics and welfare decomposition: Cooperation and Non-cooperation}

Figure 1 depicts the impulse responses of endogenous variables to a one-time positive Home markup shock in the initial period with $\left(y_{-1}, y_{-1}^{*}\right)=(0,0)$. When the countries are insular $(\rho=1)$, Home inflation and output gap responses under Cooperation and Non-cooperation, respectively, look alike in response to a Home markup shock. The terms of trade $s_{t}$ responds differently under Non-cooperation. When the countries are more risk averse $(\rho>1)$, the terms of trade plays a role like a positive (negative) markup shock to Foreign (Home) inflation. Conditional on shocks, policymakers may have incentive to deviate from Cooperation to Non-cooperation because under Non-cooperation they can manipulate the terms of trade. We further investigate the intuition behind these results as below.

Dynamics when $\rho=1$. Consider first the special case of $\rho=1$. Recall from earlier that when $\rho=1$, the two countries become insular in the sense that the exogenous shock in one country does not feedback onto the other. That is, only the Home-country variables respond to the shock. Home inflation and output gap responses in the Cooperation and Non-cooperation regimes, respectively, are qualitatively similar: The policymaker in either case commits to future deflation and mitigates the trade-off between current inflation and the output gap as in the well-studied closed economy setting. The terms of trade $s_{t}$ responds differently to a markup shock in Home country under the Non-cooperation regime. Under Cooperation, the terms of trade responds negatively to markup shocks. Under Non-cooperation, the terms of trade responds positively at the impact of the shock, so that the Home output gap $\left(x_{t}=y_{t}-\mu_{t} /(\eta+\rho)\right)$ response is more attenuated; but this is traded off with a more aggressive response in Home inflation.

Under Non-cooperation, a positive response of the terms of trade can be deduced from the

\footnotetext{
${ }^{30}$ Observe that when $\rho=1$, the term $\xi_{t}\left(\right.$ or $\xi_{t}^{*}$ ) only depends on domestic markup shocks $\mu_{t}$ (or $\mu_{t}^{*}$ ) which means that the optimal Non-cooperation policy is inward-looking. However, there remain gains from cooperation because the terms of trade externality channel is still present.
} 
risk sharing first order condition (3). Note that when $\rho=1$, the terms of trade $s_{t}$ has no direct effect on the Phillips curve equilibrium restrictions on policy-i.e., Eqs. (1) and (2)-nor the policymakers' optimal trade-offs (11) and (12). Given its welfare trade-off with inflation, the output gap will not be completely closed, so then the shock will still imply a negative output gap outcome. Since the Foreign country is "insular", $y_{t}^{*}$ remains unchanged in Foreign. Thus, the risk sharing condition implies that the terms of trade rises with the rise in $y_{t}$, upon impact of the shock (see Eq. (3)). Since Foreign still behaves in an insular manner and does not react to what Home does, it must absorb the marginal welfare loss involving $\tilde{x}_{t}=y_{t}+\mu_{t} /(\eta+\rho)$. The latter is the terms-of-trade externality effect discussed earlier (see Section 2.2.1). In this example, this is a spillover onto Foreign's welfare that is being exploited by Home.

In contrast, in the Cooperation regime, the consolidated policy maximizes the global social welfare function (6). As in the Non-cooperation regime, the shock will also yield a negative output gap, but the target output is zero in this case. Thus, the Cooperation regime's optimal plan ends up inducing a negative output in response to the Home markup shock. This translates as larger negative Home output gap (which is equal to output itself) and a negative terms of trade response upon impact. In return, Home inflation suffers a smaller fluctuation over time and output gap deviation from zero is shorter lived.

Dynamics when $\rho \neq 1$. When $\rho \neq 1$, the "non-insularity" channel (recall Section 2.1.1) against the terms-of-trade externality effect comes into consideration as well. When the countries are more risk averse $(\rho>1)$, the terms of trade plays a role akin to a positive markup shock to Foreign inflation. Since the Foreign country is no longer insular, under Non-cooperation Foreign will also react in order to offset Home's desire to manipulate the terms of trade externality. In a Markov perfect equilibrium of the Non-cooperation regime, this results in a positive Foreign output response which tends to weaken the positive terms of trade response that would have been if $\rho=1$. Also, from Home's perspective, inducing a rise in the terms of trade acts as "negative markup shock" offsetting the incentive of Home to exploit the terms of trade externality itself. In other words, Home does not need to engineer such a large response in the terms of trade in order to absorb the original positive markup shock at home. 
Figure 1: Impulse responses to a positive Home markup shock.
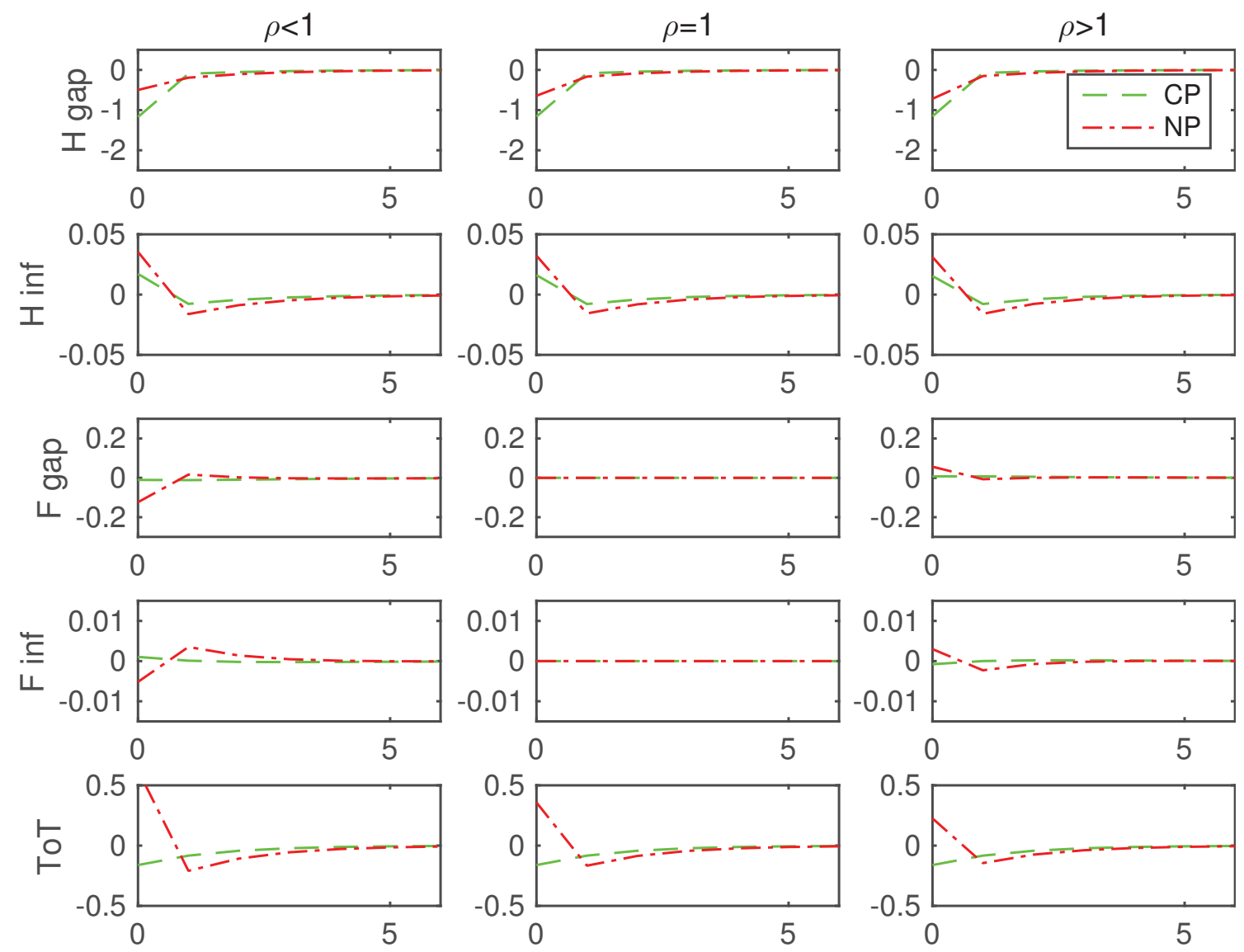

Notes: The left column is for the case of $\rho=0.5$, the center column is for $\rho=1.0$, and the right column is for $\rho=1.5$.

Unconditional welfare decomposition. Figure 2 on page 18 depicts the (negative) unconditional expected welfare measures (i.e., welfare losses) for Home and Foreign, into their respective variance arguments in (7) and (8). This is done separately for each regime under Cooperation (panel $a$ ) and Non-cooperation (panel $b$ ), as a function of a sequence of economies indexed by the risk aversion parameter $\rho{ }^{31}$ This exercise reinforces the intuition developed above. Consider the Cooperation regime. Home country suffers from fluctuations in the Home output gap (labelled as "H gap" in the figure) in the face of the Home markup shock. (Foreign also faces a similar but more attenuated problem here as we are looking at stochastic simulations with all shocks active.) Because of the asymmetry of shock volatilities working relatively more against Home, the major component contributing to the unconditional welfare loss of Home shows up as Home output gap volatility. Also note that the direct terms of trade volatility contributes negatively (i.e. compounds losses) to Home welfare when $\rho<1$, zero loss when $\rho=1$, and

\footnotetext{
${ }^{31}$ We should read this section with caution. In particular, note that when we consider the two regimes of Cooperation and Non-cooperation, we are looking at their respective equilibrium unconditional welfare outcomes separately. The discussion in this section makes no attempt to compare the welfare values across the two regime's equilibrium outcomes.
} 
positively when $\rho>1$. This is an artifact of the third term in the welfare function (7) involving $s_{t}$-this term reflects the "non-insularity" channel we outlined in Section 2.1.1 earlier. This term switches sign from negative to positive as $\rho$ is increased beyond unity, with its welfare effect taking on a zero value when $\rho=1$.

These two observations, based on unconditional welfare decompositions, again echo the previously explained incentive problem for Home. If Home were in a Non-cooperation regime, it can reduce welfare loss associated with Home output-gap fluctuations by exploiting the terms of trade externality under Non-cooperation regime: Observe that in the contrasting Non-cooperation equilibrium in panel $b$, the contribution of Home output gap variance is smaller relative to the total welfare measured in the Non-cooperation regime itself. This is gained by sacrificing Foreign welfare in terms of noisier fluctuations in the second argument, $\left(y_{t}+\mu_{t} /(\eta+\rho)\right)^{2}>0$, (labelled as "H gap*"). This term, as explained earlier, embodies the terms of trade externality effect from Home on Foreign, taking into account retaliation effects from Foreign to Home welfare in a Non-cooperation equilibrium. Consistent with the intuition developed earlier, a retaliation effect on Home's welfare (shown as "F gap") becomes very small when $\rho=1$. 
Figure 2: Welfare (loss) decomposition under Cooperation and Non-cooperation: with varying a. Cooperation:
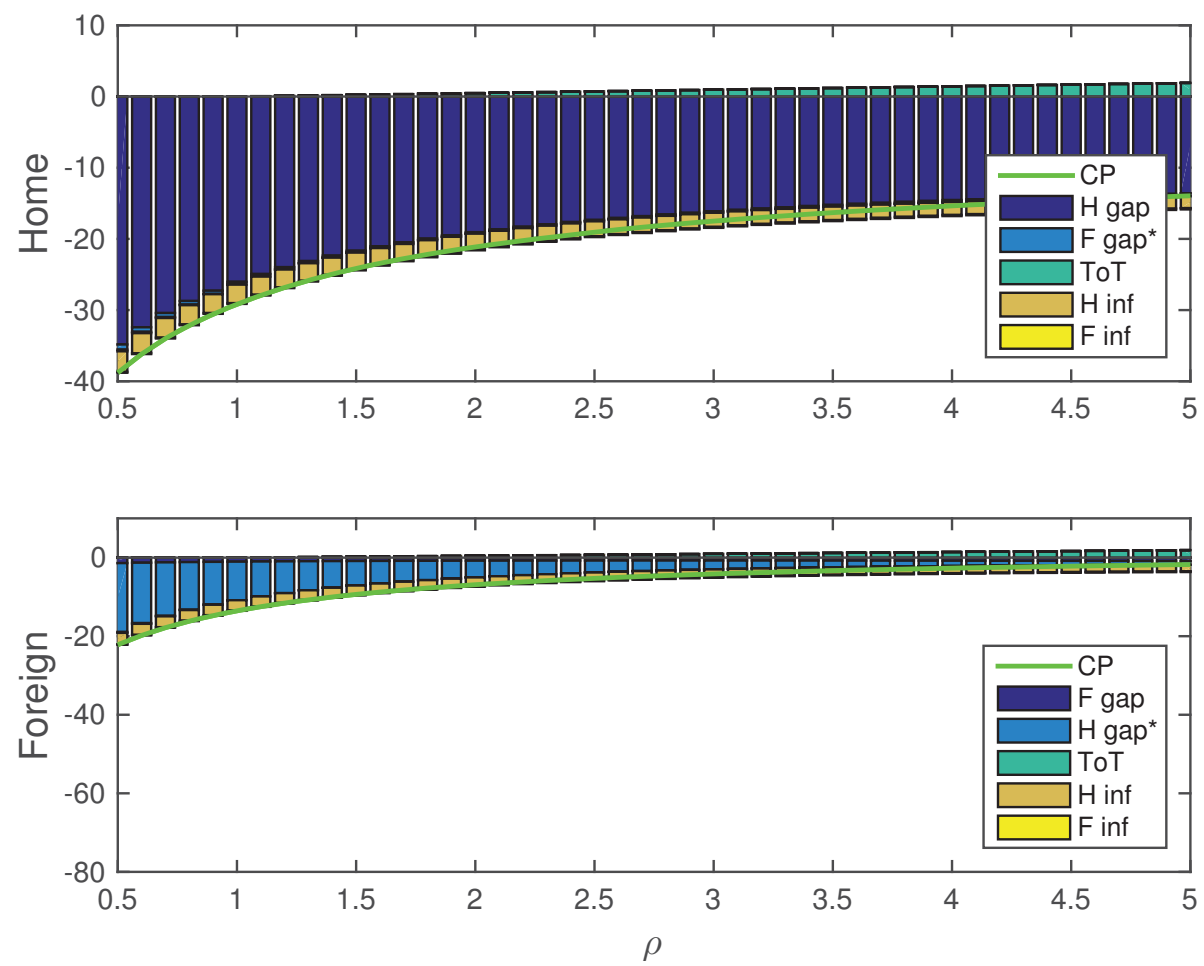

b. Non-cooperation:
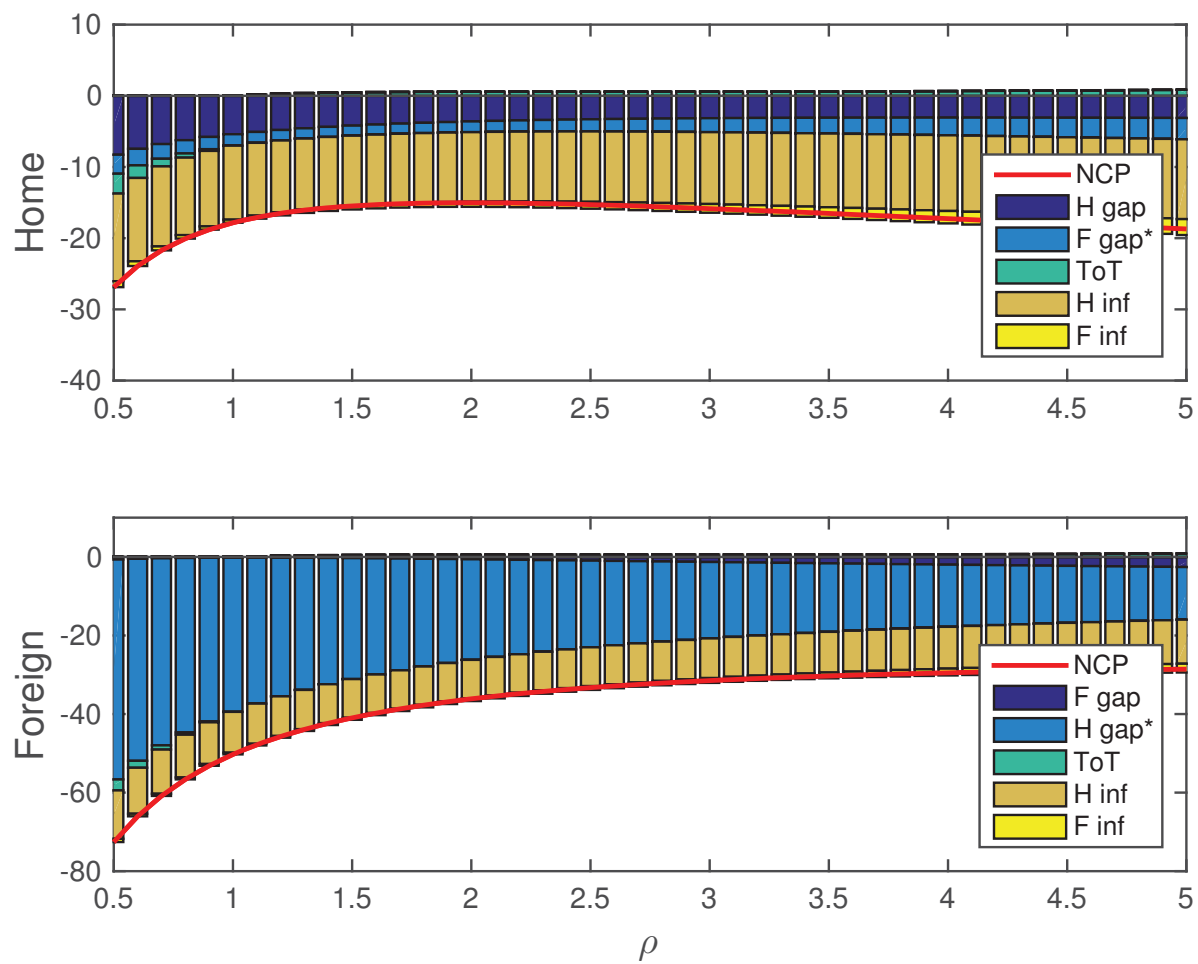


\subsection{Infeasibility of Cooperation: inspecting the mechanism}

We now address the first question raised in this paper: Under what conditions in our model will an assumed Cooperation regime fail to be incentive feasible? Conditional on the state variables (i.e., the lagged output and shocks), policymakers may have incentive to deviate from Cooperation to Non-cooperation because under the Non-cooperation regime, they can manipulate the terms of trade. ${ }^{32}$ We now study such possibilities in the model as a function of two things: relative noisiness between the country's markup shocks and risk aversion.

We let $V_{0}^{c} \leq 0$ and $V_{0}^{n} \leq 0$ denote the conditional welfare values to the Home policymaker in the stochastic steady state under the Cooperation and Non-cooperation regime, respectively. ${ }^{33}$ Likewise $V_{0}^{* c} \leq 0$ and $V_{0}^{* n} \leq 0$ are the corresponding counterparts for Foreign. (Note these values are non-positive since the welfare criteria are negative quadratic.) The statistic, $R_{0} \equiv$ $-\max \left\{V_{0}^{c} / V_{0}^{n}-1,0\right\}$, is less than zero when $V_{0}^{c}<V_{0}^{n}$ holds. If $R_{0}$ is negative, then the Noncooperation regime yields a higher welfare to Home than the Cooperation regime-i.e. there is an incentive feasibility problem on the part of Home for international cooperation. Otherwise if $R_{0}=0$ then there is no incentive to deviate from Cooperation on the part of Home. The interpretation is the same for the Foreign counterpart of this statistic, $R_{0}^{*}$.

Figure 3 on page 21 shows the (relative) conditional social welfare of Home $\left(R_{0}\right)$ and Foreign $\left(R_{0}^{*}\right)$ under Cooperation and Non-cooperation. First consider raising the Home's markup shock volatility relative to its Foreign counterpart from $\sigma_{\varepsilon} / \sigma_{\varepsilon}^{*}=2$ to 5 . This exercise shows that policymakers may have incentive to deviate when asymmetric markup shock volatility exists across the countries. ${ }^{34}$ The higher the ratio of the standard deviation of Home markup shock to its Foreign counterpart $\sigma_{\mathcal{\varepsilon}} / \sigma_{\mathcal{\varepsilon}}^{*}$, the lower is the Home social welfare under Cooperation than under Non-cooperation. When one country faces a higher probability of experiencing severe markup shocks, the policymaker has more incentive to deviate from Cooperation and behave strategically. Here, only the Home policymaker (who face a possibility of larger shocks) has more incentive to deviate.

Now consider the statistic, $R_{0}$, as a function of risk aversion $\rho$ in Figure 3 on page $21 .{ }^{35}$ The Home policymaker has the largest incentive to deviate at around $\rho=1$, but this temptation tapers off with $\rho \gtrless 1$. We explain why this is the case by identifying the (opposing) forces at play in this model.

Consider first the special case of $\rho=1$. Imagine that both countries are under the Cooperation regime, but they also consider what their payoff would be were they to deviate to the Non-cooperative equilibrium. Suppose we have a positive markup shock, $\mu_{t}>0$, to Home. If Home were to deviate to Non-cooperation, this entails a temptation for Home to try to close output gap, by raising $y_{t}$ (but trading off with higher inflation, $\pi_{t}$ ). Through the equilibrium

\footnotetext{
${ }^{32}$ Coenen et al. (2007) study a similar question in a large-scale model of the European Central Bank (i.e., the New Area Wide Model).

${ }^{33}$ This is called the stochastic or risky steady state (Coeurdacier et al., 2011), as it incorporates the future possibility of shocks hitting the economy.

${ }^{34}$ Corsetti et al. (2010) argue that strategic manipulation of the terms of trade under non-cooperation of a symmetric Nash equilibrium usually is self-defeating. However, we show that the welfare gain from Non-cooperation is non-negligible-i.e., the policymaker's has incentive to deviate from the Cooperation regime-when there is asymmetric volatility in the markup shock process that each country faces.

${ }^{35}$ When $\rho$ is too high, the objective function may not be concave as $(1-\rho) s_{t}^{2}$ has a large and positive value. It may violate the second-order conditions of the welfare maximization problem; see BB p. 487.
} 
international risk sharing channel, this induces a negative terms-of-trade externality in terms of the output gap term in Foreign's welfare function (5), making Foreign worse off, via the term $\left(y_{t}+\mu_{t} /(\eta+\rho)\right)^{2}>0$. When $\rho=1$, there is no additional feedback complication on Home or Foreign inflation via (1) and (2), respectively-i.e., there is "insularity" in the sense of there being no direct exposure of inflation to terms of trade in the market equilibrium conditions. Therefore, Home with a relatively more volatile markup shock $\left(\sigma_{\varepsilon} / \sigma_{\varepsilon}^{*}>1\right)$, has most incentive to exploit this terms-of-trade externality mechanism, but Foreign has no incentive to walk away from Cooperation.

Next, consider the case where $\rho<1$. Now there are two opposing forces at play, via the terms of trade, $s_{t}$. The first force is as explained in the previous special case of $\rho=1$. However, it is further reinforced in the same direction by the (endogenous cost-push-like) feedback of $s_{t}$ onto higher $\pi_{t}$ in (1). On one hand this strengthens the temptation to deviate from Cooperation on the part of Home. However, there is a second opposing force: By attempting to close Home output gap through raising $y_{t}$ (again, at some expense of higher $\pi_{t}$ ) were Home to deviate, international asset market equilibrium via (3), implies that $s_{t}$ will increase. Since $\rho<1$, a higher $s_{t}$ implies a similar effect of a negative cost push shock on Foreign inflation in (2). Now, Foreign-also conjecturing what its payoff would be were Foreign to walk away from Cooperation toward Non-cooperation-also has the incentive to close its output gap, by reducing $y_{t}^{*}$, but this also directly hurts Home's welfare. This second "non-insularity" force (due to $\rho<1$ ) acts as countervailing incentive (or a self-disciplining device) against Home's conjecture or intent to exploit the terms-of-trade externality channel in the first instance.

In the case where $\rho>1$, the mechanism with opposing forces is similar to the case of $\rho<1$, with the exception that the effect of an initial Home positive markup shock on inflation would be partially weakened by the feedback of $s_{t}$ akin to a negative cost-push shock. This weakens the incentive to deviate from Cooperation at the first instance for Home.

By identifying the opposing forces at play, and in particular, the interaction between the pure terms-of-trade externality channel and feedback effect of $s_{t}$ onto inflation (i.e., the "noninsularity" channel), we have explained why the temptation is largest at $\rho=1$ for Home to walk away from a Cooperation Regime toward a Non-Cooperation regime, and why this tapers off when $\rho \gtrless 1$. $^{36}$

\footnotetext{
${ }^{36}$ Note that in centering our discussion around the special case of $\rho=1$ we are not claiming a general result. When we entertain the more general setting with different country sizes $\gamma \neq 1$ later in Section 5, the basic intuition from this section still applies. However, when countries differ in their sizes, the incentive-feasibility of Cooperation from the point of view of Home or Foreign, and with respect to risk aversion $\rho$ will also be tempered by country size $\gamma$. There will be an interaction between these two parameters in terms of the opposing terms-of-trade externality versus the non-insularity (feedback) channels.
} 
Figure 3: Welfare comparison under Cooperation vs. Non-cooperation: with varying $\rho$
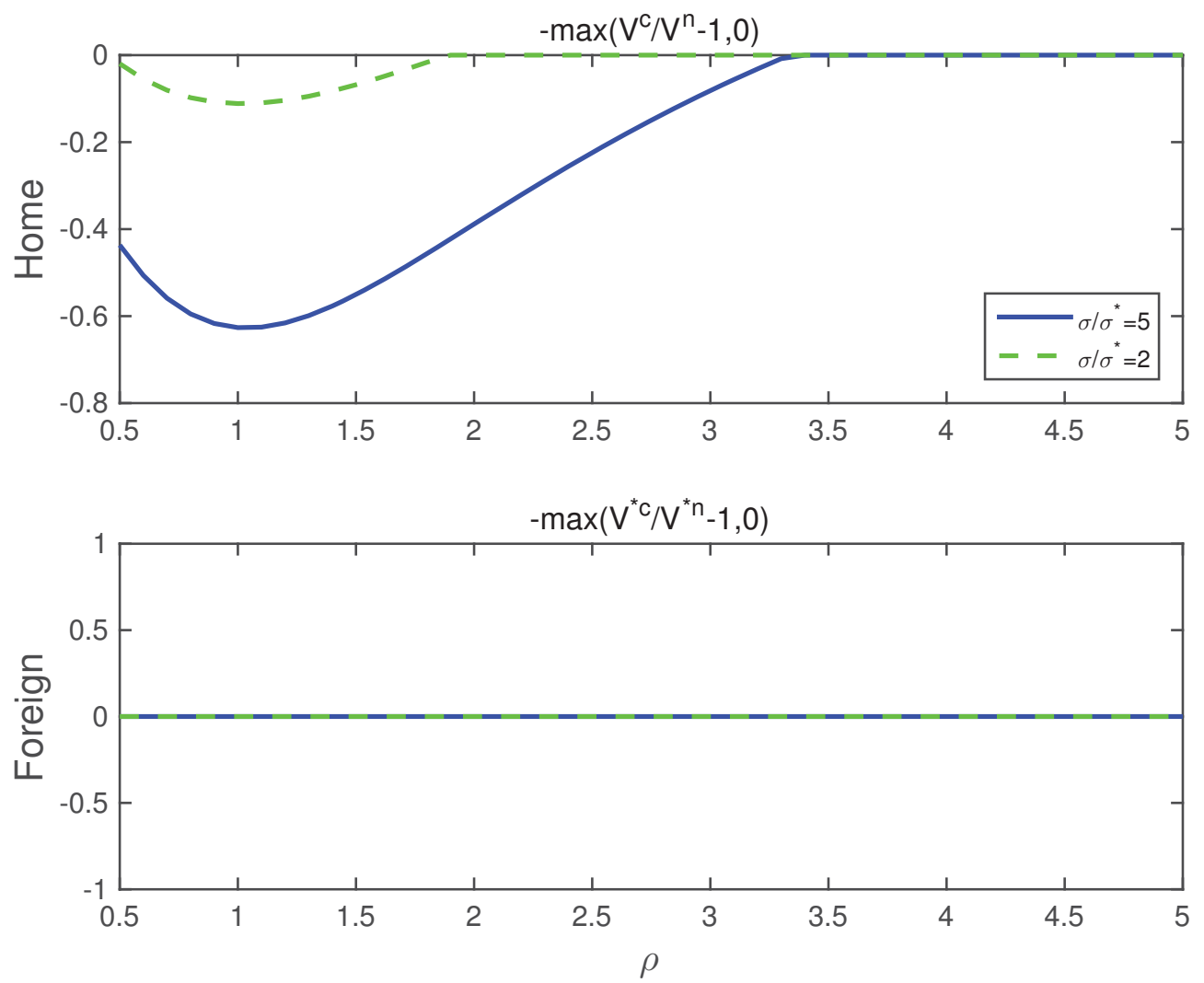

In short order, we cannot take the Cooperation regime as being always incentive feasible for the independent policymakers. Under arguably realistic settings, e.g., asymmetric volatililities of country specific shocks, the temptation to deviate from Cooperation can arise. However, this naturally leads us to ask whether the countries can do better than merely behaving under Non-cooperation. We deal with this by considering the endogenous Sustainable Cooperation regime next.

\section{Sustainable Cooperation}

Now we consider the regime with endogenously sustainable cooperation. In this setting, a dynamic state-contingent contract is recorded from date 0 between the countries, but this contract is taken to have been in place since time immemorial (given the timeless perspective underlying the welfare function derivations). The state-contingent contract ensures that each policymaker has no incentive to deviate from cooperating as long as the sustainability constraints

$$
\begin{gathered}
V_{t}=-\mathbb{E}_{t} \sum_{s=t}^{\infty} \beta^{s-t} U_{s} \geq W\left(y_{t-1}, y_{t-1}^{*}, \tau_{t}\right), \\
V_{t}^{*}=-\mathbb{E}_{t} \sum_{s=t}^{\infty} \beta^{s-t} U_{s}^{*} \geq W^{*}\left(y_{t-1}, y_{t-1}^{*}, \tau_{t}\right),
\end{gathered}
$$

hold at every date and in every state. The functions $W \equiv V^{n}$ and $W^{*} \equiv V^{* n}$ are the value functions for Home and Foreign, respectively, under the Non-cooperation regime. These outside 
option values depend on past output levels and also $\tau_{t}=\left[\mu_{t}, \mu_{t-1}, \mu_{t}^{*}, \mu_{t-1}^{*}\right]^{\prime}$ which is a vector of current and past realizations of exogenous markup shocks. ${ }^{37}$ Let the variables $\psi_{t}$ and $\psi_{t}^{*}$, respectively, denote the Lagrange multipliers on the constraints (13) and (14). In this regime, policymakers maximize the global welfare function (6) subject to the Phillips curves ((1) and (2)) and sustainability constraints ((13) and (14)) so that neither of the countries has incentive to deviate.

After some algebraic manipulation (see Appendix B.1), we have a characterization of policy trade-offs akin to (9) and (10) (under the Cooperation regime), and (11) and (12) (under the Non-cooperation regime), albeit with more complicated factors shifting the trade-offs:

$$
\begin{aligned}
& -\sigma \pi_{t}=y_{t}-\zeta_{t}-z_{t}\left(y_{t-1}-\zeta_{t-1}\right), \\
& -\sigma \pi_{t}^{*}=y_{t}^{*}-\zeta_{t}^{*}-z_{t}\left(y_{t-1}^{*}-\zeta_{t-1}^{*}\right) .
\end{aligned}
$$

for every state and date $t \geq 0$. These complications under Sustainable Cooperation show up as the variables $z_{t}$ and $\left(\zeta_{t}, \zeta_{t}^{*}\right)$. In turn, these variables encode incentive feasibility through restrictions on underlying variables:

$$
\zeta_{t}=\frac{(1+\rho+2 \eta) \vartheta_{t}-(1-\rho) \vartheta_{t}^{*}}{2(1+\eta)(\eta+\rho)} \quad \text { and } \quad \zeta_{t}^{*}=-\frac{(1+\rho+2 \eta) \vartheta_{t}^{*}-(1-\rho) \vartheta_{t}}{2(1+\eta)(\eta+\rho)}
$$

These variables are similar to the variables $\left(\xi_{t}, \xi_{t}^{*}\right)$ under Non-cooperation, but differ in that the markup shocks $\mu_{t}$ and $\mu_{t}^{*}$ are replaced with endogenously determined $\vartheta_{t}$ and $\vartheta_{t}^{*}$ and the minus sign on $\zeta_{t}^{*}$.

We discuss these additional distortions or restrictions shifting the equilibrium policy tradeoffs (15) and (16), in contrast to the Cooperation or Non-cooperation regimes' trade-offs, in terms of their underlying components, $z_{t}, v_{t}, \zeta\left(\vartheta_{t}, \vartheta_{t}^{*}\right)$, and $\zeta^{*}\left(\vartheta_{t}, \vartheta_{t}^{*}\right)$. First, $z_{t}=\frac{\Psi_{t-1}+\Psi_{t-1}^{*}}{\Psi_{t}+\Psi_{t}^{*}} \in$ $(0,1]$ is the ratio of the cumulative sum of Lagrange multipliers on the sustainability constraints (13) and (14). These cumulative-summed Lagrange multipliers, $\Psi_{t}:=\sum_{s=0}^{t} \psi_{s}$ and $\Psi_{t}^{*}:=\sum_{s=0}^{t} \psi_{s}^{*}$, are sufficient statistics on past incentive compatibility of the policymakers. The initial values are given by each country's original Pareto weight when we obtain the global welfare (see Eq. (6)); $\Psi_{-1}=\Psi_{-1}^{*}=1 / 2$. In our setting, either of the constraints may bind at any date and state. ${ }^{38}$ When either of the sustainability constraints is binding $\left(\psi_{t}>0\right.$ or $\left.\psi_{t}^{*}>0\right)$,

$$
z_{t}=\frac{\Psi_{t-1}+\Psi_{t-1}^{*}}{\Psi_{t-1}+\Psi_{t-1}^{*}+\psi_{t}+\psi_{t}^{*}}<1
$$

holds. Then the steadfastness of the past commitment via the terms with the lagged variables becomes weak so that the sustainability constraints hold.

Second, $\left(\zeta_{t}, \zeta_{t}^{*}\right)$ are related to the endogenous pseudo-Pareto weight $v_{t}$ assigned to each Home and Foreign country. Akin to the Non-cooperation setting, we have the shifters $\left(\zeta_{t}, \zeta_{t}^{*}\right)$

\footnotetext{
${ }^{37}$ We implicitly assume the following punishment as the outside option of the state-contingent contract: If either country chooses not to cooperate (i.e., either of the sustainability constraints is violated), the Non-cooperation equilibrium is realized. Since the Non-cooperation equilibrium studied earlier is Markov perfect, then it can be shown that it is also incentive-feasible.

${ }^{38}$ Fuchs and Lippi (2006) studied the situation where more than two constraints simultaneously bind in a multicountry monetary model.
} 
in the policy trade-offs, (15) and (16). However in Sustainable Cooperation, $\left(\zeta_{t}, \zeta_{t}^{*}\right)$ further depend on two endogenous statistics:

$$
\begin{aligned}
\vartheta_{t}= & \left(2 v_{t}-1\right) \mu_{t} \\
& -\beta \mathbb{E}_{t} \underbrace{\left\{\left(z_{t+1}^{-1}-1\right)\left[I_{t+1} D_{1} W\left(y_{t}, y_{t}^{*}, \tau_{t+1}\right)+I_{t+1}^{*} D_{1} W^{*}\left(y_{t}, y_{t}^{*}, \tau_{t+1}\right)\right]\right\}}_{=: \Xi_{t+1}}, \\
\vartheta_{t}^{*}= & \left(2 v_{t}-1\right) \mu_{t}^{*} \\
& +\beta \mathbb{E}_{t} \underbrace{\left\{\left(z_{t+1}^{-1}-1\right)\left[I_{t+1} D_{2} W\left(y_{t}, y_{t}^{*}, \tau_{t+1}\right)+I_{t+1}^{*} D_{2} W^{*}\left(y_{t}, y_{t}^{*}, \tau_{t+1}\right)\right]\right\}}_{=: \Xi_{t+1}^{*}},
\end{aligned}
$$

where $v_{t}=\frac{\Psi_{t}}{\Psi_{t}+\Psi_{t}^{*}} \in(0,1)$ is the pseudo-Pareto weight, given the initial value $v_{-1}=1 / 2$ is equal to the original Pareto weight. These shifters encode the feasibility of current and expected future incentives. The indicator function $I_{t+1}=1$ when the sustainability constraint in Home country is binding in period $t+1 ; I_{t+1}=0$ otherwise. Together with $z_{t+1}<1$, future possibilities of binding constraints shown as $\Xi_{t+1}$ and $\Xi_{t+1}^{*}$ may affect the trade-offs via the shifters. The state-contingent contract by the countries under Sustainable Cooperation must also take into account expected future marginal gains to each country from deviation to Non-cooperation (events which will not be realized on any equilibrium path) and this is encoded in the latter forward-looking terms in the restrictions on $\vartheta_{t}$ and $\vartheta_{t}^{*}$ above.

Third, $v_{t}$ is an endogenous state variable and it is related to how countries have temptation to deviate from cooperation-i.e., to behave strategically and to manipulate the terms of trade as in the Non-cooperation regime. Specifically, $v_{t}$ is determined by the past weight $v_{t-1}$ and the binding pattern of the current sustainability constraints.

To summarize, the conditions (15) and (16) are more general versions of the optimal policy trade-offs-their graphs projected onto $\left(y_{t}, \pi_{t}\right)$-space lie in between their corresponding policy trade-off counterparts in the Non-cooperation regime (compare the case if $z_{t}=1$ and $\left(\zeta_{t}, \zeta_{t}^{*}\right)=$ $\left(\xi_{t}, \xi_{t}^{*}\right)$ almost everywhere with (11) and (12)) and in the Cooperation regime (compare the case if $z_{t}=1$ and $\left(\zeta_{t}, \zeta_{t}^{*}\right)=(0,0)$ almost everywhere with (9) and (10)). We provide more precise conditions for when these observations arise, in the remarks below.

We have the following preliminary property on the behavior of $v_{t}$ :

Remark 1. $v_{t}=1-z_{t}\left(1-v_{t-1}\right)>v_{t-1}$ when $\psi_{t}>0$ and $v_{t}=z_{t} v_{t-1}<v_{t-1}$ when $\psi_{t}>0$, where $\psi_{t}$ and $\psi_{t}^{*}$ are the Lagrange multipliers on the Home and Foreign sustainability constraints. ${ }^{39}$

This result says that the pseudo-weight is a strictly increasing process whenever Home's sustainability constraint is currently binding. It is strictly decreasing whenever Foreign's incentive constraint is currently binding. Given the dynamics of $v_{t}$, we also have the following limiting cases:

Remark 2. (i) When $v_{t} \searrow 0$, the Foreign sustainability constraint ceases to bind; $\zeta_{t}=-\xi_{t}$ and $\zeta_{t}^{*}=\zeta_{t}^{*}$ hold in the limit. (ii) When $v_{t} \nearrow 1$, the Home sustainability constraint ceases to bind; $\zeta_{t}=\xi_{t}$ and $\zeta_{t}^{*}=-\xi_{t}^{*}$ hold in the limit. (iii) When $v_{t}=1 / 2$ for all $t \geq 0$ and all histories, i.e., the sustainability constraint never binds, and $\zeta_{t}=\zeta_{t}^{*}=0$ holds.

\footnotetext{
${ }^{39}$ This can be easily derived from the law of motion of $\Psi_{t}+\Psi_{t}^{*}$. See Appendix B.1.
} 
In terms of welfare, we can deduce that the Sustainable Cooperation regime is an (endogenously) intermediate case of the two extremes: Cooperation and Non-cooperation. When the sustainability constraints never bind, $z_{t}=1$ and $v_{t}=1 / 2$ hold, which implies $\zeta_{t}=\zeta_{t}^{*}=0$, and the solution becomes the same as in the Cooperation regime. When the Home sustainability constraint binds, for example, the pseudo weight on each country's welfare shifts to keep the Home country within the Sustainable Cooperation regime. As $v_{t} \nearrow 1$, the home-country dynamics resembles the ones under Non-cooperation as $\zeta_{t} \rightarrow \xi_{t}$ (Eq. (15) becomes Eq. (11)), whereas negative externalities affect the Foreign country as $\zeta_{t}^{*} \rightarrow-\xi_{t}^{*}$. This additional externality may make the situation worse for the Foreign country.

\subsection{Recursive characterization and solution}

The preceding description of a Sustainable Cooperation equilibrium has a recursive representation. As a result, finding the equilibrium under a Sustainable Cooperation regime boils down to finding equilibrium policy functions that satisfy a modified Euler functional operator problem-i.e., one that is modified by a recursified set of history-dependent sustainability constraints. We describe what this recursive Sustainable Cooperation equilibrium operator looks like next, and then, we detail the nonlinear approximation schemes used to numerically compute the solution.

Let $s_{-1}=\left(y_{-1}, y_{-1}^{*}, v_{-1}\right) \in Y^{2} \times N \equiv S \subset \mathbb{R}^{2} \times(0,1)$ be a vector of endogenous state variables, and, $\tau=\left(u, u_{-1}\right) \in\left(M \times M^{*}\right)^{2} \equiv T$ be a vector of exogenous state variables where $u=\left(\mu, \mu^{*}\right) \in M \times M^{*} \subset \mathbb{R}^{2}$. Note that the lagged markup shocks are included as state variables. Also let $x=h_{x}\left(s_{-1}, \tau\right)$, where $x \in\left\{y, y^{*}, \pi, \pi^{*}, z, v\right\}$, be unknown policy functions that induce a Sustainable Cooperation plans equilibrium. These functions are our objects of interest and they satisfy the following functional operator:

$$
\begin{aligned}
h_{\pi}\left(s_{-1}, \tau\right) & =\beta \sum_{u^{\prime}} P\left(u^{\prime} \mid u\right) h_{\pi}\left(s, u^{\prime}, u\right)+k \mu \\
& +\frac{k}{2}\left[(1+\rho+2 \eta) h_{y}\left(s_{-1}, \tau\right)-(1-\rho) h_{y^{*}}\left(s_{-1}, \tau\right)\right], \\
h_{\pi^{*}}\left(s_{-1}, \tau\right) & =\beta \sum_{u^{\prime}} P\left(u^{\prime} \mid u\right) \pi^{*}\left(s, u^{\prime}, u\right)+k^{*} \mu^{*} \\
& +\frac{k^{*}}{2}\left[(1+\rho+2 \eta) h_{y^{*}}\left(s_{-1}, \tau\right)-(1-\rho) h_{y}\left(s_{-1}, \tau\right)\right], \\
h_{\pi}\left(s_{-1}, \tau\right) & =-\sigma^{-1}\left[h_{y}\left(s_{-1}, \tau\right)-\zeta\left(s_{-1}, \tau\right)-h_{z}\left(s_{-1}, \tau\right)\left(y_{-1}-\zeta_{-1}\left(s_{-1}, \tau\right)\right)\right], \\
h_{\pi^{*}}\left(s_{-1}, \tau\right) & =-\sigma^{-1}\left[h_{y^{*}}\left(s_{-1}, \tau\right)-\zeta^{*}\left(s_{-1}, \tau\right)-h_{z}\left(s_{-1}, \tau\right)\left(y_{-1}^{*}-\zeta_{-1}^{*}\left(s_{-1}, \tau\right)\right)\right], \\
V\left(s_{-1}, \tau\right) & =-U\left(s_{-1}, \tau\right)+\beta \sum_{u^{\prime}} P\left(u^{\prime} \mid u\right) V\left(s, u^{\prime}, u\right) \geq W\left(y_{-1}, y_{-1}^{*}, \tau\right) \\
V^{*}\left(s_{-1}, \tau\right) & =-U^{*}\left(s_{-1}, \tau\right)+\beta \sum_{u^{\prime}} P\left(u^{\prime} \mid u\right) V^{*}\left(s, u^{\prime}, u\right) \geq W^{*}\left(y_{-1}, y_{-1}^{*}, \tau\right)
\end{aligned}
$$

where $U\left(s_{-1}, \tau\right)$ and $U^{*}\left(s_{-1}, \tau\right)$ are the per-period payoffs or losses for Home and Foreign, respectively, $W\left(y_{-1}, y_{-1}^{*}, \tau\right)$ and $W^{*}\left(y_{-1}, y_{-1}^{*}, \tau\right)$ are their respective values under the Noncooperation regime, $P$ is the joint Markov matrix for the independent markup shock process $\left\{\mu, \mu^{*}\right\}$. The functions $\left(\zeta, \zeta^{*}\right)$ and $\left(\zeta_{-1}, \zeta_{-1}^{*}\right)$ have been defined in the preceding section but now, it embeds a recursified structure with respect to the incentive compatibility requirements 
previously discussed in regard to (17) and (18). ${ }^{40}$

This system has a recursive structure with regard to $h_{\pi}\left(s_{-1}, \tau\right), h_{\pi^{*}}\left(s_{-1}, \tau\right), \Xi\left(s_{-1}, \tau\right), \Xi^{*}\left(s_{-1}, \tau\right)$, $V\left(s_{-1}, \tau\right)$, and $V\left(s_{-1}, \tau\right)$.

Approximate solution scheme. The Sustainable Cooperation problem is nonlinear, despite involving quadratic and linear forms. This is because of the occasionally binding nature of the sustainability constraints. Thus, the solution for the Sustainable Cooperation equilibrium can only be obtained numerically. ${ }^{41}$ We use a version of the policy function iteration method with occasionally binding constraints as in Kehoe and Perri (2002) and Sunakawa (2015). The occasionally binding constraints $V\left(s_{-1}, \tau\right) \geq W\left(y_{-1}, y_{-1}^{*}, \tau\right)$ and $V^{*}\left(s_{-1}, \tau\right) \geq W^{*}\left(y_{-1}, y_{-1}^{*}, \tau\right)$ must be addressed. ${ }^{42}$ The functions need to be approximated by projection onto known families of basis functions, as continuation states $s=\left(h_{y}\left(s_{-1}, \tau\right), h_{y^{*}}\left(s_{-1}, \tau\right), h_{v}\left(s_{-1}, \tau\right)\right)$ may not be on the grid points. Three-dimensional cubic spline bases are used for interpolation. We set $Y=[-3.0,3.0]$ and $N=(0.0,1.0)$ and divide them each into 5 knot points. Each element in $\tau=\left(\mu, \mu^{*}, \mu_{-1}, \mu_{-1}^{*}\right)$ follows the Markov chain described earlier. ${ }^{43}$

${ }^{40}$ We repeat it here for convenience, and show how the problem has been recursified. Recall that:

$$
\begin{aligned}
\zeta\left(s_{-1}, \tau\right) & =\frac{(1+\rho+2 \eta) \vartheta\left(s_{-1}, \tau\right)-(1-\rho) \vartheta^{*}\left(s_{-1}, \tau\right)}{2(1+\eta)(\rho+\eta)}, \\
\zeta^{*}\left(s_{-1}, \tau\right) & =-\frac{(1+\rho+2 \eta) \vartheta^{*}\left(s_{-1}, \tau\right)-(1-\rho) \vartheta\left(s_{-1}, \tau\right)}{2(\rho+\eta)(1+\eta)}, \\
\zeta_{-1}\left(s_{-1}, \tau\right) & =\frac{(1+\rho+2 \eta) \vartheta_{-1}\left(s_{-1}, \tau\right)-(1-\rho) \vartheta_{-1}^{*}\left(s_{-1}, \tau\right)}{2(1+\eta)(\rho+\eta)}, \\
\zeta_{-1}^{*}\left(s_{-1}, \tau\right) & =-\frac{(1+\rho+2 \eta) \vartheta_{-1}^{*}\left(s_{-1}, \tau\right)-(1-\rho) \vartheta\left(s_{-1}, \tau\right)}{2(\rho+\eta)(1+\eta)}
\end{aligned}
$$

and

$$
\begin{aligned}
\vartheta\left(s_{-1}, \tau\right) & =\left(2 h_{v}\left(s_{-1}, \tau\right)-1\right) \mu-\beta \sum_{u^{\prime}} P\left(u^{\prime} \mid u\right) \Xi\left(s, u^{\prime}, u\right), \\
\vartheta^{*}\left(s_{-1}, \tau\right) & =\left(2 h_{v}\left(s_{-1}, \tau\right)-1\right) \mu^{*}+\beta \sum_{u^{\prime}} P\left(u^{\prime} \mid u\right) \Xi^{*}\left(s, u^{\prime}, u\right), \\
\vartheta_{-1}\left(s_{-1}, \tau\right) & =\left(2 v_{-1}-1\right) \mu_{-1}-\beta \Xi\left(s_{-1}, \tau\right), \\
\vartheta_{-1}^{*}\left(s_{-1}, \tau\right) & =\left(2 v_{-1}-1\right) \mu_{-1}^{*}+\beta \Xi^{*}\left(s_{-1}, \tau\right) .
\end{aligned}
$$

Specifically, $\Xi\left(s_{-1}, \tau\right)$ and $\Xi^{*}\left(s_{-1}, \tau\right)$ recursify the problem as so:

$$
\begin{aligned}
\Xi\left(s_{-1}, \tau\right) & =\left(z\left(s_{-1}, \tau\right)^{-1}-1\right)\left[I\left(s_{-1}, \tau\right) D_{1} W\left(y_{-1}, y_{-1}^{*}, \tau\right)+I^{*}\left(s_{-1}, \tau\right) D_{1} W^{*}\left(y_{-1}, y_{-1}^{*}, \tau\right)\right] \\
\Xi^{*}\left(s_{-1}, \tau\right) & =\left(z\left(s_{-1}, \tau\right)^{-1}-1\right)\left[I\left(s_{-1}, \tau\right) D_{2} W\left(y_{-1}, y_{-1}^{*}, \tau\right)+I^{*}\left(s_{-1}, \tau\right) D_{2} W^{*}\left(y_{-1}, y_{-1}^{*}, \tau\right)\right]
\end{aligned}
$$

where $I\left(s_{-1}, \tau\right)$ (and $\left.I^{*}\left(s_{-1}, \tau\right)\right)$ are indicator functions that equal unity if the Home (Foreign) constraint is binding, and zero otherwise.

${ }^{41}$ Program codes are written in Fortran 90 with OpenMP shared-memory parallelization. We used a computer with 28 cores of 2.6 Ghz Intel Xeon E5-2680 v3 running on the Centos 6 GNU/Linux operating system.

${ }^{42}$ In general, these constraints may make the problem non-convex so that the numerical algorithm (based on assuming the existence of a unique functional fixed-point) may end up finding only one of multiple equilibria. We cannot prove the existence nor uniqueness of the equilibrium, but numerically we conduct robustness checks utilizing different initial guesses of the equilibrium policy functions that would have delivered the Sustainable Cooperation plan. Our numerical results do not seem to suffer from such problems of equilibrium multiplicity.

${ }^{43}$ The number of the grid points for $Y$ and $N$ are increased to check the robustness of our result. As we have seven state variables, this kind of exercise is very time-consuming as it exponentially increases the total number of grid points. 


\subsection{Dynamics and welfare decomposition of Sustainable Cooperation}

Figure 4 on page 26 shows impulse responses to a positive Home markup shock $\mu=\sigma_{\varepsilon}$ in the initial period with $\left(y_{-1}, y_{-1}^{*}\right)=(0,0)$ and $v_{-1}=v$, where $v$ is the asymptotic upper bound on the pseudo-Pareto weight. ${ }^{44}$ Comparing the responses under each regime, we can see that the responses of Home variables and the terms of trade under Sustainable Cooperation are intermediate between those under Cooperation and Non-cooperation. When $\rho$ equals 0.5 or 1.5 , i.e., the two countries are non-insular, the responses under Sustainable Cooperation become closer to those under Cooperation. ${ }^{45}$ Before we interpret these results, let us first discuss the characteristics under Sustainable Cooperation by looking at the binding pattern of the sustainability constraints.

Figure 4: Impulse responses to a positive Home markup shock: Sustainable Cooperation.
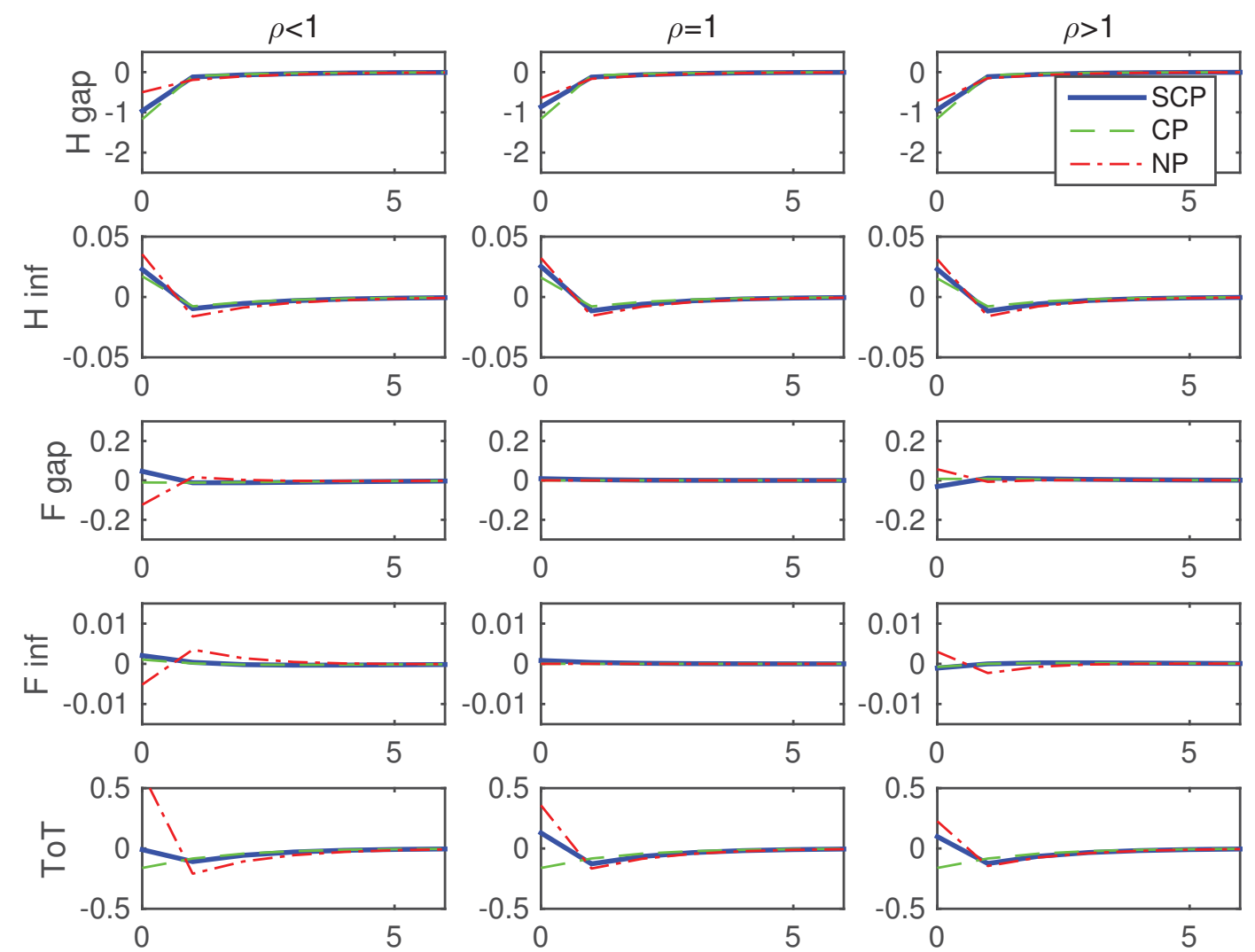

Notes: The left column is for the case of $\rho=0.5$, the center column is for $\rho=1.0$, and the right column is for $\rho=1.5$. SCP refers to Sustainable Cooperation, $\mathrm{CP}$ to Cooperation, and, NP to Non-cooperation.

Figure 5 shows the asymptotic upper bound of the pseudo-Pareto weight, $v$, for each $\rho$ indexed Sustainable Cooperation economy when all shocks are active. This indicates, from a

\footnotetext{
${ }^{44}$ Economies under each regime are simulated for sufficiently long periods to obtain the asymptotic upper bound $v$. After observing the Sustainable Cooperation economy for sufficiently long, the pseudo Pareto weight reaches its steady state.

${ }^{45}$ When $\rho=3$, as in the original calibration in BB, the responses under Sustainable Cooperation are quite similar to those under Cooperation, although the sustainability constraint is slightly binding as seen in Figure 5.
} 
timeless perspective, how much the sustainability constraint for Home is binding. ${ }^{46}$ The temptation to deviate from cooperation is the highest when $\rho=1$. That is, $v_{t}$ is away from a half and closest to one at $\rho=1$. Since the two countries are "insular" in this case, Foreign output and inflation rates do not react to the Home markup shock. If left to his own devices, the self-centered Home policymaker has every desire to set its own policy to maximize its domestic welfare, ignoring the resulting terms of trade externality on its neighbor. However, the Sustainable Cooperation would take this temptation for Home's policymaker to deviate into account. As a result, the Home sustainability constraint binds the most and the pseudo weight on each country's social welfare shifts toward the one favoring the Home country-i.e., the sustainable equilibrium has to promise the most welfare from Foreign to Home, to keep Home within the Sustainable Cooperation regime. This feature of the Sustainable Cooperation plan echoes a similar incentive problem underlying our earlier comparisons between the polar regimes of Cooperation and Non-cooperation (c.f., Figure 3). The difference here is that the incentives underlying each of these two polar regimes are now built into the Sustainable Cooperation plan itself.

Figure 5: The asymptotic values of pseudo-Pareto weight: with varying $\rho$.

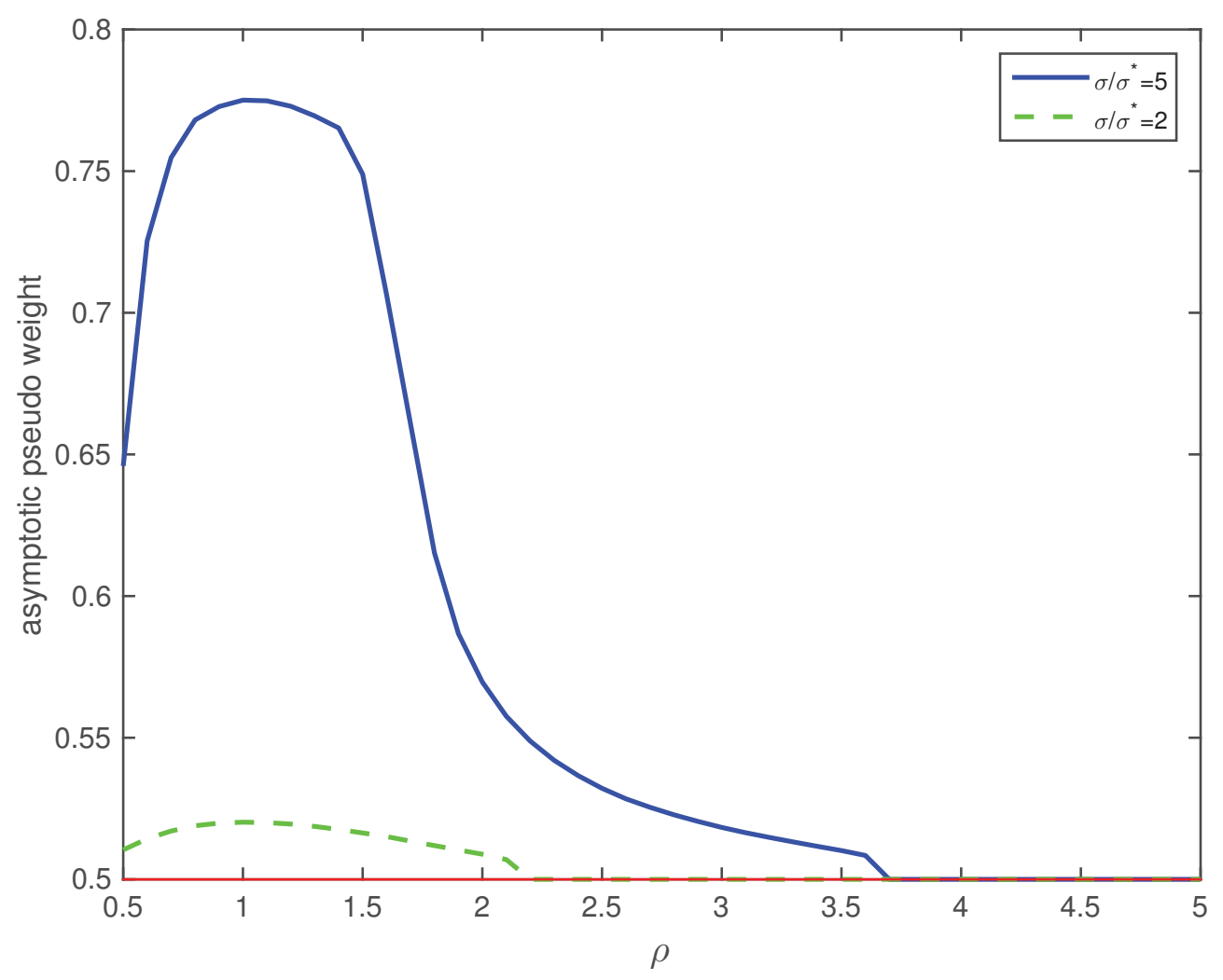

When $\rho$ is set away from unity, the sustainability constraints bind less aggressively. The pseudo weight remains closer to the value of half. That is, less welfare redistribution toward Home is needed to keep the Home country in check under the Sustainable Cooperation regime. This is because when $\rho \neq 1$, there is the feedback effect from the terms of trade acting to

\footnotetext{
${ }^{46}$ It turns out that only Home's sustainability constraint will be binding in this setting (we can check this numerically). Then we know that for each $\rho$-indexed economy, the bounded process $\left\{v_{s}\right\}$ must be monotonically increasing towards its upper bound. (Recall Proposition 1.)
} 
reinforce a markup shock (when $\rho<1$ ), and, the accompanying retaliation considerations (under Non-cooperation) from Foreign — the same set of forces explained earlier in Sections 3.1 and 3.2 when we compared the separate Cooperation and Non-cooperation regimes.

Now, let us return to Figure 4 on page 26. Since under Sustainable Cooperation there is a redistribution of welfare from Foreign to Home (under a single Home markup shock in Figure 4), we see that the responses of Foreign's variables are different from the ones under Cooperation or Non-cooperation. In particular, following the explanations above, we can see that when $\rho=1$ (in the middle column panels of the figure), the response of Home in terms of output gap, inflation and the terms of trade are similar to the Non-cooperation case, but they are more attenuated. In fact, they sit in between their corresponding impulse responses under the Cooperation and the Non-cooperation regimes. Again there is no response of Foreign variables here since it behaves optimally in an insular manner. If $\rho<1$ (see the left column panels of the figure), the intuition coming from the terms of trade externality and its non-insularity channel's feedback effects is still present. However, now the responses are much more attenuated than under the Non-cooperation regime. There is less need for shifting welfare weights from Foreign to Home compared to the case of $\rho=1$. Equivalently, in terms of resource redistribution, Sustainable Cooperation would engineer a terms of trade $s_{t}$ (or Home's net export) that is more negative (positive) for longer, relative to Non-cooperation. This mimics its counterpart under Cooperation. As a consequence, the responses in Foreign output gap and inflation under Sustainable Cooperation are much closer to those under Cooperation than under Noncooperation. ${ }^{47}$ If $\rho>1$ (i.e., the right column panels of the figure), our intuition above on the reinforcing threat of welfare redistribution also applies.

From another perspective, Figure 6 on page 29 displays the unconditional expected welfare values-a similar exercise to that earlier in Figure 2 on page 18-under a Sustainable Cooperation regime. The history-contingent contract under Sustainable Cooperation balances the incentive for Home to deviate from Cooperation to Non-cooperation, where in the latter regime Foreign bears more of the brunt of the terms-of-trade externality. Contrast Figure 6 on page 29 with panel $b$ of Figure 2 on page 18 in terms of each within-regime relative importance of each unconditional welfare component. (Note that we are not comparing the absolute levels of welfare outcomes across the two figures.) From this juxtaposition of the two figures, we can deduce that a Sustainable Cooperation plan can alleviate Home's loss associated with its output gap fluctuations (labelled as "H gap" in Figure 6 on page 29) with a relatively smaller sacrifice of Foreign's welfare accounted for by the spillover effect from stabilizing Home's output gap onto Foreign's welfare (labelled as "H gap" in Figure 6 on page 29). These relatively more attenuated welfare loss spillovers to Foreign are supported by the observation earlier that under a Sustainable Cooperation regime, the contract ensures that Foreign retaliation-inducing incentives do not arise as much in the first place, as under a Non-cooperation regime. That is, under the Sustainable Cooperation plan, welfare must be redistributed to the Home country

\footnotetext{
${ }^{47}$ Observe there is some small change in sign (from positive to negative) in the responses of Foreign inflation and output gap, under Sustainable Cooperation when one moves from the environment with $\rho<1$ to one with $\rho>1$. Although there is less of a need to redistribute resources (and welfare) from Foreign to Home in the face of a markup shock to Home, some of the impact of having to cause a Home terms of trade $\left(s_{t}\right)$ fall will still pass on to a positive (negative) inflation response because the Foreign Phillips curve is non-insular when $\rho<1(\rho>1)$. From the output-gap-inflation trade-off for Foreign, this still translates as a positive (negative) output gap response in the setting when $\rho<1(\rho>1)$.
} 
that experiences a relatively more volatile shock, but just enough and in a history-contingent way, so that overall, welfare for both countries are no worse than under a Non-cooperation regime.

Figure 6: Welfare decomposition under Sustainable Cooperation: with varying $\rho$
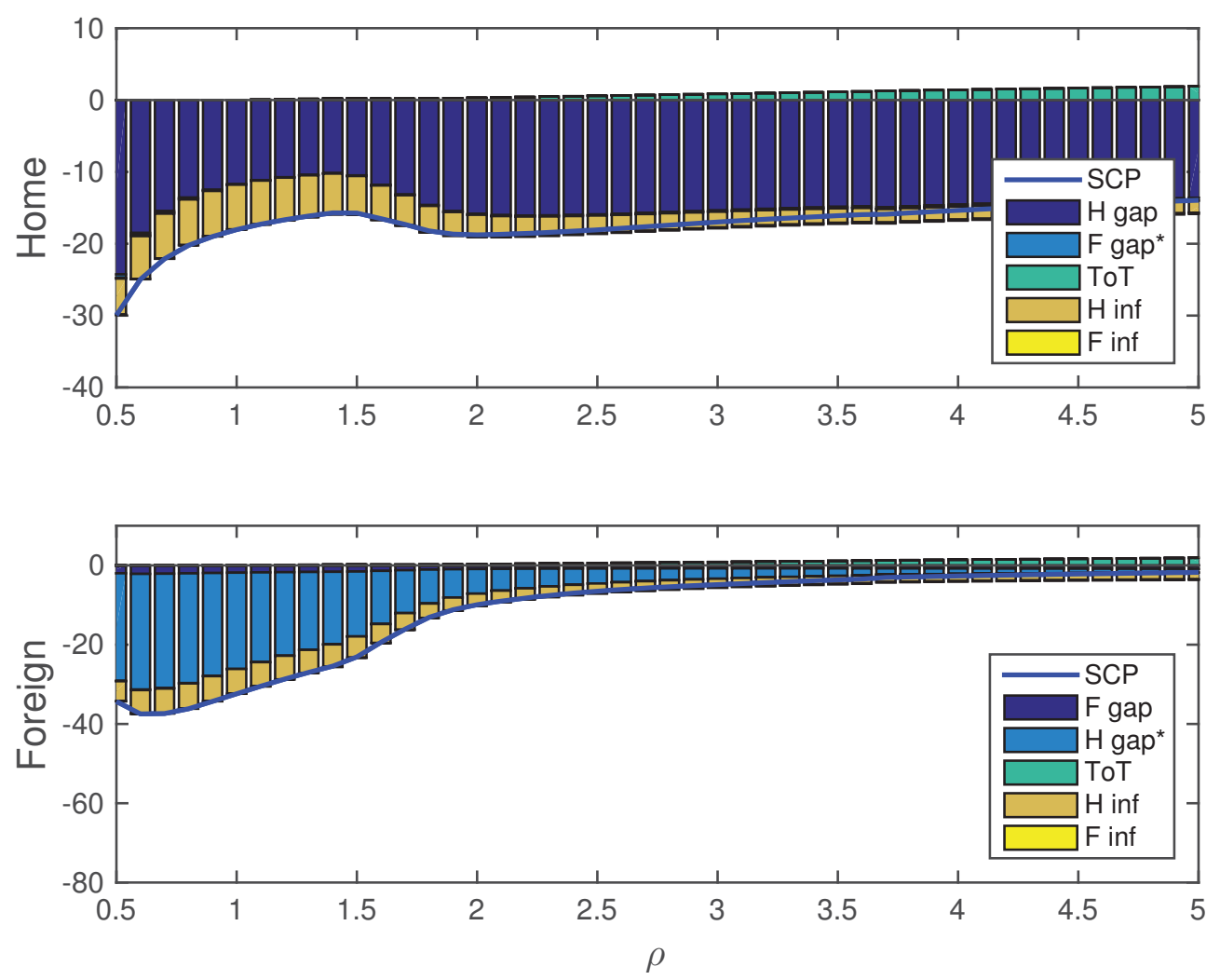

\subsection{Efficiency and redistribution properties}

In this section, we work toward addressing the third question: Under the Sustainable Cooperation regime, relative to an unattainable Cooperation regime, who gains and who loses? We begin by looking at the time- 0 welfare each country can attain under Sustainable Cooperation, relative to what is efficient in the sense of outcomes under any Pareto (equivalently Cooperation regime) allocation. Previously, when characterizing the Cooperation regime, the joint welfare function (6) assigns equal (and constant) Pareto weights to Home and Foreign's welfare. Now, consider a set of Cooperation regimes as a function of arbitrarily fixed Pareto weights, $\lambda \in(0,1)$. This set is represented by a Pareto frontier. ${ }^{48}$

\footnotetext{
${ }^{48}$ To construct this Pareto set we solve the family of problems:
}

$$
\max \left[\lambda V_{0}+(1-\lambda) V_{0}^{*}\right]
$$

subject to Eqs. (1) and (2), where $\lambda \in(0,1)$ is an arbitrary Pareto weight assigned to Home country. The baseline Cooperation regime we considered was the case of $\lambda=1 / 2$. The short-hand notations $V_{0}$ and $V_{0}^{*}$ refer to Home and Foreign's ex-ante welfare defined in (4)-(5).

The equilibrium conditions are summarized as

$$
\begin{aligned}
& -\sigma \pi_{t}=y_{t}-\tilde{\zeta}_{t}-\left(y_{t-1}-\tilde{\zeta}_{t-1}\right), \\
& -\sigma \pi_{t}^{*}=y_{t}^{*}-\tilde{\zeta}_{t}^{*}-\left(y_{t-1}^{*}-\tilde{\zeta}_{t-1}^{*}\right),
\end{aligned}
$$


The solid curve in each panel of Figure 7 shows the stochastic steady-state values of Home and Foreign, under Cooperation regimes as functions of $\lambda,\left(V_{0}(\lambda), V_{0}^{*}(\lambda)\right)$-i.e., the Pareto frontier, for each value of $\rho$. The horizontal (vertical) axes measure Home's (Foreign's) payoff. Red circles (०) show the pair of Home-Foreign payoffs under Non-cooperation (normalized to the origin), whereas the green-asterisk $(*)$ and dark-blue cross $(+)$ markers, respectively, show the values under Cooperation (with $\lambda=1 / 2$ ) and Sustainable Cooperation (assuming $v_{-1}=1 / 2$ ). (We also display an alternative set of light-blue triangles, $\triangle$, which represents Sustainable Cooperation welfare outcomes assuming $v_{-1}$ is at its asymptotic value, for robustness.) In this figure, we use the setting where $\sigma_{\varepsilon} / \sigma_{\varepsilon}^{*}=5$. All values are in terms relative to the values under Non-cooperation that are normalized to zero.

Figure 7: Pareto frontiers.
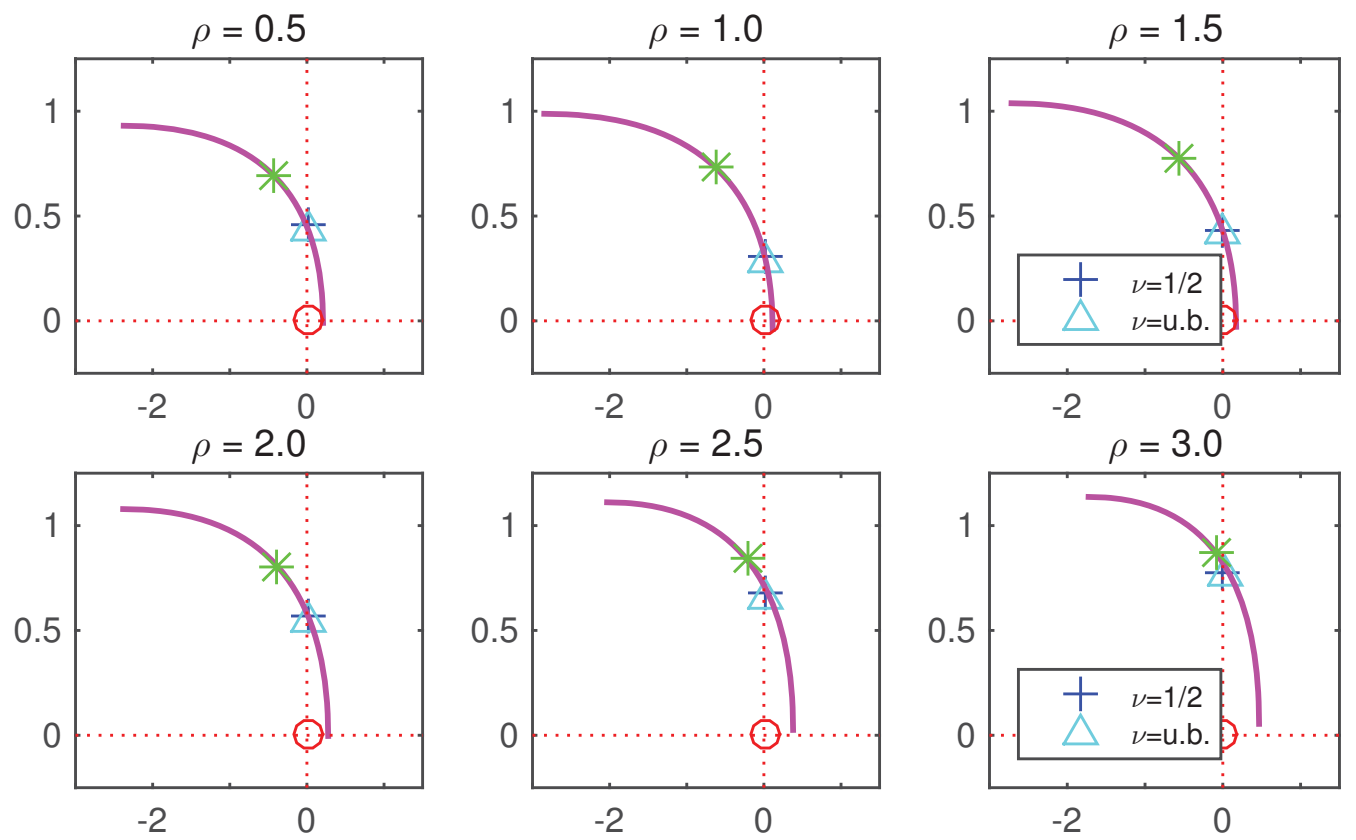

Notes: In each panel indexed by $\rho$, the horizontal axis measures (relative) Home welfare, and the vertical axis measures (relative) Foreign welfare. All values are relative to ones under Non-cooperation-e.g., for Home we have $\left(V_{0}-V_{0}^{n}\right) / V_{0}^{n}$ where $V_{0}$ is its value from any regime considered. Two assumptions regarding the initial auxiliary state of the pseudo Pareto weight $v_{-1}$ are consider for a Sustainable Cooperation (SCP) regime: Either $v_{-1}=$ $1 / 2$ (same as the Cooperation regime's Pareto weight) or $v_{-1}=v_{u . b .}$. (the asymptotic weight in the SCP economy).

Consider reading the panels in Figure 7 from left to right, and, top to bottom. When the value of $\rho$ is low, the values of $\left(V_{0}, V_{0}^{*}\right)$ under Sustainable Cooperation are on the Pareto frontier.

where $\tilde{\zeta}_{t}=\frac{(1+\rho+2 \eta) \tilde{\vartheta}_{t}-(1-\rho) \tilde{\vartheta}_{t}^{*}}{2(1+\eta)(\rho+\eta)}, \tilde{\zeta}_{t}^{*}=-\frac{(1+\rho+2 \eta) \tilde{\vartheta}_{t}^{*}-(1-\rho) \tilde{\vartheta}_{t}}{2(1+\eta)(\rho+\eta)}, \tilde{\vartheta}_{t}=(2 \lambda-1) \mu_{t}$ and $\tilde{\vartheta}_{t}^{*}=(2 \lambda-1) \mu_{t}^{*}$. There are similarities between these equations and the trade-off equations with the shifters (Eqs. (15)-(18)) under Sustainable Cooperation. Note that at the limit $\lambda=0$, i.e., the corresponding Cooperation solution effectively cares only about Foreign's welfare, so that $\tilde{\zeta}_{t}=-\tilde{\zeta}_{t}$ and $\tilde{\zeta}_{t}^{*}=\xi_{t}^{*}$ hold, but this is equivalent to the limiting case of the Sustainable Cooperation regime (with history-dependent pseudo-Pareto weights) in Remark 2(i). Conversely, when we are at the limit $\lambda=1, \tilde{\zeta}_{t}=\xi_{t}$ and $\tilde{\zeta}_{t}^{*}=-\tilde{\zeta}_{t}^{*}$ hold. Also, when $\lambda=1 / 2, \tilde{\zeta}_{t}=\tilde{\zeta}_{t}^{*}=0$ holds, so the equilibrium conditions are the same as in the baseline Cooperation regime. 
In other words, the Sustainable Cooperation equilibrium can attain an equivalent $\lambda$-Paretoefficient allocation, or, equivalently one can find a particular $\lambda^{*}$-Pareto-cooperation solution that replicates the Sustainable Cooperation equilibrium. From the Pareto frontier analysis in Figure 7, observe that Home under each Sustainable Cooperation regime, which is given by each $(+)$ or $(\triangle)$ marker, attains a welfare level similar to the value it would have attained under the Non-cooperation regime (i.e., its outside option value). Given this, the Foreign country's welfare attains the highest value on the Pareto frontier. Note that there is a point of the frontier such that the value to Foreign under that particular $\lambda$-Pareto-efficient allocation is equivalent to its outside option value too-i.e., there exists a value of $\lambda$ with which $V_{0}^{*}(\lambda)=W_{0}^{*}$, where $W_{0}^{*} \equiv V_{0}^{* n}$ is the Non-cooperation welfare for Foreign. However, in the examples in the figure, the Sustainable Cooperation regimes actually implement a welfare allocation for Foreign that is much higher than such a point.

To reinforce this insight from another perspective, consider Figure 8: Here, we show impulse response functions for terms of trade $s_{t}$, in response to a positive Home markup shock, under a particular $\lambda^{*}$-Pareto-cooperation solution that replicates Sustainable Cooperation. The terms of trade movements indicate transfers of resources between the countries: Recall, in terms of physical allocation, the terms of trade variable maps to cross-country transfers in terms of net exports between countries (e.g., net exports for Home is, $y_{t}-c_{t}=-s_{t} / 2$ and for Foreign it is $y^{*}-c_{t}^{*}=s_{t} / 2$ ). ${ }^{49}$ (Also, as we move from the top to the bottom panel in Figure 8, we vary these economies across different degrees of risk aversion $\rho$.) In short, the resource/welfare transfer scheme under the particular $\lambda^{*}$-Pareto-cooperation regime resembles its counterpart under Sustainable Cooperation very well, in terms of direction and magnitude, irrespective of the setting of $\rho$.

\footnotetext{
${ }^{49}$ Thus, inspecting $s_{t}$ allows us to deduce the direction and magnitude of resource transfers, given that we have previously describe the Sustainable Cooperation plan in terms of welfare transfers.
} 
Figure 8: Impulse responses for a particular $\lambda^{*}$-Pareto-cooperation regime relative to other regimes: baseline Cooperation, Non-cooperation and Sustainable Cooperation.
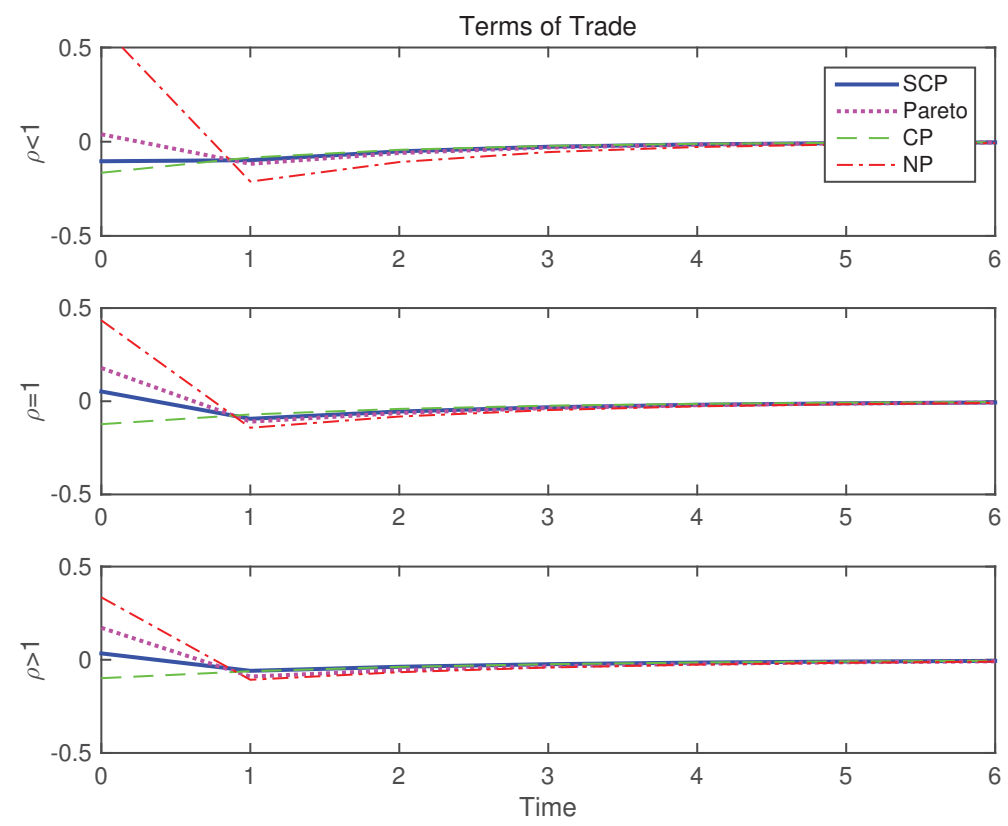

Notes: The upper row is for the case of $\rho=0.5$, the middle row is for $\rho=1.0$, and the bottom row is for $\rho=1.5$.

Let us return to Figure 7 again. When the value of $\rho$ is high (e.g. $\rho=3$ in the figure), Foreign's welfare under Non-cooperation is much lower than the lowest possible Pareto payoff it can attain-i.e., $V_{0}^{*}(\lambda)$ as $\lambda \nearrow 1$. In such a case, Foreign is better off under any Paretocooperation regime $\lambda \in(0,1)$. Equivalently, this says that Foreign's outside-option value (from Non-cooperation) has no bite. However, at the same time, Home's value is right at the point where it is equivalent to the value of its outside option (since its sustainability constraint is almost always binding) under the corresponding Sustainable Cooperation solution. (Recall from Figure 3, the Cooperation regime is not incentive feasible for Home.) Therefore, a Sustainable Cooperation equilibrium, in this setting, is no longer on the Pareto frontier.

Finally, we can also visualize the relative gains and losses under Sustainable Cooperation, relative to the other regimes. As discussed earlier, Figure 7 shows that Home has no gain from moving from a Non-cooperation regime to Sustainable Cooperation. Home faces a more volatile markup shock process (recall in this example, $\sigma_{\varepsilon} / \sigma_{\varepsilon}^{*}=5$ ) and the Sustainable Cooperation equilibrium has to deliver just enough welfare to Home to induce Home to stay in the Sustainable Cooperation regime. Still, Home is better off than the original Cooperation regime (with $\lambda=1 / 2$ ), which is not incentive feasible.

Next we focus on Foreign's relative gain in welfare from moving from a Non-cooperation regime to Sustainable Cooperation. Figure 7 shows that this is strictly positive, indicating that although there is a transfer of welfare from Foreign to Home, Foreign is still better off under the Sustainable Cooperation outcome than being out in the Non-cooperation regime. Observe that this gain for Foreign is the smallest when $\rho=1$. To understand why, recall our mechanism 
with the opposing "non-insularity feedback" and "terms-of-trade externality" forces, which underlie this model. When $\rho=1$, Foreign is effectively insular and the asymmetric termsof-trade externality force works the most in favor of Home. Also, Foreign is worse off than in the 1/2-cooperation regime so as to keep Home within the Sustainable Cooperation regime (otherwise Foreign ends up with Non-cooperation).

In short, in this exercise where Home faces a relatively more volatile shock, the Sustainable Cooperation plan reallocates welfare from Foreign to Home, but both are weakly better off than under Non-cooperation. Interestingly, we can find an arbitrary Pareto allocation that mimics the complicated Sustainable Cooperation solution quite well. Relative to Non-cooperation, the gain for Foreign in remaining under Sustainable Cooperation is the weakest when $\rho=1$.

\section{Asymmetric country size and symmetric shock}

We have considered the case of asymmetric shocks when the countries are symmetric in all other aspects. Now we generalize this to the setting with asymmetric country sizes. To keep the insights clean, we now render the country-specific shock processes symmetric. Benigno (2002) also considered the case of asymmetric country size and discussed when countries have incentive to deviate from Cooperation to Non-cooperation. Here we revisit this question with the addition of the Sustainable Cooperation regime.

When the countries are asymmetric in their size, the welfare functions for Home and Foreign countries are given by

$$
V_{0}=-\frac{1}{2} \mathbb{E}_{0} \sum_{t=0}^{\infty} \beta^{t}\left[\begin{array}{c}
\gamma(\eta+\rho)\left(y_{t}-\frac{1-\gamma}{\gamma(\eta+\rho)} \mu_{t}\right)^{2}+\frac{\gamma \sigma}{k} \pi_{t}^{2} \\
+\gamma(1-\gamma)(1-\rho)\left(y_{t}-y_{t}^{*}\right)^{2} \\
+(1-\gamma)(\eta+\rho)\left(y_{t}^{*}+\frac{1}{\eta+\rho} \mu_{t}^{*}\right)^{2}+\frac{(1-\gamma) \sigma}{k^{*}}\left(\pi_{t}^{*}\right)^{2}
\end{array}\right],
$$

and

$$
V_{0}^{*}=-\frac{1}{2} \mathbb{E}_{0} \sum_{t=0}^{\infty} \beta^{t}\left[\begin{array}{c}
(1-\gamma)(\eta+\rho)\left(y_{t}^{*}-\frac{\gamma}{(1-\gamma)(\eta+\rho)} \mu_{t}^{*}\right)^{2}+\frac{(1-\gamma) \sigma}{k^{*}}\left(\pi_{t}^{*}\right)^{2} \\
+\gamma(1-\gamma)(1-\rho)\left(y_{t}^{*}-y_{t}\right)^{2} \\
+\gamma(\eta+\rho)\left(y_{t}+\frac{1}{\eta+\rho} \mu_{t}\right)^{2}+\frac{\gamma \sigma}{k} \pi_{t}^{2}
\end{array}\right]
$$

where $\gamma \in[0,1]$ is the (Cobb-Douglas) share of Home-produced goods in the consumption index of Home consumers-i.e., it measures the size of Home relative to Foreign. ${ }^{50}$ The countries are also subject to the Phillips curves,

$$
\pi_{t}=\beta \mathbb{E}_{t} \pi_{t+1}+k \mu_{t}+k\left[(\rho+\eta) y_{t}+(1-\gamma)(1-\rho)\left(y_{t}-y_{t}^{*}\right)\right]
$$

and

$$
\pi_{t}^{*}=\beta \mathbb{E}_{t} \pi_{t+1}^{*}+k \mu_{t}^{*}+k\left[(\rho+\eta) y_{t}^{*}-\gamma(1-\rho)\left(y_{t}-y_{t}^{*}\right)\right] .
$$

The equilibrium policy trade-off conditions in the Cooperation, Non-cooperation and Sus-

\footnotetext{
${ }^{50}$ See Appendix A.2 for the derivations.
} 
tainable Cooperation regimes can be derived as respective generalizations of equations (9)-(10) (Cooperation), (11)-(12) (Non-cooperation), and (15)-(16) (Sustainable Cooperation) in which $\gamma \neq 1 / 2$. These generalized conditions are shown in Appendix B.1. Note that the global welfare function is now given by

$$
\begin{aligned}
V_{0}^{W}= & \gamma V_{0}+(1-\gamma) V_{0}^{*}, \\
=-\frac{1}{2} \mathbb{E}_{0} \sum_{t=0}^{\infty} \beta^{t}\left[\gamma(\eta+\rho) y_{t}^{2}+(1-\gamma)(\eta+\rho)\left(y_{t}^{*}\right)^{2}\right. & \\
& \left.\quad+\gamma(1-\gamma)(1-\rho)\left(y_{t}-y_{t}^{*}\right)^{2}+\frac{\gamma \sigma}{k} \pi_{t}^{2}+\frac{(1-\gamma) \sigma}{k}\left(\pi_{t}^{*}\right)^{2}\right] .
\end{aligned}
$$

Observe that $\gamma \neq 1 / 2$ now shifts the weights of each variable in the welfare functions as shown in Eqs. (19)-(20) and (23). Besides that, $\gamma$ changes the target output for Home and Foreign in the welfare functions. For example, the Home output target is $[(1-\gamma) / \gamma] \mu_{t} /(\eta+\rho)$; a lower $\gamma$ implies a higher target output given $\mu_{t}$. Also, note that $\gamma$ enters as a part of coefficient on the terms of trade in the NKPCs (21) and (22). If $\gamma$ is low, the feedback effect of Home markup shock via the terms of trade on Foreign NKPC is diminished. These effects of $\gamma \neq 1 / 2$ may temper the policymakers' incentive to manipulate the terms of trade, relative to the symmetric country size case considered earlier.

Consider again our first question within this more general environment: Can Cooperation be an incentive infeasible regime? As in Section 3.3, we compute the statistic, $R_{0} \equiv$ $-\max \left\{V_{0}^{c} / V_{0}^{n}-1,0\right\}$, which will be negative if the conditional welfare under Cooperation is dominated by that under Non-cooperation, $V_{0}^{c}<V_{0}^{n}$. Figure 9 on page 35 shows the statistics of Home $\left(R_{0}\right)$ and Foreign $\left(R_{0}^{*}\right)$ under the regimes of Cooperation and Non-cooperation. Even if the shock is symmetric among the countries, a relatively smaller Home country $(\gamma<1 / 2)$ has incentive to deviate from Cooperation to Non-cooperation. The Cooperation regime is not incentive-feasible when the countries differ in size: The lower is Home's size, the more Home has incentive to deviate from a given Cooperation regime. (Conversely, Foreign has incentive to deviate when $\gamma>1 / 2$.)

Now consider $R_{0}$ as a function of risk aversion $\rho$ in Figure 9 on page 35, as in the case of asymmetric shocks. ${ }^{51}$ Compared to the case of $\gamma=1 / 2$ with asymmetric shocks, the economy where $\rho$ is such that the Home policymaker has the largest incentive to deviate, shifts toward the right and away from unity. This is merely an artifact of $\gamma \neq 1 / 2$ (c.f., Figure 2 on page 18 earlier where the peak temptation occurs at unity). To illustrate the effect $\gamma \neq 1 / 2$ has on the location of peak temptation (as a function of risk aversion $\rho$ ), we consider the graph of the statistic $R_{0}(\rho, \gamma)$ for various values of $\gamma \in\{1 / 3.75,1 / 3.5,1 / 3.25,1 / 3\}$. (We rig this example to consider the case that the temptation to deviate from Cooperation is solely on the side of Home.)

\footnotetext{
${ }^{51}$ When $\rho$ is too high, $V^{n}$ takes a positive value and the second-order conditions may be violated so that no equilibrium can exist. See Footnote 35.
} 
Figure 9: Welfare comparison under Cooperation vs. Non-cooperation: Asymmetric country size.
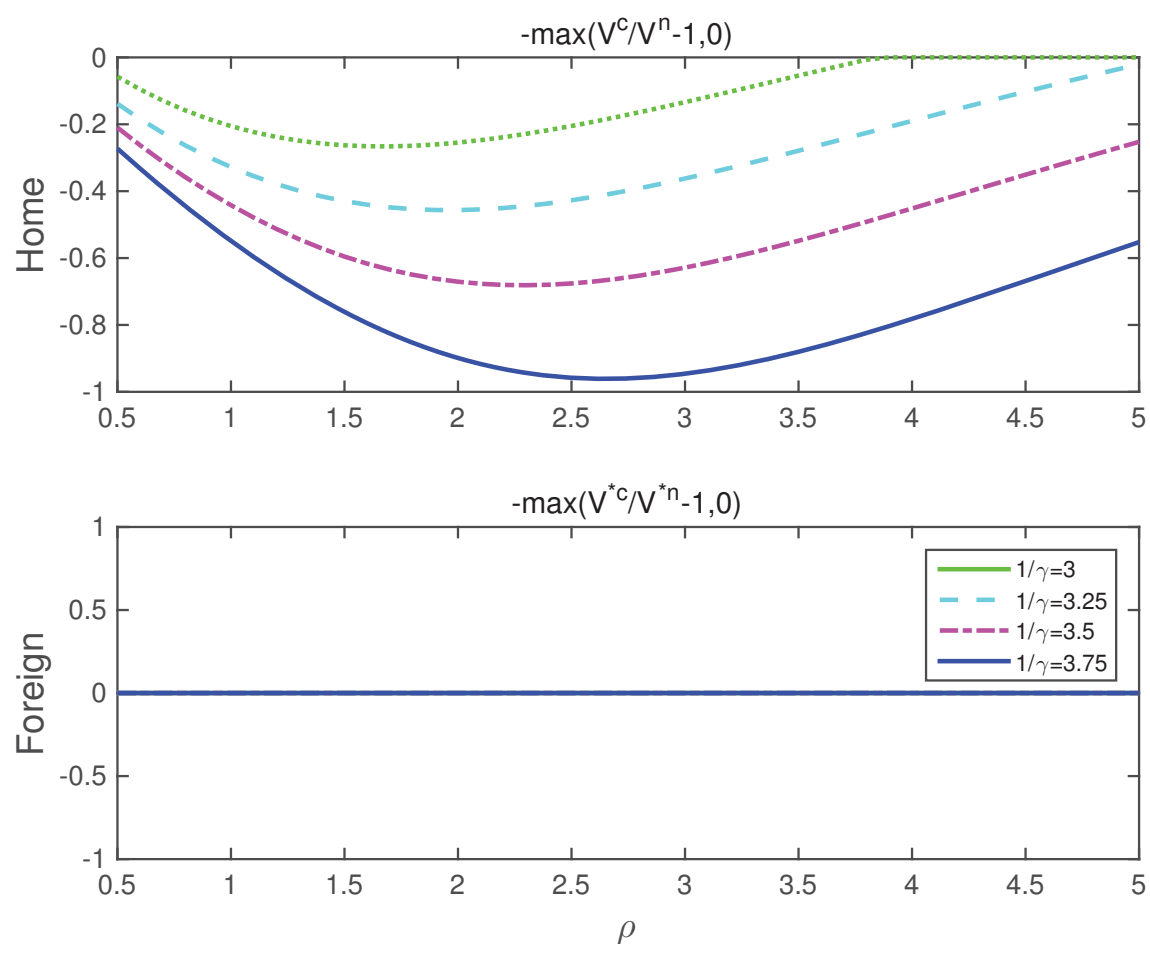

If $\gamma$ is lower (Home is smaller in size), the terms of trade externality problem diminishes, since the target output gap is higher-i.e., Home has to stabilize output gap more given a markup shock. Moreover, a lower $\gamma$ dampens the non-insularity channel of the terms of trade (for any given $\rho$ ), and its attendant feedback and Foreign retaliation effects onto Home welfare (should home attempt to exploit the terms of trade externality in a deviation to Noncooperation). With these effects, we should see that, all else equal, a lower $\gamma$ implies an environment in which Home has a relatively stronger temptation to walk away from a given Cooperation regime. Figure 9 on page 35 shows the net effect of this tension with respect to $\gamma$, which resolves in the latter direction.

Finally, consider the question of what a Sustainable Cooperation equilibrium would be like in this setting. Figure 10 on page 36 shows the asymptotic upper bound of the pseudo-Pareto weight $v_{t}$, for different environments indexed by $(\rho, \gamma)$. When $\gamma$ is close enough to $1 / 2$, Home's sustainability constraint never binds and $v_{t}=\gamma$ holds. As $\gamma$ is away from $1 / 2$, the constraint kicks in and $v_{t}$ has to be larger to keep Home within the Sustainable Cooperation regime. When $\gamma$ is too small, $v_{t}$ is bounded around $1 / 2 .^{52}$ In other words, the smaller is Home in size, the greater is the need for welfare redistribution from Foreign to Home, hence asymptotically a larger pseudo Pareto weight in favor of Home. Similar to the insight from the comparative welfare analysis between the two exogenous regimes of Cooperation and Non-cooperation in Figure 9 on page 35 earlier, here endogenously, a Sustainable Cooperation regime will need to balance the terms of trade externality threat against the non-insularity feedback effect. Hence, for each $\gamma$ economy, there will be a $\rho$ that defines the point where the most (asymptotically)

\footnotetext{
${ }^{52}$ That is, as the countries are symmetric in all other respects, the Foreign country's sustainability constraint becomes relevant when $v_{t}$ exceeds $1 / 2$.
} 
welfare redistribution has to be promised to Home. This point shifts toward a higher $\rho$ as $\gamma$ becomes smaller, again echoing a similar property in Figure 9 on page 35 earlier.

In short, even though two countries are symmetric but for their size, the smaller (i.e., Home when $\gamma<1 / 2$ ) country has an incentive to deviate from an assumed Cooperation to a Noncooperation regime. In contrast, a Sustainable Cooperation plan takes this incentive problem into account and thus has to endogenously place more weight on Home's welfare over time, the smaller is Home in size.

Figure 10: The asymptotic values of pseudo-Pareto weight across economies with different $\rho$ and various asymmetric country size.

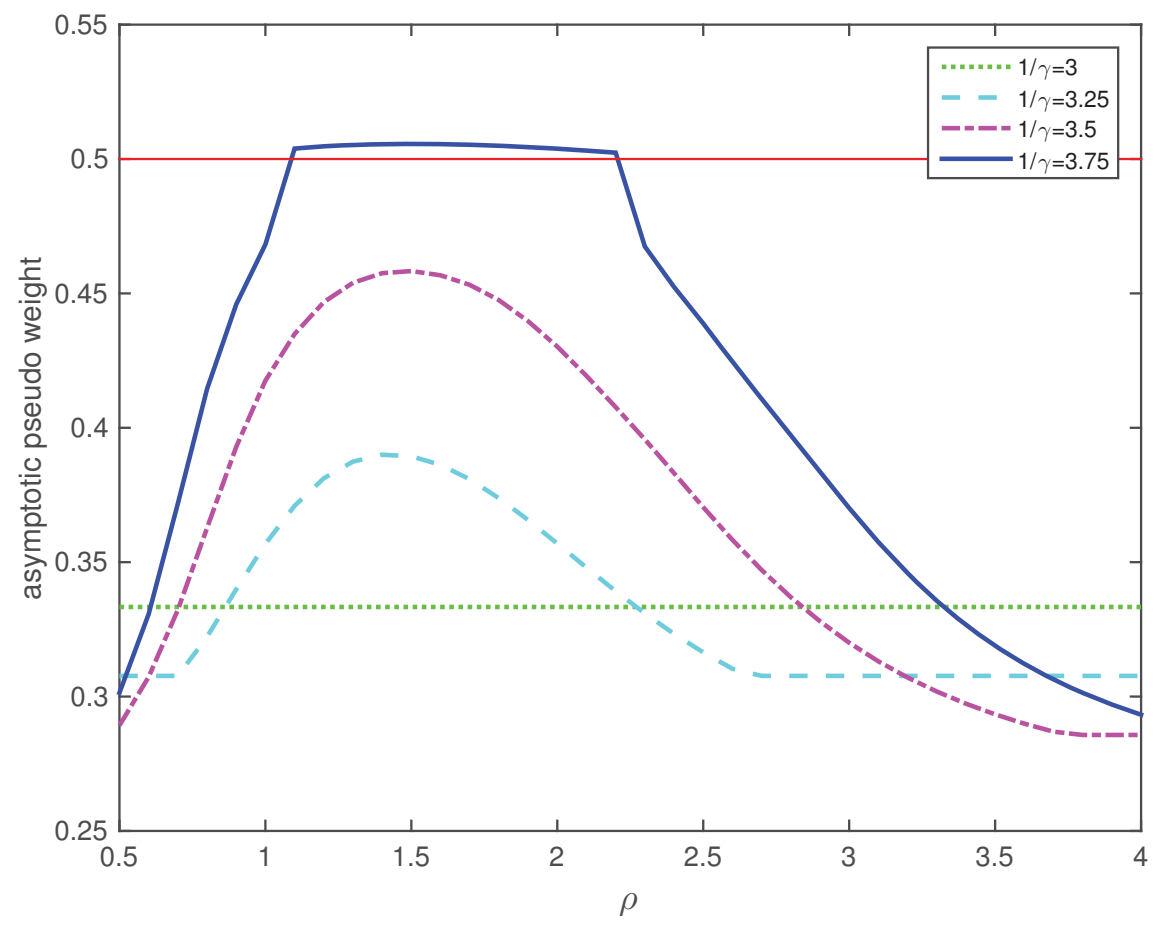

\section{Conclusion}

In a well-known symmetric two-country model (with the exception of asymmetric markup shocks), we show that the incentive to deviate from an international monetary policy Cooperation regime is large when agents' constant relative risk aversion parameter is at unity. However, in a Sustainable Cooperation regime, no country has an incentive to deviate from its (constrained efficient) cooperative equilibrium. Instead countries in such a program are willing to tolerate welfare redistributions whenever asymmetric shocks hit them, in return for better-than-Non-cooperation outcomes. Thus the responses of inflation and output gap in both countries under Sustainable Cooperation are different from the ones under Cooperation and Non-cooperation. In particular, for the country faced with a more volatile markup shock, inflation, output gap and terms of trade outcomes have dynamics that are intermediate to the Cooperation and Non-cooperation regimes.

A similar insight obtains when we generalize the model to a setting where countries face identical (but independent) markup shock processes, but they differ only in terms of country 
size. In that setting, the smaller country will tend to have the incentive to walk away from an assumed Cooperation regime. In contrast, a Sustainable Cooperation plan in such a world will take into account such incentives, and enforce the right cooperative outcome by inducing history-contingent transfers of resources (and thus, welfare) from the larger country toward its smaller counterpart.

We showed that these transfers also manifest in a terms of trade (or equivalently net export) dynamic that is not as volatile or drastic as its counterpart under Non-cooperation; and its dynamic is not as placid as its corresponding (incentive infeasible) Cooperation outcome either.

To sum up, monetary cooperation should not be taken for granted to be an always- and everywhere-tenable proposition. When the markup shock is the dominant driver of economic fluctuations, the considerations of Sustainable Cooperation is particularly important when two countries are insular in structural relationship-i.e., they face the greatest temptation to exploit the terms of trade externality channel under Non-cooperation-and face asymmetric volatilities in structural shocks, or, when they differ in economic size. In such situations, it is important to acknowledge that the best allocations and prices central banks can achieve are somewhere between those under Cooperation and Non-cooperation. In relation to real-world central banking practice, we do see some anecdotal outcomes in which central banks may appear to be coordinating and cooperating sometimes, despite verbal rhetoric that seem to indicate otherwise. 


\section{References}

Benigno, G. And P. Benigno (2003): "Price Stability in Open Economies," Review of Economic Studies, 70, 743-764.

(2006): "Designing targeting rules for international monetary policy cooperation," Journal of Monetary Economics, 53, 473-506.

BENIGNO, P. (2002): “A simple approach to International monetary policy cooperation," Journal of International Economics, 57, 177-196.

Benigno, P. AND M. WoOdFord (2005): "Inflation Stabilization and Welfare: The Case of a Distorted Steady State," Journal of the European Economic Association, 3, 1185-1236.

(2012): "Linear-quadratic Approximation of Optimal Policy Problems," Journal of Economic Theory, $147,1-42$.

BiLbiIE, F. O. (2011): “Designing domestic institutions for international monetary policy cooperation: A Utopia?" Journal of International Money and Finance, 30, 393-409.

Bodenstein, M., L. Guerrieri, And J. LaBriola (2014): “Macroeconomic Policy Games,” Finance and Economics Discussion Series 2014-87, Board of Governors of the Federal Reserve System.

CALvo, G. A. (1983): "Staggered Prices in a Utility-Maximizing Framework," Journal of Monetary Economics, 12, 383-398.

CANZONERI, M. B., R. E. CUMBY, AND B. T. DiBA (2005): “The need for international policy coordination: what's old, what's new, what's yet to come?" Journal of International Economics, 66, 363-384.

Chari, V., A. Dovis, AND P. Kehoe (2014): “Rethinking Optimal Currency Areas," 2014 Meeting Papers 826, Society for Economic Dynamics.

Chari, V. V. AND P. J. Kehoe (1990): “Sustainable Plans,” Journal of Political Economy, 98, 783-802.

ClARIDA, R., J. GALI, AND M. GERTLER (2002): “A simple framework for international monetary policy analysis," Journal of Monetary Economics, 49, 879-904.

Coenen, G., G. Lombardo, F. Smets, And R. Straub (2007): “International Transmission and Monetary Policy Cooperation," in International Dimensions of Monetary Policy, National Bureau of Economic Research, Inc, NBER Chapters, 157-192.

Coeurdacier, N., H. Rey, And P. Winant (2011): “The Risky Steady State," American Economic Review, 101, 398-401.

Cooper, R. N. (1969): “Macroeconomic Policy Adjustment in Interdependent Economies," Quarterly Journal of Economics, 83, 1-24.

Corsetti, G., L. Dedola, And S. Leduc (2010): "Optimal monetary policy in open economies," in Handbook of Monetary Economics, ed. by B. Friedman and M. Woodford, North Holland, vol. III.

Corsetti, G. AND P. Pesenti (2001): “Welfare And Macroeconomic Interdependence," Quarterly Journal of Economics, 116, 421-445.

Debortoli, D. AND R. Nunes (2006): “On Linear Quadratic Approximations," MPRA Paper 544, University Library of Munich, Germany.

Dixit, A. K. AND J. E. Stiglitz (1977): "Monopolistic Competition and Optimum Product Diversity," American Economic Review, 67, 297-308.

ENGEL, C. (2015): “International Coordination of Central Bank Policy," Working Paper 20952, National Bureau of Economic Research.

FUCHS, W. AND F. LipPI (2006): "Monetary Union with Voluntary Participation," Review of Economic Studies, 73, 437-457. 
FujiWARA, I. AND Y. TERANishi (2013): “Financial Stability in Open Economies," CAMA Working Paper Series.

HAMADA, K. (1976): “A Strategic Analysis of Monetary Interdependence," Journal of Political Economy, $84,677-700$.

Hume, D. (1752): Political Discourses, R. Fleming.

JENSEN, H. (2000): “Optimal monetary policy cooperation through state-independent contracts with targets," European Economic Review, 44, 517-539.

KeHOE, P. J. AND F. PeRRI (2002): “International Business Cycles with Endogenous Incomplete Markets," Econometrica, 70, 907-928.

KHAn, A., R. G. KING, AND A. L. Wolman (2003): "Optimal Monetary Policy," Review of Economic Studies, 70, 825-860.

KIM, J. AND S. H. KIM (2003): "Spurious welfare reversals in international business cycle models," Journal of International Economics, 60, 471-500. 1001.

(2007): “Two Pitfalls of Linearization Methods," Journal of Money, Credit and Banking, 39, 995-

King, R. And A. L. Wolman (1999): "What Should the Monetary Authority Do When Prices Are Sticky?" in Monetary Policy Rules, National Bureau of Economic Research, Inc, NBER Chapters, 349404 .

Kletzer, K. M. And B. D. Wright (2000): “Sovereign Debt As Intertemporal Barter," The American Economic Review, 90, 621-639.

LeVine, P., J. Pearlman, AND R. Pierse (2008): “Linear-quadratic approximation, external habit and targeting rules," Journal of Economic Dynamics and Control, 32, 3315-3349.

McCallum, B. T. AND E. Nelson (2004): “Timeless perspective vs. discretionary monetary policy in forward-looking models," Federal Reserve Bank of St.Louis Review, 86, 43-56.

Obstfeld, M. And K. Rogoff (1995): “Exchange Rate Dynamics Redux," Journal of Political Economy, $103,624-60$.

Persson, T. AND G. TABellini (1995): “Double-edged incentives: Institutions and policy coordination," in Handbook of International Economics, ed. by G. M. Grossman and K. Rogoff, Elsevier, vol. 3 of Handbook of International Economics, chap. 38, 1973-2030.

(2002): Political Economics: Explaining Economic Policy, Zeuthen lecture book series, MIT Press.

SAuER, S. (2010): “Discretion Rather Than Rules? When Is Discretionary Policymaking Better Than the Timeless Perspective?" International Journal of Central Banking, 6, 1-29.

SunAKAWA, T. (2015): “A Quantitative Analysis of Optimal Sustainable Monetary Policies," Journal of Economic Dynamics and Control, 52, 119-135.

Svensson, L. E. O. And S. VAn Wijnbergen (1989): “Excess Capacity, Monopolistic Competition, and International Transmission of Monetary Disturbances," Economic Journal, 99, 785-805.

TILLE, C. (2001): "The role of consumption substitutability in the international transmission of monetary shocks," Journal of International Economics, 53, 421-444. 
- Supplementary (Online) Appendix - 


\section{Appendix}

This appendix has two parts. In part A, we show the original nonlinear model and derive the linear-quadratic representation, which is also done in Benigno and Benigno (2006). ${ }^{53}$ In part $\mathrm{B}$, we derive the equilibrium conditions in each regime, which are shown in the main text. We also provide the computation procedure in more details.

\section{A Microfoundations and Welfare Derivations}

In this appendix, we provide the microfoundations and second-order welfare derivations of the well-known model of Benigno and Benigno (2006) (BB). We will also discuss on a particular type of Ramsey policy-making assumption (i.e., with timeless-perspective commitment) underlying all three policy regimes considered in the paper, and the role this plays in a correct quadratic approximation of the social welfare functions in the LQ framework.

\section{A.1 Model microfoundations}

\section{A.1.1 Household}

There is a representative household in each country. We focus on the household in the Home country. By symmetry, the same applies to the household in the Foreign country. The domestic household minimizes its total expenditure

$$
P_{t} C_{t}=P_{H t} C_{H t}+P_{F t} C_{F t}
$$

subject to the aggregator $C_{t}=\gamma^{-\gamma}(1-\gamma)^{-(1-\gamma)}\left(C_{H, t}\right)^{\gamma}\left(C_{F, t}\right)^{1-\gamma}$, where $C_{t}$ is total consumption (per capita), $C_{H}$ and $C_{F}$ are bundles of consumption goods produced in Home and Foreign countries. The consumer price index is denoted as $P_{t}$. The price indices, respectively, $P_{H}$ and $P_{F}$, relate to goods produced in the Home and Foreign countries. The parameter $\gamma \in[0,1]$ is the size of Home country. Therefore, $(1-\gamma)$ is the size of Foreign country. By inspecting the consumption index above, we can see that a larger $\gamma$ implies a "smaller" Home country in that its agents are more dependent on Foreign-produced goods. The FONCs are

$$
\begin{aligned}
& C_{H, t}=\gamma\left(\frac{P_{H, t}}{P_{t}}\right)^{-1} C_{t} \\
& C_{F, t}=(1-\gamma)\left(\frac{P_{F, t}}{P_{t}}\right)^{-1} C_{t} .
\end{aligned}
$$

They yield the demand function for each bundle of consumption of the domestic household. By substituting them into the aggregator, the price index is can be derived as $P_{t}=P_{H, t}^{\gamma} P_{F, t}^{1-\gamma}$.

The household minimizes expenditure on bundles of Home and Foreign goods subject to

\footnotetext{
${ }^{53}$ Benigno and Benigno (2006) considered more general cases than ours, which also made the discussion a bit too complicated. We consider only the markup shock and symmetric country size in the baseline case, and provide a clear presentation compared to the general cases including other shocks and asymmetries considered in Benigno and Benigno (2006)
} 
the aggregators $C_{H, t}=\left[\left(\frac{1}{\gamma}\right)^{\frac{1}{\sigma}} \int_{0}^{\gamma} C_{H t}(h)^{\frac{\sigma-1}{\sigma}} \mathrm{d} h\right]^{\frac{\sigma}{\sigma-1}}$ and $C_{F, t}=\left[\left(\frac{1}{1-\gamma}\right)^{\frac{1}{\sigma}} \int_{\gamma}^{1} C_{F t}(f)^{\frac{\sigma-1}{\sigma}} \mathrm{d} f\right]^{\frac{\sigma}{\sigma-1}}$, where $\sigma$ is the elasticity of substitution between differentiated products à la Dixit and Stiglitz (1977). There is an infinite number of firms indexed by $i \in[0,1]$, and index $i=h \in[0, \gamma)$ are for the domestic firms and $i=f \in[\gamma, 1.0]$ are for the Foreign firms. Each good, $C_{H}(i)$ or $C_{F}(i)$, is produced by firms in both countries. The FONCs to the expenditure minimization problem are

$$
\begin{aligned}
& C_{H, t}(h)=\frac{1}{\gamma}\left[\frac{P_{H, t}(h)}{P_{H, t}}\right]^{-\sigma} C_{H, t}, \\
& C_{F, t}(f)=\frac{1}{1-\gamma}\left[\frac{P_{F, t}(f)}{P_{F, t}}\right]^{-\sigma} C_{F, t} .
\end{aligned}
$$

Plugging these into the consumption aggregators, we have $P_{H, t}=\left\{\frac{1}{\gamma} \int_{0}^{\gamma}\left[P_{H, t}(h)\right]^{1-\sigma} \mathrm{d} h\right\}^{\frac{1}{1-\sigma}}$ and $P_{F, t}=\left\{\frac{1}{1-\gamma} \int_{\gamma}^{1}\left[P_{F, t}(f)\right]^{1-\sigma} \mathrm{d} f\right\}^{\frac{1}{1-\sigma}}$ as the price indices of Home and Foreign goods, respectively.

Given the above market structure, the domestic household maximizes its life-time utility

$$
\mathbb{E}_{0} \sum_{t=0}^{\infty} \beta^{t}\left[\frac{C_{t}^{1-\rho}}{1-\rho}-\frac{1}{\gamma} \int_{0}^{\gamma} \frac{h_{t}(h)^{1+\eta}}{1+\eta} \mathrm{d} h\right]
$$

subject to

$$
\mathbb{E}_{t}\left[m_{t, t+1} A_{t+1}\right]+D_{t}+P_{t} C_{t}=A_{t}+\left(1+i_{t-1}\right) D_{t-1}+\frac{1}{\gamma} \int_{0}^{\gamma} W_{t}(h) h_{t}(h) \mathrm{d} h+\Pi_{t},
$$

where $m_{t, t+1} A_{t+1}$ is the purchase of state-contingent securities by the household, which pays $A_{t+1}$ for each state realized in the next period. $D_{t}$ is the amount of one-period bond, which pays $\left(1+i_{t}\right) D_{t}$ for any state in the next period. $W_{t}(h)$ and $h_{t}(h)$ are firm-specific nominal wage and hours worked. $\Pi_{t}$ is the transfer from firms owned by the household. $\beta$ is the discount factor, $\rho$ is the coefficient of relative risk aversion, $\eta$ is Frisch elasticity of labor disutility. The FONCs are given by

$$
\begin{aligned}
& h_{t}(h)^{\eta}=\frac{W_{t}(h)}{P_{t}} C_{t}^{-\rho}, \\
& m_{t, t+1}=\beta \frac{C_{t+1}^{-\rho} P_{t}}{C_{t}^{-\rho} P_{t+1}}, \\
& C_{t}^{-\rho}=\beta\left(1+i_{t}\right) \mathbb{E}_{t}\left\{\frac{P_{t}}{P_{t+1}} C_{t+1}^{-\rho}\right\} .
\end{aligned}
$$

By symmetry, the same results described above also apply for the household in the Foreign country. We denote the variables in the Foreign country with asterisk $(*)$. 


\section{A.1.2 Law of one price, complete risk sharing and the terms of trade}

As in $\mathrm{BB}$, we assume that the law of one price $P_{H, t}(i)=E_{t} P_{H, t}^{*}(i)$ and $P_{F, t}(i)=E_{t} P_{F, t}^{*}(i)$ hold for each good $i \in[0,1]$ produced in both of the Home and Foreign countries, where $E_{t}$ is the nominal exchange rate. This implies $P_{t}=E_{t} P_{t}^{*}, P_{H t} / P_{t}=P_{H t}^{*} / P_{t}^{*}$ and $P_{F t} / P_{t}=P_{F t}^{*} / P_{t}^{*}$. Also, from the international trade of state-contingent securities,

$$
\begin{gathered}
m_{t, t+1}=\frac{C_{t+1}^{-\rho}}{C_{t}^{-\rho}} \frac{P_{t}}{P_{t+1}}=\frac{\left(C_{t+1}^{*}\right)^{-\rho}}{\left(C_{t}^{*}\right)^{-\rho}} \frac{E_{t} P_{t}^{*}}{E_{t+1} P_{t+1}^{*}}, \\
\Leftrightarrow\left(\frac{C_{t}}{C_{t}^{*}}\right)^{-\rho} \frac{E_{t} P_{t}^{*}}{P_{t}}=\left(\frac{C_{t+1}}{C_{t+1}^{*}}\right)^{-\rho} \frac{E_{t+1} P_{t+1}^{*}}{P_{t+1}} .
\end{gathered}
$$

Without loss of generality, we assume that countries are initially symmetric. This implies that $\left(C_{t} / C_{t}^{*}\right)^{-\rho} E_{t} P_{t}^{*} / P_{t}=1$ holds for all states and dates. Combined with the assumption of the law of one price, $C_{t}=C_{t}^{*}$ holds; i.e., complete risk sharing of consumption among countries. Note that in the international economics literature this setting is synonymous with the notion of producer currency pricing (PCP).

Terms of trade for the Home country is defined as $S_{t} \equiv P_{F t} / P_{H t}=P_{F t}^{*} / P_{H t}^{*}$, which implies $P_{t} / P_{H t}=\left(P_{H t} / P_{F t}\right)^{\gamma-1}=S_{t}^{1-\gamma}$ and $P_{t} / P_{F t}=\left(P_{H t} / P_{F t}\right)^{\gamma}=S_{t}^{-\gamma}$. The market clearing conditions for both countries imply ${ }^{54}$

$$
\begin{aligned}
\gamma Y_{H, t} & \equiv \gamma C_{H t}+(1-\gamma) C_{H t}^{*}, \\
& =\gamma^{2}\left(\frac{P_{H, t}}{P_{t}}\right)^{-1} C_{t}+(1-\gamma) \gamma\left(\frac{P_{H, t}^{*}}{P_{t}^{*}}\right)^{-1} C_{t}^{*}, \\
& =\gamma\left(\frac{P_{H, t}}{P_{t}}\right)^{-1} C_{t}, \\
& =\gamma S_{t}^{1-\gamma} C_{t},
\end{aligned}
$$

and

$$
\begin{aligned}
(1-\gamma) Y_{F, t}^{*} & \equiv(1-\gamma) C_{F t}+\gamma C_{F t}^{*}, \\
& =(1-\gamma)^{2}\left(\frac{P_{F, t}}{P_{t}}\right)^{-1} C_{t}+\gamma(1-\gamma)\left(\frac{P_{F, t}^{*}}{P_{t}^{*}}\right)^{-1} C_{t}^{*} \\
& =(1-\gamma)\left(\frac{P_{F, t}}{P_{t}}\right)^{-1} C_{t}, \\
& =(1-\gamma) S_{t}^{-\gamma} C_{t} .
\end{aligned}
$$

Then we have

$$
S_{t}=\frac{Y_{H, t}}{Y_{F, t}^{*}}
$$

That is, the terms of trade is determined by the relative output (in terms of per capita) only.

\footnotetext{
${ }^{54}$ We define $Y_{H, t}$ and $Y_{F, t}^{*}$ as per capita variables following BB in pp. 478-479.
} 


\section{A.1.3 Firms}

There is a continuum of firms indexed by $i \in[0,1]$. We focus on the domestic firms $i=h \in$ $[0, \gamma)$. The same results apply for the Foreign firms $i=f \in[\gamma, 1.0]$. Each firm has a linear production technology which transfers firm-specific labor into differentiated good, $Y_{t}(h)=$ $h_{t}(h)$. The period-by-period profit for firm producing good $h$ is given by

$$
\begin{aligned}
\Pi_{t}(h) & =P_{t}(h) Y_{t}(h)-\left(1-\tau_{t}\right) W_{t}(h) Y_{t}(h) \\
& =\left[P_{t}(h)-\left(1-\tau_{t}\right) W_{t}(h)\right] Y_{t}(h)
\end{aligned}
$$

where $\tau_{t}$ is a subsidy to each firm, which is necessary to eliminate the distortion stemming from monopolistic competition. Note that the market clearing condition for good $h$ implies:

$$
\begin{aligned}
Y_{t}(h) & =\gamma C_{H, t}(h)+(1-\gamma) C_{H, t}^{*}(h), \\
& =\left[\frac{P_{H t}(h)}{P_{H, t}}\right]^{-\sigma} C_{H, t}+\left[\frac{P_{H t}^{*}(h)}{P_{H, t}^{*}}\right]^{-\sigma} C_{H, t}^{*} \\
& =\gamma\left[\frac{P_{H t}(h)}{P_{H, t}}\right]^{-\sigma}\left(\frac{P_{H, t}}{P_{t}}\right)^{-1} C_{t}+(1-\gamma)\left[\frac{P_{H, t}^{*}(h)}{P_{H, t}^{*}}\right]^{-\sigma}\left(\frac{P_{H, t}^{*}}{P_{t}^{*}}\right)^{-1} C_{t}^{*}, \\
& =\left[\frac{P_{H t}(h)}{P_{H, t}}\right]^{-\sigma}\left(\frac{P_{H, t}}{P_{t}}\right)^{-1} C_{t} .
\end{aligned}
$$

Given the demand function, the firm $h$ chooses $\bar{P}_{H, t}=P_{H, t+i}(h)$ for $i>0$ so as to maximize

$$
\mathbb{E}_{t} \sum_{i=0}^{\infty} \alpha^{i} m_{t, t+i}\left[\bar{P}_{H, t}-\left(1-\tau_{t+i}\right) W_{t+i}(h)\right] \underbrace{\left[\frac{\bar{P}_{H, t}}{P_{H, t+i}}\right]^{-\sigma}\left(\frac{P_{H, t+i}}{P_{t+i}}\right)^{-1} C_{t+i}}_{=Y_{t+i}(h)},
$$

where $\alpha$ is the probability of fixing prices a la Calvo (1983). The random variable $m_{t, t+i}=$ $\beta^{i} C_{t+i}^{-\rho} P_{t} /\left(C_{t}^{-\rho} P_{t+i}\right)$ is the stochastic discount factor. Note that $W_{t+i}(h)$ is given for the firm. The optimality condition is

$$
\mathbb{E}_{t} \sum_{i=0}^{\infty} \alpha^{i} m_{t, t+i}\left[\frac{\bar{P}_{H, t}}{P_{H, t+i}}\right]^{-\sigma}\left(\frac{P_{H, t+i}}{P_{t+i}}\right)^{-1} C_{t+i}\left[\bar{P}_{H, t}-\frac{\sigma}{\sigma-1}\left(1-\tau_{t+i}\right) W_{t+i}(h)\right]=0 .
$$

This can be further transformed in a recursive fashion

$$
\begin{aligned}
& \left(\frac{\bar{P}_{H, t}}{P_{H, t}}\right)^{1+\eta \sigma} F_{t}=K_{t}, \\
& F_{t}=\mathcal{M}_{t}^{-1} C_{t}^{1-\rho}+\alpha \beta \mathbb{E}_{t} \Pi_{H, t+1}^{\sigma-1} F_{t+1}, \\
& K_{t}=Y_{H, t}^{1+\eta}+\alpha \beta \mathbb{E}_{t} \Pi_{H, t+1}^{\sigma(1+\eta)} K_{t+1},
\end{aligned}
$$

where $\mathcal{M}_{t}=\left(1-\tau_{t}\right) \sigma /(\sigma-1)$ is a markup shock as a function of exogenous variations $\tau$ in the subsidy to firms; and $\Pi_{H, t}=P_{H, t} / P_{H, t-1}$ is the gross domestic inflation rate. Furthermore, 
the Home price index $P_{H, t}=\left\{\frac{1}{\gamma} \int_{0}^{\gamma}\left[P_{H, t}(h)\right]^{1-\sigma} \mathrm{d} h\right\}^{\frac{1}{1-\sigma}}$ can be written as

$$
P_{H, t}^{1-\sigma}=\alpha P_{H t-1}^{1-\sigma}+(1-\alpha) \bar{P}_{H, t}^{1-\sigma} .
$$

That is, only the $1-\alpha$ fraction of the domestic firms can set the new price $\bar{P}_{H, t}$. It can be further arranged as

$$
\frac{\bar{P}_{H, t}}{P_{H, t}}=\left[\frac{1-\alpha\left(\frac{P_{H t-1}}{P_{H, t}}\right)^{1-\sigma}}{1-\alpha}\right]^{\frac{1}{1-\sigma}} .
$$

Using the demand function of good $h, Y_{t}(h)=\left[\frac{P_{H t}(h)}{P_{H, t}}\right]^{-\sigma}\left(\frac{P_{H, t}}{P_{t}}\right)^{-1} C_{t}=\left[\frac{P_{H t}(h)}{P_{H, t}}\right]^{-\sigma} Y_{H, t}$ and the linear production technology of firm $h, h_{t}(h)=Y_{t}(h)$, the disutility from working is

$$
\begin{aligned}
& \frac{1}{\gamma} \int_{0}^{\gamma} \frac{h_{t}(h)^{1+\eta}}{1+\eta} \mathrm{d} h, \\
= & \frac{1}{\gamma} \frac{Y_{H, t}^{1+\eta}}{1+\eta} \int_{0}^{\gamma}\left[\frac{P_{H, t}(h)}{P_{H, t}}\right]^{-\sigma(1+\eta)} \mathrm{d} h, \\
= & \frac{Y_{H, t}^{1+\eta}}{1+\eta} \Delta_{t} .
\end{aligned}
$$

Also, the Home price dispersion $\Delta_{t} \equiv \frac{1}{\gamma} \int_{0}^{\gamma}\left[\frac{P_{H, t}(h)}{P_{H, t}}\right]^{-\sigma(1+\eta)} \mathrm{d} h \geq 1$ can be further transformed into

$$
\begin{aligned}
\Delta_{t} & =\alpha \frac{1}{\gamma} \int_{0}^{\gamma}\left[\frac{P_{H, t-1}(h)}{P_{H, t}}\right]^{-\sigma(1+\eta)} \mathrm{d} h+(1-\alpha)\left(\frac{\bar{P}_{H, t}}{P_{H, t}}\right)^{-\sigma(1+\eta)} \\
& =\alpha\left(\frac{P_{H, t-1}}{P_{H, t}}\right)^{-\sigma(1+\eta)} \Delta_{t-1}+(1-\alpha)\left[\frac{1-\alpha\left(\frac{P_{H t-1}}{P_{H, t}}\right)^{1-\sigma}}{1-\alpha}\right]^{\frac{\sigma(1+\eta)}{\sigma-1}} .
\end{aligned}
$$

\section{A.1.4 Equilibrium conditions}

The equilibrium conditions in the model described above are

$$
\begin{gathered}
Y_{H, t}=S_{t}^{1-\gamma} C_{t,} \\
\frac{Y_{H, t}}{Y_{F, t}^{*}}=S_{t} \\
{\left[\frac{1-\alpha\left(\frac{1}{\Pi_{H, t}}\right)^{1-\sigma}}{1-\alpha}\right]^{\frac{1+\eta \sigma}{1-\sigma}} F_{t}=K_{t},} \\
F_{t}=\mathcal{M}_{t}^{-1} C_{t}^{1-\rho}+\alpha \beta \mathbb{E}_{t} \Pi_{H, t+1}^{\sigma-1} F_{t+1}, \\
K_{t}=Y_{H, t}^{1+\eta}+\alpha \beta \mathbb{E}_{t} \pi \Pi_{H, t+1}^{\sigma(1+\eta)} K_{t+1},
\end{gathered}
$$




$$
\begin{gathered}
\Delta_{t}=\alpha\left(\frac{1}{\Pi_{H, t}}\right)^{-\sigma(1+\eta)} \Delta_{t-1}+(1-\alpha)\left[\frac{1-\alpha\left(\frac{1}{\Pi_{H, t}}\right)^{1-\sigma}}{1-\alpha}\right]^{\frac{\sigma(1+\eta)}{\sigma-1}}, \\
{\left[\frac{1-\alpha\left(\frac{1}{\Pi_{F, t}^{*}}\right)^{1-\sigma}}{1-\alpha}\right]^{\frac{1+\eta \sigma}{1-\sigma}} F_{t}^{*}=K_{t}^{*},} \\
F_{t}^{*}=\mathcal{M}_{t}^{*-1} C_{t}^{1-\rho}+\alpha \beta \mathbb{E}_{t}\left(\Pi_{F, t+1}^{*}\right)^{\sigma-1} F_{t+1}^{*}, \\
K_{t}^{*}=\left(Y_{F, t}^{*}\right)^{1+\eta}+\alpha \beta \mathbb{E}_{t}\left(\Pi_{F, t+1}^{*}\right)^{\sigma(1+\eta)} K_{t+1}^{*}, \\
\Delta_{t}^{*}=\alpha\left(\frac{1}{\Pi_{F, t}^{*}}\right)^{-\sigma(1+\eta)} \Delta_{t-1}^{*}+(1-\alpha)\left[\frac{1-\alpha\left(\frac{1}{\Pi_{F, t}^{*}}\right)^{1-\sigma}}{1-\alpha}\right]^{\frac{\sigma(1+\eta)}{\sigma-1}} .
\end{gathered}
$$

We have 12 endogenous variables $\left\{F_{t}, K_{t}, \Delta_{t}, F_{t}^{*}, K_{t}^{*}, \Delta_{t}^{*}, C_{t}, Y_{H, t}, Y_{F, t}^{*}, \Pi_{H, t}, \Pi_{F, t}^{*}, S_{t}\right\}$ and 10 Eqs. (24)-(33). Note that consumption Euler equation is redundant in the equilibrium characterization once monetary policies are given. Note that the equilibrium is indeterminate without any policies, due to the lack of $2(=12-10)$ equilibrium conditions. Monetary policy must be defined to pin down the equilibrium. Policy is then determined by resolving the optimal policy trade-offs under one of the three regimes we consider in the paper: Cooperation, Noncooperation, or Sustainable Cooperation.

\section{A.1.5 Cooperation and Non-cooperation policies}

The policymakers under Cooperation jointly maximize

$$
\mathbb{E}_{0} \sum_{t=0}^{\infty} \beta^{t}\left\{\gamma\left[\frac{C_{t}^{1-\rho}}{1-\rho}-\frac{Y_{H, t}^{1+\eta}}{1+\eta} \Delta_{t}\right]+(1-\gamma)\left[\frac{C_{t}^{* 1-\rho}}{1-\rho}-\frac{Y_{F, t}^{* 1+\eta}}{1+\eta} \Delta_{t}^{*}\right]\right\}
$$

where $\frac{1}{\gamma} \int_{0}^{\gamma} \frac{h_{t}(h)^{1+\eta}}{1+\eta} \mathrm{d} h=\frac{\gamma_{H, t}^{1+\eta}}{1+\eta} \Delta_{t}$ and $\frac{1}{1-\gamma} \int_{\gamma}^{1} \frac{h_{t}(f)^{1+\eta}}{1+\eta} \mathrm{d} f=\frac{Y_{F, t}^{* 1+\eta}}{1+\eta} \Delta_{t}^{*}$, subject to the equilibrium conditions above. Under Non-cooperation, the domestic policymaker maximizes

$$
\mathbb{E}_{0} \sum_{t=0}^{\infty} \beta^{t}\left[\frac{C_{t}^{1-\rho}}{1-\rho}-\frac{Y_{H, t}^{1+\eta}}{1+\eta} \Delta_{t}\right]
$$

subject to the model above, given $\Pi_{F, t}^{*}$; On the other hand, the Foreign policymaker maximizes

$$
\mathbb{E}_{0} \sum_{t=0}^{\infty} \beta^{t}\left[\frac{C_{t}^{* 1-\rho}}{1-\rho}-\frac{Y_{F, t}^{* 1+\eta}}{1+\eta} \Delta_{t}^{*}\right]
$$

subject to the model above, given $\Pi_{H, t}$.

We need to compute the steady state under Cooperation and Non-cooperation. We know that $\Pi_{H}=\Pi_{F}^{*}=1$ in the steady state. We also assume that $\mathcal{M}=\mathcal{M}^{*}=1$. Therefore, the model must be approximated around the steady state: $K=F=K^{*}=F^{*}=(1-\alpha \beta)^{-1}$ and 
$\Delta=\Delta^{*}=Y_{H}=Y_{F}^{*}=C=S=1$.

\section{A.1.6 Log-linearization}

The log-linearized equilibrium conditions around the steady state are

$$
\begin{gathered}
y_{H, t}-(1-\gamma) s_{t}=c_{t}, \\
s_{t}=y_{H, t}-y_{F, t \prime}^{*} \\
\frac{\alpha(1+\eta \sigma)}{1-\alpha} \pi_{H, t}+f_{t}=k_{t}, \\
f_{t}=(1-\alpha \beta)(1-\rho) c_{t}-(1-\alpha \beta) \mu_{t}+\alpha \beta(\sigma-1) \mathbb{E}_{t} \pi_{H, t+1}+\alpha \beta \mathbb{E}_{t} f_{t+1}, \\
k_{t}=(1-\alpha \beta)(1+\eta) y_{H, t}+\alpha \beta \sigma(1+\eta) \mathbb{E}_{t} \pi_{H, t+1}+\alpha \beta \mathbb{E}_{t} k_{t+1}, \\
\frac{\alpha(1+\eta \sigma)}{1-\alpha} \pi_{F, t}^{*}+f_{t}^{*}=k_{t}^{*}, \\
f_{t}^{*}=(1-\alpha \beta)(1-\rho) c_{t}^{*}-(1-\alpha \beta) \mu_{t}^{*}+\alpha \beta(\sigma-1) \mathbb{E}_{t} \pi_{F, t+1}^{*}+\alpha \beta \mathbb{E}_{t} f_{t+1}^{*}, \\
k_{t}^{*}=(1-\alpha \beta)(1+\eta) y_{F, t}^{*}+\alpha \beta \sigma(1+\eta) \mathbb{E}_{t} \pi_{F, t+1}^{*}+\alpha \beta \mathbb{E}_{t} k_{t+1}^{*},
\end{gathered}
$$

Note that the log deviation of a variable $X_{t}$ from the steady state $X$ is defined in lowercase as $x_{t} \equiv \log \left(X_{t} / X\right)$ and the Taylor approximation of $X_{t}$ up to the first order is $X_{t} \approx X\left(1+x_{t}\right){ }^{55}$ Given $\Pi_{H}=\Pi_{F}=1$ in the steady state, $\pi_{t} \equiv \pi_{H, t}=\log \left(\Pi_{H, t}\right) \approx \Pi_{H, t}-1$ and $\pi_{t}^{*} \equiv \pi_{F, t}^{*}=$ $\log \left(\Pi_{F, t}\right) \approx \Pi_{F, t}-1$ are the net domestic and Foreign inflation rates. Note that $\delta_{t}=\delta_{t}^{*}=0$, i.e., the price dispersion terms have no effect at the first order. We also define $y_{t} \equiv y_{H, t}$ and $y_{t}^{*} \equiv y_{F, t}^{*}$. These equations are summarized as follows:

$$
\begin{gathered}
\pi_{t}=\frac{(1-\alpha \beta)(1-\alpha)}{\alpha(1+\eta \sigma)}\left[\mu_{t}+(\rho+\eta) y_{t}+(1-\gamma)(1-\rho) s_{t}\right]+\beta \mathbb{E}_{t} \pi_{t+1}, \\
\pi_{t}^{*}=\frac{(1-\alpha \beta)(1-\alpha)}{\alpha(1+\eta \sigma)}\left[\mu_{t}+(\rho+\eta) y_{t}^{*}-\gamma(1-\rho) s_{t}\right]+\beta \mathbb{E}_{t} \pi_{t+1}^{*},
\end{gathered}
$$

and

$$
s_{t}=y_{t}-y_{t}^{*}
$$

which corresponds to Eqs. (1)-(2) (with $\gamma=1 / 2)$ or (21)-(22) in Section 5.

\section{A.2 Welfare approximation for $L Q$ framework}

Instead of the nonlinear Cooperation and Non-cooperation policies explained above, we will consider the LQ framework, following BB. For that purpose, the objective functions must be correctly approximated so that the welfare ordering of policies (under various regimes) in the

\footnotetext{
${ }^{55}$ We will also use the same lowercase Greek convention for Greek-lettered variables-e.g., $x$ is to $X$, as $\delta$ is to $\Delta$ , or, as $\mu$ is to $\mathcal{M}$.
} 
LQ framework preserves that in the original nonlinear setting of the model (see e.g., Benigno and Woodford, 2012; Debortoli and Nunes, 2006; Levine et al., 2008; Bodenstein et al., 2014).

Let $x_{t}$ denote the percentage deviation of the level of a variable $X_{t}$ from its deterministic steady-state point $X$. Note that for a variable $X_{t}$, the Taylor approximation up to the second order is $X_{t}-X \approx X\left(x_{t}+\frac{1}{2} x_{t}^{2}\right)$. Thus,

$$
\begin{aligned}
\frac{C_{t}^{1-\rho}}{1-\rho} & \approx \frac{C^{1-\rho}}{1-\rho}+C^{-\rho}\left(C_{t}-C\right)-\frac{\rho C^{-\rho-1}}{2}\left(C_{t}-C\right)^{2} \\
& \approx C^{1-\rho}\left(\frac{C_{t}-C}{C}\right)-\frac{\rho C_{t}^{1-\rho}}{2}\left(\frac{C_{t}-C}{C}\right)^{2}+\text { t.i.p. } \\
& =c_{t}+\frac{1-\rho}{2} c_{t}^{2}+\text { t.i.p. }
\end{aligned}
$$

where t.i.p. stands for terms independent of policy. Similarly,

$$
\frac{Y_{t}^{1+\eta}}{1+\eta} \approx y_{t}+\frac{1+\eta}{2} y_{t}^{2}+\text { t.i.p. }
$$

Note that $C^{1-\rho}=Y^{1+\eta}=1$.

\section{A.2.1 Cooperation}

$$
\begin{aligned}
& \frac{C_{t}^{1-\rho}}{1-\rho}-\gamma \frac{Y_{H, t}^{1+\eta}}{1+\eta} \Delta_{t}-(1-\gamma) \frac{\left(Y_{F, t}^{*}\right)^{1+\eta}}{1+\eta} \Delta_{t}^{*}, \\
= & -\gamma\left(y_{t}-c_{t}+\frac{1+\eta}{2} y_{t}^{2}-\frac{1-\rho}{2} c_{t}^{2}+\delta_{t}\right) \\
& -(1-\gamma)\left(y_{t}^{*}-c_{t}+\frac{1+\eta}{2}\left(y_{t}^{*}\right)^{2}-\frac{1-\rho}{2} c_{t}^{2}+\delta_{t}^{*}\right)+\text { t.i.p., } \\
= & -\gamma \frac{1+\eta}{2} y_{t}^{2}-(1-\gamma) \frac{1+\eta}{2}\left(y_{t}^{*}\right)^{2} \\
& +\gamma \frac{1-\rho}{2}\left(y_{t}-(1-\gamma) s_{t}\right)^{2}+(1-\gamma) \frac{1-\rho}{2}\left(y_{t}^{*}+\gamma s_{t}\right)^{2} \\
& -\gamma \delta_{t}-(1-\gamma) \delta_{t}^{*}+\text { t.i.p., } \\
= & -\gamma \frac{\rho+\eta}{2} y_{t}^{2}-(1-\gamma) \frac{\rho+\eta}{2}\left(y_{t}^{*}\right)^{2}-\gamma(1-\gamma) \frac{1-\rho}{2} s_{t}^{2} \\
& -\gamma \delta_{t}-(1-\gamma) \delta_{t}^{*}+\text { t.i.p., }
\end{aligned}
$$

where we use $s_{t}=y_{t}-y_{t}^{*}$, and $y_{t}-c_{t}=(1-\gamma) s_{t}, y_{t}^{*}-c_{t}=-\gamma s_{t}$, noting that $s_{t}=-s_{t}^{*}$. Note that a second-order approximation of the price-dispersion term

$$
\Delta_{t}=\alpha\left(\frac{1}{\Pi_{H, t}}\right)^{-\sigma(1+\sigma \eta)} \Delta_{t-1}+(1-\alpha)\left[\frac{1-\alpha\left(\frac{1}{\Pi_{H, t}}\right)^{1-\sigma}}{1-\alpha}\right]^{\frac{\sigma(1+\eta \sigma)}{\sigma-1}}
$$


leads to

$$
\mathbb{E}_{0} \sum_{t=0}^{\infty} \beta^{t} \Delta_{t} \approx \mathbb{E}_{0} \sum_{t=0}^{\infty} \beta^{t} \frac{\sigma}{2 k} \pi_{t}^{2}
$$

which is approximately a second order transform of inflation. Thus, the joint/global welfare function used for studying the Cooperation regime and also the Sustainable Cooperation regime, can be approximated up to the second order as

$$
\begin{aligned}
& -\mathbb{E}_{0} \sum_{t=0}^{\infty} \beta^{t}\left[\gamma \delta_{t}+(1-\gamma) \delta_{t}^{*}+\gamma \frac{\rho+\eta}{2} y_{t}^{2}+(1-\gamma) \frac{\rho+\eta}{2}\left(y_{t}^{*}\right)^{2}+\gamma(1-\gamma) \frac{1-\rho}{2} s_{t}^{2}\right], \\
= & -\frac{1}{2} \mathbb{E}_{0} \sum_{t=0}^{\infty} \beta^{t}\left[\begin{array}{c}
\frac{\gamma \sigma}{k} \pi_{t}^{2}+\frac{(1-\gamma) \sigma}{k}\left(\pi_{t}^{*}\right)^{2} \\
+\gamma(\rho+\eta) y_{t}^{2}+(1-\gamma)(\rho+\eta)\left(y_{t}^{*}\right)^{2} \\
+\gamma(1-\gamma)(1-\rho)\left(y_{t}-y_{t}^{*}\right)^{2}
\end{array}\right] .
\end{aligned}
$$

This corresponds to (6) in Section 3 (if we set countries to the same size, $\gamma=1 / 2$ ) or (23) in Section 5 .

\section{A.2.2 Non-cooperation}

Domestic instantaneous welfare is

$$
\begin{aligned}
& \frac{C_{t}^{1-\rho}}{1-\rho}-\frac{Y_{H, t}^{1+\eta}}{1+\eta} \Delta_{t} \\
\approx & c_{t}+\frac{1-\rho}{2} c_{t}^{2}-y_{t}-\frac{1+\eta}{2} y_{t}^{2}-\delta_{t}+\text { t.i.p., } \\
= & -(1-\gamma) s_{t}+\frac{1-\rho}{2} c_{t}^{2}-\frac{1+\eta}{2}\left(c_{t}+(1-\gamma) s_{t}\right)^{2}-\delta_{t}+\text { t.i.p., }
\end{aligned}
$$

Similarly, for the Foreign country we have

$$
\begin{aligned}
& \frac{\left(C_{t}^{*}\right)^{1-\rho}}{1-\rho}-\frac{\left(Y_{F, t}^{*}\right)^{1+\eta}}{1+\eta} \Delta_{t}^{*}, \\
\approx & c_{t}^{*}+\frac{1-\rho}{2}\left(c_{t}^{*}\right)^{2}-y_{t}^{*}-\frac{1+\eta}{2}\left(y_{t}^{*}\right)^{2}-\delta_{t}^{*}+\text { t.i.p., } \\
= & \gamma s_{t}+\frac{1-\rho}{2} c_{t}^{2}-\frac{1+\eta}{2}\left(c_{t}-\gamma s_{t}\right)^{2}-\delta_{t}^{*}+\text { t.i.p., }
\end{aligned}
$$

Note that each approximation includes the log-linear term of $s_{t}$. The linear terms in the approximated welfare induce spurious welfare evaluation in the LQ framework. The correct LQ approximation must be derived with a purely quadratic welfare function (Kim and Kim, 2003, 2007; Benigno and Woodford, 2005, 2012; Benigno and Benigno, 2006; Fujiwara and Teranishi, 2013). We need to substitute out the linear terms of $s_{t}$. For this purpose, we approximate the NK Phillips curve up to the second order. 
Second order approximation of the NK Phillips Curve. By following Benigno and Benigno (2006), the second order approximation of the NK Phillips curve leads to

$$
\begin{aligned}
& k \mathbb{E}_{0} \sum_{t=0}^{\infty} \beta^{t}\left(\eta y_{t}+\rho c_{t}-\tilde{p}_{H, t}+\mu_{t}\right) \\
\approx & K_{0}-\frac{k}{2} \mathbb{E}_{0} \sum_{t=0}^{\infty} \beta^{t}\left(\eta y_{t}+\rho c_{t}-\tilde{p}_{H, t}+\mu_{t}\right)\left((2-\rho) c_{t}+\eta y_{t}-\tilde{p}_{H, t}+\mu_{t}\right) \\
& -\frac{\sigma(1+\eta)}{2} \mathbb{E}_{0} \sum_{t=0}^{\infty} \beta^{t} \pi_{t}^{2} .
\end{aligned}
$$

where $\tilde{p}_{H, t}=\log \left(P_{H, t} / P_{t}\right)=\log P_{H, t}^{1-\gamma} P_{F, t}^{\gamma-1}=(\gamma-1) s_{t}$ and $K_{0}$ is given and under the timeless perspective, assumed to be zero (Benigno and Woodford, 2005, 2012). Therefore, we can have the approximated condition:

$$
\begin{aligned}
& \mathbb{E}_{0} \sum_{t=0}^{\infty} \beta^{t}\left(\eta y_{t}+\rho c_{t}+(1-\gamma) s_{t}+\mu_{t}\right) \\
= & -\frac{1}{2} \mathbb{E}_{0} \sum_{t=0}^{\infty} \beta^{t}\left(\eta y_{t}+\rho c_{t}+(1-\gamma) s_{t}+\mu_{t}\right)\left((2-\rho) c_{t}+\eta y_{t}+(1-\gamma) s_{t}+\mu_{t}\right) \\
& -\frac{\sigma(1+\eta)}{2 k} \mathbb{E}_{0} \sum_{t=0}^{\infty} \beta^{t} \pi_{t}^{2} .
\end{aligned}
$$

Similarly for the Foreign Phillips curve, we have

$$
\begin{aligned}
& \mathbb{E}_{0} \sum_{t=0}^{\infty} \beta^{t}\left(\eta y_{t}^{*}+\rho c_{t}-\gamma s_{t}+\mu_{t}^{*}\right) \\
= & -\frac{1}{2} \mathbb{E}_{0} \sum_{t=0}^{\infty} \beta^{t}\left(\eta y_{t}^{*}+\rho c_{t}-\gamma s_{t}+\mu_{t}^{*}\right)\left((2-\rho) c_{t}+\eta y_{t}^{*}-\gamma s_{t}+\mu_{t}^{*}\right) \\
& -\frac{\sigma(1+\eta)}{2 k} \mathbb{E}_{0} \sum_{t=0}^{\infty} \beta^{t}\left(\pi_{t}^{*}\right)^{2} .
\end{aligned}
$$

From these approximations, we have the linear terms replaced by quadratic terms:

$$
\begin{aligned}
\mathbb{E}_{0} \sum_{t=0}^{\infty} \beta^{t} s_{t}= & -\frac{1}{2(1+\eta)} \mathbb{E}_{0} \sum_{t=0}^{\infty} \beta^{t}\left[(\eta+\rho) c_{t}+(1-\gamma)(1+\eta) s_{t}+\mu_{t}\right] \times \\
& {\left[(2-\rho+\eta) c_{t}+(1-\gamma)(1+\eta) s_{t}+\mu_{t}\right]-\frac{\sigma}{2 k} \mathbb{E}_{0} \sum_{t=0}^{\infty} \beta^{t} \pi_{t}^{2} } \\
& +\frac{1}{2(1+\eta)} \mathbb{E}_{0} \sum_{t=0}^{\infty} \beta^{t}\left((\eta+\rho) c_{t}-\gamma(1+\eta) s_{t}+\mu_{t}^{*}\right) \times \\
& {\left[(2-\rho+\eta) c_{t}-\gamma(1+\eta) s_{t}+\mu_{t}^{*}\right]+\frac{\sigma}{2 k} \mathbb{E}_{0} \sum_{t=0}^{\infty} \beta^{t}\left(\pi_{t}^{*}\right)^{2} . }
\end{aligned}
$$


By substituting (38) into (36), and after tedious calculations, we have

$$
\begin{aligned}
V_{0}=-\mathbb{E}_{0} \sum_{t=0}^{\infty} \beta^{t} U_{t} \\
=-\frac{1}{2} \mathbb{E}_{0} \sum_{t=0}^{\infty} \beta^{t}\left[\begin{array}{c}
\gamma(\eta+\rho)\left(y_{t}-\frac{1-\gamma}{\gamma(\eta+\rho)} \mu_{t}\right)^{2}+\frac{\gamma \sigma}{k} \pi_{t}^{2} \\
+\gamma(1-\gamma)(1-\rho)\left(y_{t}-y_{t}^{*}\right)^{2} \\
+(1-\gamma)(\eta+\rho)\left(y_{t}^{*}+\frac{1}{\eta+\rho} \mu_{t}^{*}\right)^{2}+\frac{(1-\gamma) \sigma}{k^{*}}\left(\pi_{t}^{*}\right)^{2}
\end{array}\right] .
\end{aligned}
$$

This corresponds to (4) in Section 2. Similarly we can derive (5) as well.

\section{A.3 Remarks: Time-0 vs. timeless welfare measures}

Timeless within-country policy commitment and welfare. In the last section, when deriving the second-order accurate approximation of the original welfare functions, we had followed Benigno and Benigno (2006) and assumed the timeless perspective on policy commitments (see also Benigno and Woodford, 2005, 2012). Specifically, this perspective refers to the commitment of each country's policymaker to its policy plan (including its initial policy), and with respect to all agents' expectations. This is assumed in each regime that we consider: Cooperation, Non-cooperation, and Sustainable Cooperation.

Algebraically, this assumption was imbedded in the steps when we eliminated linear terms earlier, in order to combine second-order approximations of equilibrium conditions with secondorder utility-function derivations. The resulting welfare function for each country would have contained a linearly separable term involving agents' date- 0 expected total welfare conditional on particular transitions of past outcomes that would taken their beliefs to that state and point in time. We had subsumed such a term as $K_{0}$ in the previous section. The reason we can do so is that—as detailed in Benigno and Benigno (2006)—each policymaker ties its hands with respect to his date- 0 policy and merely continues it from the history generated by the same plan (from some infinite past) preceding the current policymaker. Thus, we can focus on timeinvariant policy functions enforcing each regime's policy plan, or equivalently, their respective time-independent characterizations of policy trade-offs in (9)-(10) for the case of Cooperation, (11)-(12) for the regime of Non-cooperation, and, (15)-(16) for that of Sustainable Cooperation.

This notion of timeless within-country commitment by policymakers to continue with past plans, while being used to derive the date- 0 and state-contingent welfare functions (4) and (5), should not be confused with another notion of timelessness when evaluating these welfare functions. Next, we discuss two ways of evaluating the welfare functions (4) and (5), depending on the purpose that these methods will serve.

Conditional (time-0) and unconditional (timeless) welfare measures. In the paper, we utilized two different welfare metrics depending on the question at hand: One, if we are only interested in a decomposition into the components comprising the welfare outcome within a particular regime, then we can evaluate welfare with respect to the ergodic and unconditional distribution of a given policy regime's equilibrium. By doing so, we would have additionally built into the measured welfare outcome an infinitely (in practice, sufficiently) long history 
of within-country commitment policy outcomes. For practical purposes in the paper, we call this implementation the welfare metric under the timeless perspective, or simply, the unconditional welfare measure. In the paper, this welfare metric, respectively for Home (7) and Foreign (8), is used in the decompositions in Figure 2 on page 18, and, Figure 6 on page 29.56

Two, the unconditional welfare metric under the timeless perspective would not be so useful when we are comparing relative welfare outcomes across different policy regimes. That is because given each regime's equilibrium outcome, the corresponding implementation of an unconditional timeless-perspective welfare measure would be with respect to an ergodic distribution likely to be different from another regime's or equilibrium's outcome. Hence, we can only compare welfare outcomes from different equilibria/regimes if these welfare measures are conditioned on the same initial state vector. This, we label the time- 0 conditional welfare measure. In the paper we also call this the stochastic steady-state welfare measure. In this model, we condition them on the same initial natural states, and in terms of output this would be $y_{-1}=y_{-1}^{*}=0 .{ }^{57}$

\section{B LQ Framework: Alternative Policy Regimes}

In this appendix, we derive equilibrium policy trade-offs for the three regimes considered. We also discuss the computation procedure for the Sustainable Cooperation equilibrium's functional operator problem. This is a problem solving for nonlinear functions despite the underlying model is the LQ framework presented in Section 2. For comparability we also solve the Cooperation equilibrium and the Non-cooperation equilibrium using the same technique, despite this being a regular LQ Markov-perfect equilibrium problem. ${ }^{58}$

\section{B.1 Equilibrium policy trade-off characterizations}

In this section, we will derive the FONCs in each Cooperation, Non-cooperation and Sustainable Cooperation regime.

\footnotetext{
${ }^{56}$ Recall that (7) and (8) are unconditional expected utility functions decomposable into their respective unconditional variance arguments. This facilitates additional insights into the mechanism of the model. (See the discussions around Figure 2 on page 18, and, Figure 6 on page 29 in the paper.) In our numerical implementation of these measures, economies under each regime are simulated over very long periods and only the outcomes in the last 200 periods (i.e., 50 years in the quarterly model) are used when we calculate the variances of these variables in the functions $E V$ and $E V^{*}$.

${ }^{57}$ However, there will be another auxiliary state variable $v$, interpretable as the (relative) pseudo-Pareto weight, when one considers the Sustainable Cooperation regime later. (This variable is non-existent in the other two regimes of Cooperation and Non-cooperation.) In this case, we also need to start the Sustainable Cooperation equilibrium outcome off at some point for the initial auxiliary state $v_{-1}$, apart from setting the same initial natural state, $y_{-1}=$ $y_{-1}^{*}=0$, when comparing this regime's stochastic steady-state welfare measure with the other regimes'. In the paper we consider two possible cases: In the baseline setting we have $v_{-1}=1 / 2$, which is the deterministic steady state of the model and is the same as the time-invariant Pareto weight in the Cooperation regime. Also, this is the convention in defining a Ramsey equilibrium steady state value (King and Wolman, 1999; Khan et al., 2003). We also consider $v_{-1}$ being equal to the stochastic steady state of the model, i.e., its asymptotic upper bound (in short we called it "u.b.") in a particular Sustainable Cooperation equilibrium, but this does not change our results. Note that even though we adopt the LQ approximation, the deterministic and stochastic steady state values are different due to the occasionally binding sustainability constraints.

${ }^{58}$ Computing the Cooperation equilibrium is a straight forward application of computing the Sustainable equilibrium; therefore we did not show it here.
} 


\section{B.1.1 Cooperation}

We consider the following maximization problem:

$$
\max \left[\lambda V_{0}+(1-\lambda) V_{0}^{*}\right]
$$

where

$$
\begin{aligned}
V_{0}=-\mathbb{E}_{0} \sum_{t=0}^{\infty} \beta^{t} U_{t} \\
=-\frac{1}{2} \mathbb{E}_{0} \sum_{t=0}^{\infty} \beta^{t}\left[\begin{array}{c}
\gamma(\eta+\rho)\left(y_{t}-\frac{1-\gamma}{\gamma(\eta+\rho)} \mu_{t}\right)^{2}+\frac{\gamma \sigma}{k} \pi_{t}^{2} \\
+\gamma(1-\gamma)(1-\rho)\left(y_{t}-y_{t}^{*}\right)^{2} \\
+(1-\gamma)(\eta+\rho)\left(y_{t}^{*}+\frac{1}{\eta+\rho} \mu_{t}^{*}\right)^{2}+\frac{(1-\gamma) \sigma}{k^{*}}\left(\pi_{t}^{*}\right)^{2}
\end{array}\right],
\end{aligned}
$$

and

$$
\begin{aligned}
V_{0}^{*}=-\mathbb{E}_{0} \sum_{t=0}^{\infty} \beta^{t} U_{t}^{*} \\
=-\frac{1}{2} \mathbb{E}_{0} \sum_{t=0}^{\infty} \beta^{t}\left[\begin{array}{c}
(1-\gamma)(\eta+\rho)\left(y_{t}^{*}-\frac{\gamma}{(1-\gamma)(\eta+\rho)} \mu_{t}^{*}\right)^{2}+\frac{(1-\gamma) \sigma}{k^{*}}\left(\pi_{t}^{*}\right)^{2} \\
+\gamma(1-\gamma)(1-\rho)\left(y_{t}^{*}-y_{t}\right)^{2} \\
+\gamma(\eta+\rho)\left(y_{t}+\frac{1}{\eta+\rho} \mu_{t}\right)^{2}+\frac{\gamma \sigma}{k} \pi_{t}^{2}
\end{array}\right],
\end{aligned}
$$

and $\lambda \in[0,1]$ is a constant parameter, subject to

$$
\pi_{t}=\beta \mathbb{E}_{t} \pi_{t+1}+k \mu_{t}+k\left[(\rho+\eta) y_{t}+(1-\gamma)(1-\rho)\left(y_{t}-y_{t}^{*}\right)\right]
$$

and

$$
\pi_{t}^{*}=\beta \mathbb{E}_{t} \pi_{t+1}^{*}+k^{*} \mu_{t}^{*}+k^{*}\left[(\rho+\eta) y_{t}^{*}-\gamma(1-\rho)\left(y_{t}-y_{t}^{*}\right)\right],
$$

where $k=k^{*}=(1-\alpha)(1-\alpha \beta) /[\alpha(1+\sigma \eta)]$. When $\lambda=\gamma$, it reduces to the Cooperation regime ( $\gamma=1 / 2$ in the case of symmetric country size). When $\lambda \neq \gamma$, it reduces to the $\lambda$ Pareto-cooperation regime considered in Section 4.3. 
The FONCs are

$$
\begin{aligned}
\partial y_{t}: & -2 \lambda \gamma(\eta+\rho)\left(y_{t}-\frac{1-\gamma}{\gamma(\eta+\rho)} \mu_{t}\right)-2 \lambda \gamma(1-\gamma)(1-\rho)\left(y_{t}-y_{t}^{*}\right) \\
& -2(1-\lambda) \gamma(\eta+\rho)\left(y_{t}+\frac{1}{\eta+\rho} \mu_{t}\right)+2(1-\lambda) \gamma(1-\gamma)(1-\rho)\left(y_{t}^{*}-y_{t}\right) \\
& +k(\rho+\eta+(1-\gamma)(1-\rho)) \phi_{t}-k^{*} \gamma(1-\rho) \phi_{t}^{*}=0, \\
\partial y_{t}^{*}: \quad & -2 \lambda(1-\gamma)(\eta+\rho)\left(y_{t}^{*}+\frac{1}{\eta+\rho} \mu_{t}^{*}\right)+2 \lambda \gamma(1-\gamma)(1-\rho)\left(y_{t}-y_{t}^{*}\right) \\
& -2(1-\lambda)(1-\gamma)(\eta+\rho)\left(y_{t}^{*}-\frac{\gamma}{(1-\gamma)(\eta+\rho)} \mu_{t}^{*}\right)-2(1-\lambda) \gamma(1-\gamma)(1-\rho)\left(y_{t}^{*}-y_{t}\right) \\
& +k^{*}(\rho+\eta+\gamma(1-\rho)) \phi_{t}^{*}-k(1-\gamma)(1-\rho) \phi_{t}=0, \\
\partial \pi_{t}: \quad & -\frac{2 \gamma \sigma}{k} \pi_{t}-\phi_{t}+\phi_{t-1}=0, \\
\partial \pi_{t}^{*}: \quad & -\frac{2(1-\gamma) \sigma}{k^{*}} \pi_{t}^{*}-\phi_{t}^{*}+\phi_{t-1}^{*}=0 .
\end{aligned}
$$

We define $\tilde{\mu}_{t}=(\lambda-\gamma) \mu_{t}$ and $\tilde{\mu}_{t}^{*}=(\lambda-\gamma) \mu_{t}^{*}$. Then, The first two equations are solved for

$$
\begin{aligned}
\phi_{t} & =\frac{2 \gamma}{k} y_{t}-\frac{2 \gamma}{k} \frac{[\eta+\rho+\gamma(1-\rho)] \tilde{\mu}_{t}-\gamma(1-\rho) \tilde{\mu}_{t}^{*}}{\gamma(1+\eta)(\rho+\eta)}, \\
\phi_{t}^{*} & =\frac{2(1-\gamma)}{k^{*}} y_{t}^{*}+\frac{2(1-\gamma)}{k^{*}} \frac{[\eta+\rho+(1-\gamma)(1-\rho)] \tilde{\mu}_{t}^{*}-(1-\gamma)(1-\rho) \tilde{\mu}_{t}}{(1-\gamma)(\rho+\eta)(1+\eta)} .
\end{aligned}
$$

The Cooperation equilibrium policy trade-off conditions are summarized as

$$
\begin{aligned}
& -\sigma \pi_{t}=y_{t}-\tilde{\zeta}_{t}-\left(y_{t-1}-\tilde{\zeta}_{t-1}\right), \\
& -\sigma \pi_{t}^{*}=y_{t}^{*}-\tilde{\zeta}_{t}^{*}-\left(y_{t-1}^{*}-\tilde{\zeta}_{t-1}^{*}\right),
\end{aligned}
$$

where $\tilde{\zeta}_{t}=\frac{[\eta+\rho+\gamma(1-\rho)] \tilde{\mu}_{t}-\gamma(1-\rho) \tilde{\mu}_{t}^{*}}{\gamma(1+\eta)(\rho+\eta)}$ and $\tilde{\zeta}_{t}^{*}=-\frac{[\eta+\rho+(1-\gamma)(1-\rho)] \tilde{\mu}_{t}^{*}-(1-\gamma)(1-\rho) \tilde{\mu}_{t}}{(1-\gamma)(\rho+\eta)(1+\eta)}$.

Note that, when $\lambda=\gamma, \tilde{\mu}_{t}=\tilde{\mu}_{t}^{*}=\tilde{\zeta}_{t}=\tilde{\zeta}_{t}^{*}=0 \forall t$ holds and the equilibrium conditions reduce to:

$$
\begin{aligned}
& -\sigma \pi_{t}=y_{t}-y_{t-1}, \\
& -\sigma \pi_{t}^{*}=y_{t}^{*}-y_{t-1}^{*} .
\end{aligned}
$$

\section{B.1.2 Non-cooperation}

For the Home country, the FONCs are

$$
\begin{aligned}
\partial y_{t}: \quad & -2 \gamma(\eta+\rho)\left(y_{t}-\frac{1-\gamma}{\gamma(\eta+\rho)} \mu_{t}\right)-2 \gamma(1-\gamma)(1-\rho)\left(y_{t}-y_{t}^{*}\right) \\
& +k(\rho+\eta+(1-\gamma)(1-\rho)) \varphi_{1, t}-k^{*} \gamma(1-\rho) \varphi_{2, t}=0, \\
\partial y_{t}^{*}: \quad & -2(1-\gamma)(\eta+\rho)\left(y_{t}^{*}+\frac{1}{\eta+\rho} \mu_{t}^{*}\right)+2 \gamma(1-\gamma)(1-\rho)\left(y_{t}-y_{t}^{*}\right) \\
& +k^{*}(\rho+\eta+\gamma(1-\rho)) \varphi_{2, t}-k(1-\gamma)(1-\rho) \varphi_{1, t}=0, \\
\partial \pi_{t}: \quad & -\frac{2 \gamma \sigma}{k} \pi_{t}-\varphi_{1, t}+\varphi_{1, t-1}=0,
\end{aligned}
$$


The first two equations are solved for

$$
\begin{aligned}
\varphi_{1, t} & =\frac{2 \gamma}{k} y_{t}-\frac{2 \gamma}{k} \frac{1-\gamma}{\gamma} \frac{(\eta+\rho+\gamma(1-\rho)) \mu_{t}-\gamma(1-\rho) \mu_{t}^{*}}{(\eta+\rho)(1+\eta)} \\
\varphi_{2, t} & =\frac{2(1-\gamma)}{k^{*}} y_{t}^{*}+\frac{2(1-\gamma)}{k^{*}} \frac{(\eta+\rho+(1-\gamma)(1-\rho)) \mu_{t}^{*}-(1-\gamma)(1-\rho) \mu_{t}}{(\eta+\rho)(1+\eta)} .
\end{aligned}
$$

For the Foreign country, the FONCs are

$$
\begin{aligned}
\partial y_{t}: & -2 \gamma(\eta+\rho)\left(y_{t}+\frac{1}{\eta+\rho} \mu_{t}\right)+2 \gamma(1-\gamma)(1-\rho)\left(y_{t}^{*}-y_{t}\right) \\
& +k(\rho+\eta+(1-\gamma)(1-\rho)) \varphi_{1, t}^{*}-k^{*} \gamma(1-\rho) \varphi_{2, t}^{*}=0, \\
\partial y_{t}^{*}: \quad & -2(1-\gamma)(\eta+\rho)\left(y_{t}^{*}-\frac{\gamma}{(1-\gamma)(\eta+\rho)} \mu_{t}^{*}\right)-2 \gamma(1-\gamma)(1-\rho)\left(y_{t}^{*}-y_{t}\right) \\
& +k^{*}(\rho+\eta+\gamma(1-\rho)) \varphi_{2, t}^{*}-k(1-\gamma)(1-\rho) \varphi_{1, t}^{*}=0, \\
\partial \pi_{t}^{*}: \quad & -\frac{2(1-\gamma) \sigma}{k^{*}} \pi_{t}^{*}-\varphi_{2, t}^{*}+\varphi_{2, t-1}^{*}=0 .
\end{aligned}
$$

The first two equations are solved for

$$
\begin{aligned}
\varphi_{1, t}^{*} & =\frac{2 \gamma}{k} y_{t}+\frac{2 \gamma}{k} \frac{(\eta+\rho+\gamma(1-\rho)) \mu_{t}-\gamma(1-\rho) \mu_{t}^{*}}{(\eta+\rho)(1+\eta)} \\
\varphi_{2, t}^{*} & =\frac{2(1-\gamma)}{k^{*}} y_{t}^{*}-\frac{2(1-\gamma)}{k^{*}} \frac{\gamma}{1-\gamma} \frac{(\eta+\rho+(1-\gamma)(1-\rho)) \mu_{t}^{*}-(1-\gamma)(1-\rho) \mu_{t}}{(\eta+\rho)(1+\eta)} .
\end{aligned}
$$

The Non-cooperation equilibrium policy trade-off conditions are obtained as

$$
\begin{aligned}
& -\sigma \pi_{t}=y_{t}-\xi_{t}-y_{t-1}+\xi_{t-1}, \\
& -\sigma \pi_{t}^{*}=y_{t}^{*}-\xi_{t}^{*}-y_{t-1}^{*}+\xi_{t-1}^{*},
\end{aligned}
$$

where

$$
\begin{aligned}
\xi_{t} & =\frac{1-\gamma}{\gamma} \frac{(\eta+\rho+\gamma(1-\rho)) \mu_{t}-\gamma(1-\rho) \mu_{t}^{*}}{(\eta+\rho)(1+\eta)} \\
\xi_{t}^{*} & =\frac{\gamma}{1-\gamma} \frac{(\eta+\rho+(1-\gamma)(1-\rho)) \mu_{t}^{*}-(1-\gamma)(1-\rho) \mu_{t}}{(\eta+\rho)(1+\eta)}
\end{aligned}
$$

are the variables related to the terms of trade externality. When $\gamma=1 / 2$ in the case of symmetric country size, we have

$$
\begin{aligned}
& \xi_{t}=\frac{(1+\rho+2 \eta) \mu_{t}-(1-\rho) \mu_{t}^{*}}{2(\eta+\rho)(1+\eta)} \\
& \xi_{t}^{*}=\frac{(1+\rho+2 \eta) \mu_{t}^{*}-(1-\rho) \mu_{t}}{2(\eta+\rho)(1+\eta)}
\end{aligned}
$$




\section{B.1.3 Sustainable Cooperation}

Set up the Lagrangean in Period 0 as

$$
\begin{aligned}
\mathcal{L}_{0}= & -\mathbb{E}_{0} \sum_{t=0}^{\infty} \beta^{t}\left\{\gamma U_{t}+(1-\gamma) U_{t}^{*}\right. \\
& +\phi_{t}\left(-\pi_{t}+\beta \mathbb{E}_{t} \pi_{t+1}+k \mu_{t}+k\left[(\rho+\eta) y_{t}+(1-\gamma)(1-\rho)\left(y_{t}-y_{t}^{*}\right)\right]\right) \\
& +\phi_{t}^{*}\left(-\pi_{t}^{*}+\beta \mathbb{E}_{t} \pi_{t+1}^{*}+k^{*} \mu_{t}^{*}+k^{*}\left[(\rho+\eta) y_{t}^{*}-\gamma(1-\rho)\left(y_{t}-y_{t}^{*}\right)\right]\right) \\
& \left.+\psi_{t}\left[-\mathbb{E}_{t} \sum_{s=t}^{\infty} \beta^{s-t} U_{s}-W\left(y_{t-1}, y_{t-1}^{*}, \tau_{t}\right)\right]+\psi_{t}^{*}\left[-\mathbb{E}_{t} \sum_{s=t}^{\infty} \beta^{s-t} U_{s}^{*}-W^{*}\left(y_{t-1}, y_{t-1}^{*}, \tau_{t}\right)\right]\right\}, \\
= & -\mathbb{E}_{0} \sum_{t=0}^{\infty} \beta^{t}\left\{\Psi_{t} U_{t}+\Psi_{t}^{*} U_{t}^{*}\right. \\
& +\phi_{t}\left(-\pi_{t}+k \mu_{t}+k\left[(\rho+\eta) y_{t}+(1-\gamma)(1-\rho)\left(y_{t}-y_{t}^{*}\right)\right]\right)-\phi_{t-1} \pi_{t} \\
& +\phi_{t}^{*}\left(-\pi_{t}^{*}+k^{*} \mu_{t}^{*}+k^{*}\left[(\rho+\eta) y_{t}^{*}-\gamma(1-\rho)\left(y_{t}-y_{t}^{*}\right)\right]\right)-\phi_{t-1}^{*} \pi_{t}^{*} \\
& \left.-\psi_{t} W\left(y_{t-1}, y_{t-1}^{*}, \tau_{t}\right)-\psi_{t}^{*} W^{*}\left(y_{t-1}, y_{t-1}^{*}, \tau_{t}\right)\right\},
\end{aligned}
$$

where $\Psi_{t}=\Psi_{t-1}+\psi_{t}$ and $\Psi_{t}^{*}=\Psi_{t-1}^{*}+\psi_{t}^{*}$ given $\Psi_{-1}=\gamma$ and $\Psi_{-1}^{*}=1-\gamma$.

The FONCs are

$$
\begin{aligned}
\partial y_{t}: & -2 \Psi_{t} \gamma(\eta+\rho)\left(y_{t}-\frac{1-\gamma}{\gamma(\eta+\rho)} \mu_{t}\right)-2 \Psi_{t} \gamma(1-\gamma)(1-\rho)\left(y_{t}-y_{t}^{*}\right) \\
& -2 \Psi_{t}^{*} \gamma(\eta+\rho)\left(y_{t}+\frac{1}{\eta+\rho} \mu_{t}\right)+2 \Psi_{t}^{*} \gamma(1-\gamma)(1-\rho)\left(y_{t}^{*}-y_{t}\right) \\
& +k(\rho+\eta+(1-\gamma)(1-\rho)) \phi_{t}-k^{*} \gamma(1-\rho) \phi_{t}^{*} \\
& -\beta \mathbb{E}_{t}\left\{\psi_{t+1} D_{1} W\left(y_{t}, y_{t}^{*}, \tau_{t+1}\right)+\psi_{t+1}^{*} D_{1} W^{*}\left(y_{t}, y_{t}^{*}, \tau_{t+1}\right)\right\}=0, \\
\partial y_{t}^{*}: \quad & -2 \Psi_{t}(1-\gamma)(\eta+\rho)\left(y_{t}^{*}+\frac{1}{\eta+\rho} \mu_{t}^{*}\right)+2 \Psi_{t} \gamma(1-\gamma)(1-\rho)\left(y_{t}-y_{t}^{*}\right) \\
& -2 \Psi_{t}^{*}(1-\gamma)(\eta+\rho)\left(y_{t}^{*}-\frac{\gamma}{(1-\gamma)(\eta+\rho)} \mu_{t}^{*}\right)-2 \Psi_{t}^{*} \gamma(1-\gamma)(1-\rho)\left(y_{t}^{*}-y_{t}\right) \\
& +k^{*}(\rho+\eta+\gamma(1-\rho)) \phi_{t}^{*}-k(1-\gamma)(1-\rho) \phi_{t} \\
& -\beta \mathbb{E}_{t}\left\{\psi_{t+1} D_{2} W\left(y_{t}, y_{t}^{*}, \tau_{t+1}\right)+\psi_{t+1}^{*} D_{2} W^{*}\left(y_{t}, y_{t}^{*}, \tau_{t+1}\right)\right\}=0, \\
\partial \pi_{t}: \quad & -\frac{2 \gamma \sigma}{k}\left(\Psi_{t}+\Psi_{t}^{*}\right) \pi_{t}-\phi_{t}+\phi_{t-1}=0, \\
\partial \pi_{t}^{*}: \quad & -\frac{2(1-\gamma) \sigma}{k^{*}}\left(\Psi_{t}+\Psi_{t}^{*}\right) \pi_{t}^{*}-\phi_{t}^{*}+\phi_{t-1}^{*}=0 .
\end{aligned}
$$


Normalizing with $\Psi_{t}+\Psi_{t}^{*}$, we have:

$$
\begin{aligned}
& -2 \gamma(\eta+\rho) y_{t}-2 \gamma(1-\gamma)(1-\rho)\left(y_{t}-y_{t}^{*}\right) \\
& +k(\rho+\eta+(1-\gamma)(1-\rho)) \tilde{\phi}_{t}-k^{*} \gamma(1-\rho) \tilde{\phi}_{t}^{*} \\
& +2\left(v_{t}-\gamma\right) \mu_{t}-\beta \mathbb{E}_{t} \Xi_{t+1}=0, \\
& -2(1-\gamma)(\eta+\rho) y_{t}^{*}+2 \gamma(1-\gamma)(1-\rho)\left(y_{t}-y_{t}^{*}\right) \\
& +k^{*}(\rho+\eta+\gamma(1-\rho)) \tilde{\phi}_{t}^{*}-k(1-\gamma)(1-\rho) \tilde{\phi}_{t} \\
& -2\left(v_{t}-\gamma\right) \mu_{t}^{*}-\beta \mathbb{E}_{t} \Xi_{t+1}^{*}=0, \\
& -\frac{2 \gamma \sigma}{k} \pi_{t}-\tilde{\phi}_{t}+z_{t} \tilde{\phi}_{t-1}=0, \\
& -\frac{2(1-\gamma) \sigma}{k^{*}} \pi_{t}^{*}-\tilde{\phi}_{t}^{*}+z_{t} \tilde{\phi}_{t-1}^{*}=0 .
\end{aligned}
$$

where $\tilde{\phi}_{t}=\phi_{t} /\left(\Psi_{t}+\Psi_{t}^{*}\right), \tilde{\phi}_{t}^{*}=\phi_{t}^{*} /\left(\Psi_{t}+\Psi_{t}^{*}\right), v_{t}=\Psi_{t} /\left(\Psi_{t}+\Psi_{t}^{*}\right), z_{t}=\left(\Psi_{t-1}+\Psi_{t-1}^{*}\right) /\left(\Psi_{t}+\right.$ $\left.\Psi_{t}^{*}\right)$, and

$$
\begin{aligned}
& \Xi_{t+1}:=\frac{\psi_{t+1}}{\Psi_{t}+\Psi_{t}^{*}} D_{1} W\left(y_{t}, y_{t}^{*}, \tau_{t+1}\right)+\frac{\psi_{t+1}^{*}}{\Psi_{t}+\Psi_{t}^{*}} D_{1} W^{*}\left(y_{t}, y_{t}^{*}, \tau_{t+1}\right), \\
& \Xi_{t+1}^{*}:=\frac{\psi_{t+1}}{\Psi_{t}+\Psi_{t}^{*}} D_{2} W\left(y_{t}, y_{t}^{*}, \tau_{t+1}\right)+\frac{\psi_{t+1}^{*}}{\Psi_{t}+\Psi_{t}^{*}} D_{2} W^{*}\left(y_{t}, y_{t}^{*}, \tau_{t+1}\right) .
\end{aligned}
$$

Then, the first two equations are solved for

$$
\begin{aligned}
\tilde{\phi}_{t} & =\frac{2 \gamma}{k} y_{t}-\frac{2 \gamma}{k} \frac{[\eta+\rho+\gamma(1-\rho)] \vartheta_{t}-\gamma(1-\rho) \vartheta_{t}^{*}}{2 \gamma(1+\eta)(\rho+\eta)} \\
\tilde{\phi}_{t}^{*} & =\frac{2(1-\gamma)}{k^{*}} y_{t}^{*}+\frac{2(1-\gamma)}{k^{*}} \frac{[\eta+\rho+(1-\gamma)(1-\rho)] \vartheta_{t}^{*}-(1-\gamma)(1-\rho) \vartheta_{t}}{2(1-\gamma)(\rho+\eta)(1+\eta)} .
\end{aligned}
$$

where $\vartheta_{t}:=2\left(v_{t}-\gamma\right) \mu_{t}-\beta \mathbb{E}_{t} \Xi_{t+1}, \vartheta_{t}^{*}:=2\left(v_{t}-\gamma\right) \mu_{t}^{*}+\beta \mathbb{E}_{t} \Xi_{t+1}^{*}$. Note that either of the sustainability constraints binds at a time. Then we have

$$
\begin{aligned}
\vartheta_{t}= & 2\left(v_{t}-\gamma\right) \mu_{t} \\
& -\beta \mathbb{E}_{t} \underbrace{\left\{\left(z_{t+1}^{-1}-1\right)\left[I_{t+1} D_{1} W\left(y_{t}, y_{t}^{*}, \tau_{t+1}\right)+I_{t+1}^{*} D_{1} W^{*}\left(y_{t}, y_{t}^{*}, \tau_{t+1}\right)\right]\right\}}_{=\Xi_{t+1}}, \\
\vartheta_{t}^{*}= & 2\left(v_{t}-\gamma\right) \mu_{t}^{*} \\
& +\beta \mathbb{E}_{t} \underbrace{\left\{\left(z_{t+1}^{-1}-1\right)\left[I_{t+1} D_{2} W\left(y_{t}, y_{t}^{*}, \tau_{t+1}\right)+I_{t+1}^{*} D_{2} W^{*}\left(y_{t}, y_{t}^{*}, \tau_{t+1}\right)\right]\right\}}_{=\Xi_{t+1}^{*}} .
\end{aligned}
$$

The indicator function $I_{t}=1$ when the sustainability constraint in Home country is binding in period $t ; I_{t}=0$ otherwise. The Sustainable Cooperation equilibrium policy trade-off conditions are summarized as

$$
\begin{aligned}
& -\sigma \pi_{t}=y_{t}-\zeta_{t}-z_{t}\left(y_{t-1}-\zeta_{t-1}\right), \\
& -\sigma \pi_{t}^{*}=y_{t}^{*}-\zeta_{t}^{*}-z_{t}\left(y_{t-1}^{*}-\zeta_{t-1}^{*}\right),
\end{aligned}
$$


where

$$
\begin{aligned}
\zeta_{t} & =\frac{[\eta+\rho+\gamma(1-\rho)] \vartheta_{t}-\gamma(1-\rho) \vartheta_{t}^{*}}{2 \gamma(1+\eta)(\rho+\eta)}, \\
\zeta_{t}^{*} & =-\frac{[\eta+\rho+(1-\gamma)(1-\rho)] \vartheta_{t}^{*}-(1-\gamma)(1-\rho) \vartheta_{t}}{2(1-\gamma)(\rho+\eta)(1+\eta)}, \\
\zeta_{t-1} & =\frac{[\eta+\rho+\gamma(1-\rho)] \vartheta_{t-1}-\gamma(1-\rho) \vartheta_{t-1}^{*}}{2 \gamma(1+\eta)(\rho+\eta)}, \\
\zeta_{t-1}^{*} & =-\frac{[\eta+\rho+(1-\gamma)(1-\rho)] \vartheta_{t-1}^{*}-(1-\gamma)(1-\rho) \vartheta_{t-1}}{2(1-\gamma)(\rho+\eta)(1+\eta)} .
\end{aligned}
$$

Note that $\vartheta_{t}=2\left(v_{t}-\gamma\right) \mu_{t}-\beta \mathbb{E}_{t} \Xi_{t+1}, \vartheta_{t}^{*}=2\left(v_{t}-\gamma\right) \mu_{t}^{*}+\beta \mathbb{E}_{t} \Xi_{t+1}^{*}, \vartheta_{t-1}=2\left(v_{t-1}-\gamma\right) \mu_{t-1}-$ $\beta \Xi_{t}$ and $\vartheta_{t-1}^{*}=2\left(v_{t-1}-\gamma\right) \mu_{t-1}^{*}+\beta \Xi_{t}^{*}$. There are no expectational operators in front of $\Xi_{t}$ and $\Xi_{t}^{*}$, as they are the result of optimization in period $t$.

When $\gamma=1 / 2$, we have

$$
\begin{aligned}
\zeta_{t} & =\frac{(1+\rho+2 \eta) \vartheta_{t}-(1-\rho) \vartheta_{t}^{*}}{2(1+\eta)(\eta+\rho)}, \\
\zeta_{t}^{*} & =-\frac{(1+\rho+2 \eta) \vartheta_{t}^{*}-(1-\rho) \vartheta_{t}}{2(1+\eta)(\eta+\rho)}, \\
\vartheta_{t} & =\left(2 v_{t}-1\right) \mu_{t}-\beta \mathbb{E}_{t} \Xi_{t+1}, \\
\vartheta_{t}^{*} & =\left(2 v_{t}-1\right) \mu_{t}^{*}+\beta \mathbb{E}_{t} \Xi_{t+1}^{*} .
\end{aligned}
$$

\section{B.2 Computational procedure}

The initial guess of the functions is set as $h_{x}^{(0)}\left(s_{-1}, \tau\right)$ for $x=\left\{\pi, \pi^{*}, V, V^{*}, \Xi, \Xi^{*}\right\}$ on each grid point $\left(s_{-1}, \tau\right) \in Y^{2} \times(0,1) \times M^{2} \times\left(M^{*}\right)^{2}$. In each iteration $i=1,2, \ldots$, given the functions $h_{x}^{(i-1)}\left(s_{-1}, \tau\right)$ whose values are defined on each grid point $\left(s_{-1}, \tau\right)$, first we assume the sustainability constraints are slack. That is, $z\left(s_{-1}, \tau\right)=1, v\left(s_{-1}, \tau\right)=v_{-1}$ and $\Xi\left(s_{-1}, \tau\right)=\Xi^{*}\left(s_{-1}, \tau\right)=$ 0 . Then the relevant equations are solved

$$
\begin{aligned}
\pi & =\beta \hat{h}_{\pi, u}^{(i-1)}\left(y, y^{*}, v_{-1}\right)+k \mu \\
& +k\left[(\rho+\eta+(1-\gamma)(1-\rho)) y-(1-\gamma)(1-\rho) y^{*}\right], \\
\pi^{*} & =\beta \hat{h}_{\pi^{*}, u}^{(i-1)}\left(y, y^{*}, v_{-1}\right)+k^{*} \mu^{*} \\
& +k^{*}\left[(\rho+\eta+(1-\gamma)(1-\rho)) y^{*}-(1-\gamma)(1-\rho) y\right],
\end{aligned}
$$


where

$$
\begin{aligned}
\pi & =-\sigma^{-1}\left[y-\zeta-\left(y-1-\zeta_{-1}\right)\right] \\
\pi^{*} & =-\sigma^{-1}\left[y^{*}-\zeta^{*}-\left(y_{-1}^{*}-\zeta_{-1}^{*}\right)\right] \\
\zeta & =\frac{[\eta+\rho+\gamma(1-\rho)] \vartheta-\gamma(1-\rho) \vartheta^{*}}{2 \gamma(1+\eta)(\rho+\eta)} \\
\zeta^{*} & =-\frac{[\eta+\rho+(1-\gamma)(1-\rho)] \vartheta^{*}-(1-\gamma)(1-\rho) \vartheta}{2(1-\gamma)(\rho+\eta)(1+\eta)} \\
\zeta_{-1} & =\frac{[\eta+\rho+\gamma(1-\rho)] \vartheta_{-1}-\gamma(1-\rho) \vartheta_{-1}^{*}}{2 \gamma(1+\eta)(\rho+\eta)} \\
\zeta_{-1}^{*} & =-\frac{[\eta+\rho+(1-\gamma)(1-\rho)] \vartheta_{-1}^{*}-(1-\gamma)(1-\rho) \vartheta_{-1}}{2(1-\gamma)(\rho+\eta)(1+\eta)}
\end{aligned}
$$

and

$$
\begin{aligned}
\vartheta & =2\left(v_{-1}-\gamma\right) \mu-\beta \hat{h}_{\Xi, u}^{(i-1)}\left(y, y^{*}, v_{-1}\right), \\
\vartheta^{*} & =2\left(v_{-1}-\gamma\right) \mu^{*}+\beta \hat{h}_{\Xi^{*}, u}^{(i-1)}\left(y, y^{*}, v_{-1}\right), \\
\vartheta_{-1} & =2\left(v_{-1}-\gamma\right) \mu_{-1}, \\
\vartheta_{-1}^{*} & =2\left(v_{-1}-\gamma\right) \mu_{-1}^{*},
\end{aligned}
$$

for $\left(y, y^{*}, \pi, \pi^{*}\right)$ using a non-linear optimization routine. Then the candidate values of welfare, $\left(V, V^{*}\right)$ are also obtained by

$$
\begin{aligned}
& V=-U\left(y, y^{*}, \pi, \pi^{*}, \mu, \mu^{*}\right)+\beta \hat{h}_{V, u}^{(i-1)}\left(y, y^{*}, v_{-1}\right), \\
& V^{*}=-U^{*}\left(y, y^{*}, \pi, \pi^{*}, \mu, \mu^{*}\right)+\beta \hat{h}_{V^{*}, u}^{(i-1)}\left(y, y^{*}, v_{-1}\right),
\end{aligned}
$$

where

$$
\begin{aligned}
U\left(y, y^{*}, \pi, \pi^{*}, \mu, \mu^{*}\right)= & \gamma(\eta+\rho)\left(y-\frac{1-\gamma}{\gamma} \frac{1}{\eta+\rho} \mu\right)^{2}+\frac{\gamma \sigma}{k} \pi^{2} \\
& +\gamma(1-\gamma)(1-\rho)\left(y-y^{*}\right)^{2} \\
& +(1-\gamma)(\eta+\rho)\left(y^{*}+\frac{1}{\eta+\rho} \mu^{*}\right)^{2}+\frac{(1-\gamma) \sigma}{k^{*}}\left(\pi^{*}\right)^{2}, \\
U^{*}\left(y, y^{*}, \pi, \pi^{*}, \mu, \mu^{*}\right)= & (1-\gamma)(\eta+\rho)\left(y^{*}-\frac{\gamma}{1-\gamma} \frac{1}{\eta+\rho} \mu^{*}\right)^{2}+\frac{(1-\gamma) \sigma}{k^{*}}\left(\pi^{*}\right)^{2} \\
& +\frac{1}{2}(1-\rho)\left(y^{*}-y\right)^{2} \\
& +\gamma(\eta+\rho)\left(y+\frac{1}{\eta+\rho} \mu\right)^{2}+\frac{\gamma \sigma}{k} \pi^{2} .
\end{aligned}
$$

Also, $\hat{h}_{x, u}(s)=\sum_{u^{\prime}} P\left(u^{\prime} \mid u\right) h_{x}\left(s, u^{\prime}, u\right)$ where $x=\left\{\pi, \pi^{*}, \Xi, \Xi^{*}, V, V^{*}\right\}$, and the $h_{x}$ functions are approximated using three-dimensional splines for $s \in Y^{2} \times(0,1)$, which may be off the grid points.

Then we proceed to check if the sustainability constraints are binding with the candidate values of welfare, $\left(V, V^{*}\right) . W\left(y_{-1}, y_{-1}^{*}, \tau\right)$ and $W^{*}\left(y_{-1}, y_{-1}^{*}, \tau\right)$ are also numerically obtained 
with the projection method (see the end of this section). Note that only the Home or Foreign constraint is binding at a time and there are two possible cases, (i) the Home constraint is binding or (ii) the Foreign constraint is binding.

- (i) When the Home constraint is binding, $V \leq W\left(y_{-1}, y_{-1}^{*}, \tau\right)$ : The relevant equations are solved

$$
\begin{aligned}
\pi & =\beta \hat{h}_{\pi, \tau}^{(i-1)}\left(y, y^{*}, v\right)+k \mu \\
& +k\left[(\rho+\eta+(1-\gamma)(1-\rho)) y-(1-\gamma)(1-\rho) y^{*}\right], \\
\pi^{*} & =\beta \hat{h}_{\pi^{*}, \tau}^{(i-1)}\left(y, y^{*}, v\right)+k^{*} \mu^{*} \\
& +k^{*}\left[(\rho+\eta+(1-\gamma)(1-\rho)) y^{*}-(1-\gamma)(1-\rho) y\right], \\
W\left(y_{-1}, y_{-1}^{*}, \tau\right) & =-U\left(y, y^{*}, \pi, \pi^{*}, \mu, \mu^{*}\right)+\beta \hat{h}_{V, \tau}^{(i-1)}\left(y, y^{*}, v\right)
\end{aligned}
$$

where $v=1-z\left(1-v_{-1}\right), z \in(0,1)$,

$$
\begin{aligned}
\pi & =-\sigma^{-1}\left[y-\zeta-z\left(y-1-\zeta_{-1}\right)\right] \\
\pi^{*} & =-\sigma^{-1}\left[y^{*}-\zeta^{*}-z\left(y_{-1}^{*}-\zeta_{-1}^{*}\right)\right] \\
\zeta & =\frac{[\eta+\rho+\gamma(1-\rho)] \vartheta-\gamma(1-\rho) \vartheta^{*}}{2 \gamma(1+\eta)(\rho+\eta)}, \\
\zeta^{*} & =-\frac{[\eta+\rho+(1-\gamma)(1-\rho)] \vartheta^{*}-(1-\gamma)(1-\rho) \vartheta}{2(1-\gamma)(\rho+\eta)(1+\eta)}, \\
\zeta_{-1} & =\frac{[\eta+\rho+\gamma(1-\rho)] \vartheta_{-1}-\gamma(1-\rho) \vartheta_{-1}^{*}}{2 \gamma(1+\eta)(\rho+\eta)}, \\
\zeta_{-1}^{*} & =-\frac{[\eta+\rho+(1-\gamma)(1-\rho)] \vartheta_{-1}^{*}-(1-\gamma)(1-\rho) \vartheta_{-1}}{2(1-\gamma)(\rho+\eta)(1+\eta)}
\end{aligned}
$$

and

$$
\begin{aligned}
\vartheta & =2(v-\gamma) \mu-\beta \hat{h}_{\Xi, \tau}^{(i-1)}\left(y, y^{*}, v\right), \\
\vartheta^{*} & =2(v-\gamma) \mu^{*}+\beta \hat{h}_{\Xi *, \tau}^{(i-1)}\left(y, y^{*}, v\right), \\
\vartheta_{-1} & =2\left(v_{-1}-\gamma\right) \mu_{-1}-\beta\left(z^{-1}-1\right) D_{1} W\left(y_{-1}, y_{-1}^{*}, \tau\right), \\
\vartheta_{-1}^{*} & =2\left(v_{-1}-\gamma\right) \mu_{-1}^{*}+\beta\left(z^{-1}-1\right) D_{2} W\left(y_{-1}, y_{-1}^{*}, \tau\right),
\end{aligned}
$$

for $\left(y, y^{*}, \pi, \pi^{*}\right)$ and $(z, v)$. Note that the latter is now endogenously solved.

- (ii) When the Foreign constraint is binding, $V \leq W^{*}\left(y_{-1}, y_{-1}^{*}, \tau\right)$ : The relevant equations are solved

$$
\begin{aligned}
\pi & =\beta \hat{h}_{\pi, \tau}^{(i-1)}\left(y, y^{*}, v\right)+k \mu \\
& +k\left[(\rho+\eta+(1-\gamma)(1-\rho)) y-(1-\gamma)(1-\rho) y^{*}\right], \\
\pi^{*} & =\beta \hat{h}_{\pi^{*}, \tau}^{(i-1)}\left(y, y^{*}, v\right)+k^{*} \mu^{*} \\
& +k^{*}\left[(\rho+\eta+(1-\gamma)(1-\rho)) y^{*}-(1-\gamma)(1-\rho) y\right], \\
W^{*}\left(y_{-1}, y_{-1}^{*}, \tau\right) & =-U^{*}\left(y, y^{*}, \pi, \pi^{*}, \mu, \mu^{*}\right)+\beta \hat{h}_{V^{*}, \tau}^{(i-1)}\left(y, y^{*}, v\right)
\end{aligned}
$$


where $v=z v_{-1}, z \in(0,1)$,

$$
\begin{aligned}
\pi & =-\sigma^{-1}\left[y-\zeta-z\left(y-1-\zeta_{-1}\right)\right] \\
\pi^{*} & =-\sigma^{-1}\left[y^{*}-\zeta^{*}-z\left(y_{-1}^{*}-\zeta_{-1}^{*}\right)\right] \\
\zeta & =\frac{[\eta+\rho+\gamma(1-\rho)] \vartheta-\gamma(1-\rho) \vartheta^{*}}{2 \gamma(1+\eta)(\rho+\eta)} \\
\zeta^{*} & =-\frac{[\eta+\rho+(1-\gamma)(1-\rho)] \vartheta^{*}-(1-\gamma)(1-\rho) \vartheta}{2(1-\gamma)(\rho+\eta)(1+\eta)} \\
\zeta_{-1} & =\frac{[\eta+\rho+\gamma(1-\rho)] \vartheta_{-1}-\gamma(1-\rho) \vartheta_{-1}^{*}}{2 \gamma(1+\eta)(\rho+\eta)}, \\
\zeta_{-1}^{*} & =-\frac{[\eta+\rho+(1-\gamma)(1-\rho)] \vartheta_{-1}^{*}-(1-\gamma)(1-\rho) \vartheta_{-1}}{2(1-\gamma)(\rho+\eta)(1+\eta)}
\end{aligned}
$$

and

$$
\begin{aligned}
\vartheta & =2(v-\gamma) \mu-\beta \hat{h}_{\Xi, \tau}^{(i-1)}\left(y, y^{*}, v\right), \\
\vartheta^{*} & =2(v-\gamma) \mu^{*}+\beta \hat{h}_{\Xi^{*}, \tau}^{(i-1)}\left(y, y^{*}, v\right), \\
\vartheta_{-1} & =2\left(v_{-1}-\gamma\right) \mu_{-1}-\beta\left(z^{-1}-1\right) D_{1} W^{*}\left(y_{-1}, y_{-1}^{*}, \tau\right), \\
\vartheta_{-1}^{*} & =2\left(v_{-1}-\gamma\right) \mu_{-1}^{*}+\beta\left(z^{-1}-1\right) D_{2} W^{*}\left(y_{-1}, y_{-1}^{*}, \tau\right),
\end{aligned}
$$

for $\left(y, y^{*}, \pi, \pi^{*}\right)$ and $(z, v)$.

After checking binding constraints, calculate $\left(\Xi, \Xi^{*}\right)$ following the binding pattern of the constraints:

$$
\begin{gathered}
\Xi= \begin{cases}\left(z^{-1}-1\right) D_{1} W\left(y_{-1}, y_{-1}^{*}, \tau\right) & \text { if } I\left(s_{-1}, \tau\right)=1, \\
\left(z^{-1}-1\right) D_{1} W^{*}\left(y_{-1}, y_{-1}^{*}, \tau\right) & \text { if } I^{*}\left(s_{-1}, \tau\right)=1, \\
0 & \text { otherwise. }\end{cases} \\
\Xi^{*}= \begin{cases}\left(z^{-1}-1\right) D_{2} W\left(y_{-1}, y_{-1}^{*}, \tau\right) & \text { if } I\left(s_{-1}, \tau\right)=1, \\
\left(z^{-1}-1\right) D_{2} W^{*}\left(y_{-1}, y_{-1}^{*}, \tau\right) & \text { if } I^{*}\left(s_{-1}, \tau\right)=1, \\
0 & \text { otherwise. }\end{cases}
\end{gathered}
$$

Once we finish solving the relevant equations at each grid point, the functions $h_{x}^{(i)}\left(s_{-1}, \tau\right)=$ $\left\{x_{s_{-1}, \tau}\right\}_{\left(s_{-1}, \tau\right) \in S \times T}$ for $x=\left\{\pi, \pi^{*}, V, V^{*}, \Xi, \Xi^{*}\right\}$ are updated.

The algorithm is summarized as follows:

1. Set the initial guess of the functions $h_{x}^{(0)}\left(s_{-1}, \tau\right)$ where $x=\left\{\pi, \pi^{*}, V, V^{*}, \Xi, \Xi^{*}\right\}$ on each grid point $\left(s_{-1}, \tau\right) \in Y^{2} \times(0,1) \times M^{2} \times\left(M^{*}\right)^{2}=S \times T$.

2. In each iteration $i=1,2, \ldots$, given the functions $h_{x}^{(i-1)}\left(s_{-1}, \tau\right)$ and on each grid point $\left(s_{-1}, \tau\right)$ :

(a) Assume the sustainability constraints are slack, and solve the equilibrium conditions for $\left(y, y^{*}, \pi, \pi^{*}\right)$. Note that $z=1$ and $v=v_{-1}$. Once the relevant equations are solved, the candidate values of welfare, $\left(V, V^{*}\right)$, are also obtained. 
(b) Check if the sustainability constraints are binding with the candidate values of welfare. If the Home (or Foreign) constraint is binding, set $V=W\left(y_{-1}, y_{-1}^{*}, \tau\right)$ (or $\left.V^{*}=W^{*}\left(y_{-1}, y_{-1}^{*}, \tau\right)\right)$ and re-solve the equilibrium conditions for $\left(y, y^{*}, \pi, \pi^{*}\right)$ and $(z, v)$.

(c) Calculate $\left(\Xi, \Xi^{*}\right)$ following the binding pattern of the constraints.

3. Update the functions $h_{x}^{(i)}\left(s_{-1}, \tau\right)=\left\{x_{s_{-1}, \tau}\right\}_{\left(s_{-1}, \tau\right) \in S \times T}$ for $x=\left\{\pi, \pi^{*}, V, V^{*}, \Xi, \Xi^{*}\right\}$.

4. Iterate $2-4$ until the functions converge at each grid point, i.e., $\left\|h_{x}^{(i)}\left(s_{-1}, \tau\right)-h_{x}^{(i-1)}\left(s_{-1}, \tau\right)\right\|<$ $\epsilon$, where $\|\cdot\|$ is the uniform norm and $\epsilon$ is a very small real number.

Non-cooperation $W\left(y_{-1}, y_{-1}^{*}, \tau\right)$ and $W^{*}\left(y_{-1}, y_{-1}^{*}, \tau\right)$ are also numerically obtained with the policy function iteration method. Let $s_{-1}=\left(y_{-1}, y_{-1}^{*}\right), \tau=\left(\mu, \mu^{*}, \mu_{-1}, \mu_{-1}^{*}\right)$ be a vector of endogenous and exogenous variable each and $x=h_{x}\left(s_{-1}, \tau\right)$ be the policy functions where $x=\left\{y, y^{*}, \pi, \pi^{*}\right\}$. A similar policy function iteration algorithm above (but the state space is different as there is no $v_{-1}$ ) is used to compute the policy functions. In Step 2 in the above algorithm, the equilibrium conditions are solved

$$
\begin{aligned}
\pi & =\beta \hat{h}_{\pi, \tau}^{(i-1)}\left(y, y^{*}\right)+k \mu \\
& +k\left[(\rho+\eta+(1-\gamma)(1-\rho)) y-(1-\gamma)(1-\rho) y^{*}\right], \\
\pi^{*} & =\beta \hat{h}_{\pi^{*}, \tau}^{(i-1)}\left(y, y^{*}\right)+k^{*} \mu^{*} \\
& +k^{*}\left[(\rho+\eta+(1-\gamma)(1-\rho)) y^{*}-(1-\gamma)(1-\rho) y\right],
\end{aligned}
$$

where

$$
\begin{aligned}
\pi & =-\sigma^{-1}\left[y-\xi-\left(y_{-1}-\xi_{-1}\right)\right] \\
\pi^{*} & =-\sigma^{-1}\left[y^{*}-\xi^{*}-\left(y_{-1}^{*}-\xi_{-1}^{*}\right)\right] \\
\xi & =\frac{1-\gamma}{\gamma} \frac{(\eta+\rho+\gamma(1-\rho)) \mu-\gamma(1-\rho) \mu^{*}}{(\eta+\rho)(1+\eta)}, \\
\xi^{*} & =\frac{\gamma}{1-\gamma} \frac{(\eta+\rho+(1-\gamma)(1-\rho)) \mu^{*}-(1-\gamma)(1-\rho) \mu}{(\eta+\rho)(1+\eta)}, \\
\xi_{-1} & =\frac{1-\gamma}{\gamma} \frac{(\eta+\rho+\gamma(1-\rho)) \mu_{-1}-\gamma(1-\rho) \mu_{-1}^{*}}{(\eta+\rho)(1+\eta)}, \\
\xi_{-1}^{*} & =\frac{\gamma}{1-\gamma} \frac{(\eta+\rho+(1-\gamma)(1-\rho)) \mu_{-1}^{*}-(1-\gamma)(1-\rho) \mu_{-1}}{(\eta+\rho)(1+\eta)},
\end{aligned}
$$

for $\left(y, y^{*}, \pi, \pi^{*}\right)$. Once the relevant equations are solved, the value functions are also obtained by

$$
\begin{aligned}
& W=-U\left(y, y^{*}, \pi, \pi^{*}, \mu, \mu^{*}\right)+\beta \hat{h}_{W, \tau}^{(i-1)}\left(y, y^{*}\right), \\
& W^{*}=-U^{*}\left(y, y^{*}, \pi, \pi^{*}, \mu, \mu^{*}\right)+\beta \hat{h}_{W^{*}, \tau}^{(i-1)}\left(y, y^{*}\right) .
\end{aligned}
$$

Note that $\hat{h}_{x, \tau}(s)=\sum_{\tau^{\prime}} P\left(\tau^{\prime} \mid \tau\right) h_{x}\left(s, \tau^{\prime}\right)$ where $x=\left\{\pi, \pi^{*}, W, W^{*}\right\}$ are approximated by using two-dimensional splines for $s \in Y^{2}$ conditioned on $\tau$. 